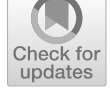

Cite as

Nano-Micro Lett.

(2020) 13:13

Received: 13 July 2020

Accepted: 16 August 2020

Published online: 29 October 2020

(C) The Author(s) 2020

\section{DFT-Guided Design and Fabrication of Carbon-Nitride-Based Materials for Energy Storage Devices: A Review}

\author{
David Adekoya ${ }^{1}$, Shangshu Qian ${ }^{1}$, Xingxing Gu${ }^{1}$, William Wen ${ }^{1}$, Dongsheng $\mathrm{Li}^{2}$, \\ Jianmin $\mathrm{Ma}^{3}$, Shanqing Zhang ${ }^{1}$
}

\title{
HIGHLIGHTS
}

- Comprehensive summary of crystalline structures and morphologies of carbon nitride-based materials (CNBMs).

- Density functional theory computation for the design of functional CNBMs for rechargeable battery applications.

- The experimental synthesis strategies of CNBMs for rechargeable battery application.

\begin{abstract}
Carbon nitrides (including $\mathrm{CN}, \mathrm{C}_{2} \mathrm{~N}, \mathrm{C}_{3} \mathrm{~N}, \mathrm{C}_{3} \mathrm{~N}_{4}, \mathrm{C}_{4} \mathrm{~N}$, and $\mathrm{C}_{5} \mathrm{~N}$ ) are a unique family of nitrogen-rich carbon materials with multiple beneficial properties in crystalline structures, morphologies, and electronic configurations. In this review, we provide a comprehensive review on these materials properties, theoretical advantages, the synthesis and modification strategies of different carbon nitride-based materials (CNBMs) and their application in existing and emerging rechargeable battery systems, such as lithium-ion batteries, sodium and potassium-ion batteries, lithium sulfur batteries, lithium oxygen batteries, lithium metal batteries, zinc-ion batteries, and solid-state batteries. The central theme of this review is to apply the theoretical and computational design to guide the experimental synthesis of CNBMs for energy storage, i.e., facilitate the application of first-principle studies and density functional theory for electrode material design, synthesis, and characterization of different CNBMs for the aforementioned rechargeable batteries. At last, we conclude with the challenges, and prospects of CNBMs, and propose future perspectives and strategies for further advancement of CNBMs for rechargeable batteries.
\end{abstract}

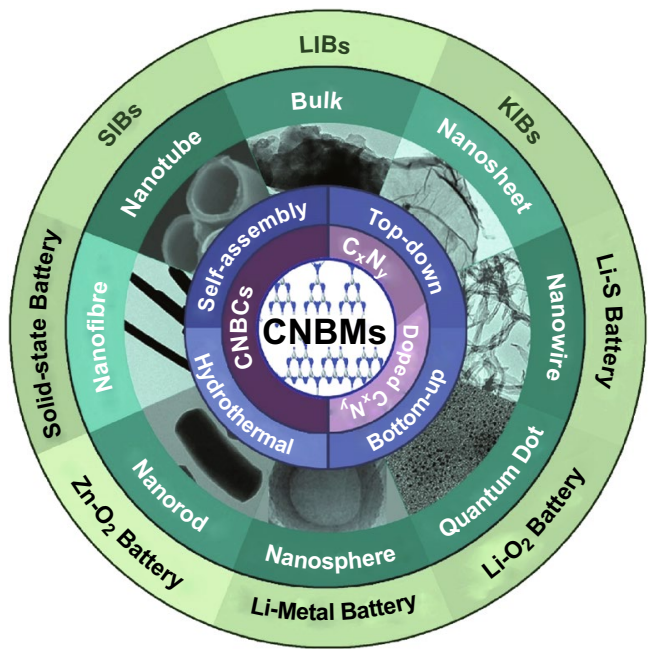

KEYWORDS Carbon nitrides; Metal-ion batteries; Density functional theory; $\mathrm{g}_{-} \mathrm{C}_{3} \mathrm{~N}_{4}$; Anode

Shanqing Zhang, s.zhang@griffith.edu.au

1 Centre for Clean Environment and Energy, School of Environment and Science, Griffith University, Gold Coast Campus, Gold Coast, QLD 4222, Australia

2 College of Materials and Chemical Engineering, Key Laboratory of Inorganic Nonmetallic Crystalline and Energy Conversion Materials, China Three Gorges University, Yichang 443002, People's Republic of China

3 Key Laboratory of Materials Processing and Mold (Zhengzhou University), Ministry of Education, Zhengzhou, People's Republic of China 


\section{Introduction}

Rechargeable metal ion batteries (MIBs) are one of the most reliable portable energy storage devices today because of their high power density, exceptional energy capacity, high cycling stability, and low self-discharge [1,2]. Lithium-ion batteries (LIBs) remain the most developed and commercially viable alternative among all rechargeable batteries, and graphite is widely accepted as a preferred negative electrode (anode) material for LIBs [3]. Graphite is affordable, and it does not suffer significant volumetric changes (compared to other metal-based electrodes); it operates at a very low voltage close to that of lithium metal $(\sim 0.1 \mathrm{~V})$ and exhibits moderately stable cycle life with a theoretical capacity of $372 \mathrm{mAh} g\left(\mathrm{LiC}_{6}\right)$. Despite these positive characteristics, the performance of graphite is still very limited, and one of the effective ways to modulate its properties and electrochemical performance is through nitrogen doping [4]. Precisely, the work of Liu et al. showed that the N-doping of graphene results in improved conductivity and charge transfer, which boosts its performance and cyclability [5].

Carbon nitrides are a family of nitrogen-rich graphite analogues which contain a high nitrogen content and porous defect sites for effective charge transfer in energy storage devices [6, 7]. However, carbon nitrides are limited by poor electrical conductivity, chemical inertness, and ineffective intercalation/deintercalation process [8]. Due to these issues, several research studies have focused on the design of unique carbon-nitride-based materials (CNBMs), including pure carbon nitrides, doped carbon nitrides (DCNs) as well as carbon-nitride-based composites (CNBCs) [9]. Most of these reports have focused on $\mathrm{g}^{-} \mathrm{C}_{3} \mathrm{~N}_{4}$ because it is easy to synthesize, low cost, environmentally safe, and it has a theoretical capacity of $524 \mathrm{mAh} \mathrm{g}^{-1}\left(\mathrm{Li}_{2} \mathrm{C}_{3} \mathrm{~N}_{4}\right)$. In contrast, though other carbon nitride structures (such as $\mathrm{CN}, \mathrm{C}_{2} \mathrm{~N}$, $\mathrm{C}_{3} \mathrm{~N}, \mathrm{C}_{4} \mathrm{~N}$, and $\mathrm{C}_{5} \mathrm{~N}$ ) which have been studied through density functional theory (DFT) calculations exhibit exceptional structural and electronic properties which demonstrates their capabilities as promising MIB electrode materials, they have attracted less attention.

On the other hand, DFT has been adopted more and more in studying CNBMs and their electronic properties [10]. In fact, DFT could provide effective guidance for the synthesis of electrode materials and/or interpretation of the structure-performance relationship in energy storage devices, including LIBs, sodium- and potassium-ion batteries (SIBs and PIBs), lithium-sulfur batteries (Li-S), lithium-oxygen (Li- $\mathrm{O}_{2}$ ) batteries, lithium metal batteries (LMBs), zinc air batteries (ZABs), and solid-state batteries (SSBs). This review aims to comprehensively discuss the relationships between the structural and electronic properties and the MIB performance of pure carbon nitrides, doped carbon nitrides, and CNBCs, summaries the theoretical computation for the design of functional CNBMs for different rechargeable MIB applications, and generalizes the synthesis strategies of pure carbon nitrides and CNBCs for rechargeable metal ion battery application (Fig. 1). At the end of this work, we also offer a perspective on the existing challenges of carbon nitrides for energy storage devices and relevant resolving strategies.

\section{CNBMs}

To study the carbon nitrides, we must begin by exploring their crystalline structure, structural and electronic properties, and functionality. Carbon nitrides are a family of nitrogen-rich carbon materials, and they have different crystalline structures and molecular configurations. Generally, there are seven types of nitrogen species (Fig. 2), with at least two most common species of nitrogen (the graphitic-N and pyridinic-N). The nature of the nitrogen and its percentage concentration has been proven to impact the electronic configuration and characteristic of the carbon nitride for different applications. The classification of carbon nitrides is often based on the carbon to nitrogen content (i.e., the $\mathrm{C} / \mathrm{N}$ ratio) which is often associated with the degree of surface defects in their structure [11]. The carbon nitrides discussed in this review are categorized based on the dominant $\mathrm{N}$ species in their crystalline structure.

\subsection{Pure Carbon Nitrides}

Based on their generic family molecular formula of $\mathrm{C}_{x} \mathrm{~N}_{y}$, the carbon nitride family includes $\mathrm{CN}\left(\mathrm{C}_{2} \mathrm{~N}_{2}, \mathrm{C}_{3} \mathrm{~N}_{3}, \mathrm{C}_{4} \mathrm{~N}_{4}\right)$, $\mathrm{C}_{2} \mathrm{~N}, \mathrm{C}_{3} \mathrm{~N}, \mathrm{C}_{3} \mathrm{~N}_{2}, \mathrm{C}_{3} \mathrm{~N}_{4}, \mathrm{C}_{3} \mathrm{~N}_{5}, \mathrm{C}_{3} \mathrm{~N}_{6}, \mathrm{C}_{3} \mathrm{~N}_{7}, \mathrm{C}_{4} \mathrm{~N}, \mathrm{C}_{4} \mathrm{~N}_{3}, \mathrm{C}_{5} \mathrm{~N}$, $\mathrm{C}_{6} \mathrm{~N}_{6}, \mathrm{C}_{6} \mathrm{~N}_{8}, \mathrm{C}_{9} \mathrm{~N}_{4}, \mathrm{C}_{9} \mathrm{~N}_{7}, \mathrm{C}_{10} \mathrm{~N}_{3}, \mathrm{C}_{10} \mathrm{~N}_{9}$, and $\mathrm{C}_{14} \mathrm{~N}_{12}[11$, 13]. All these carbon nitride materials possess some similarity with graphene in that they are all two-dimensional (2D) materials with $s p^{2} / s p^{3}$ hybridized conjugated $\mathrm{C}$ atoms 


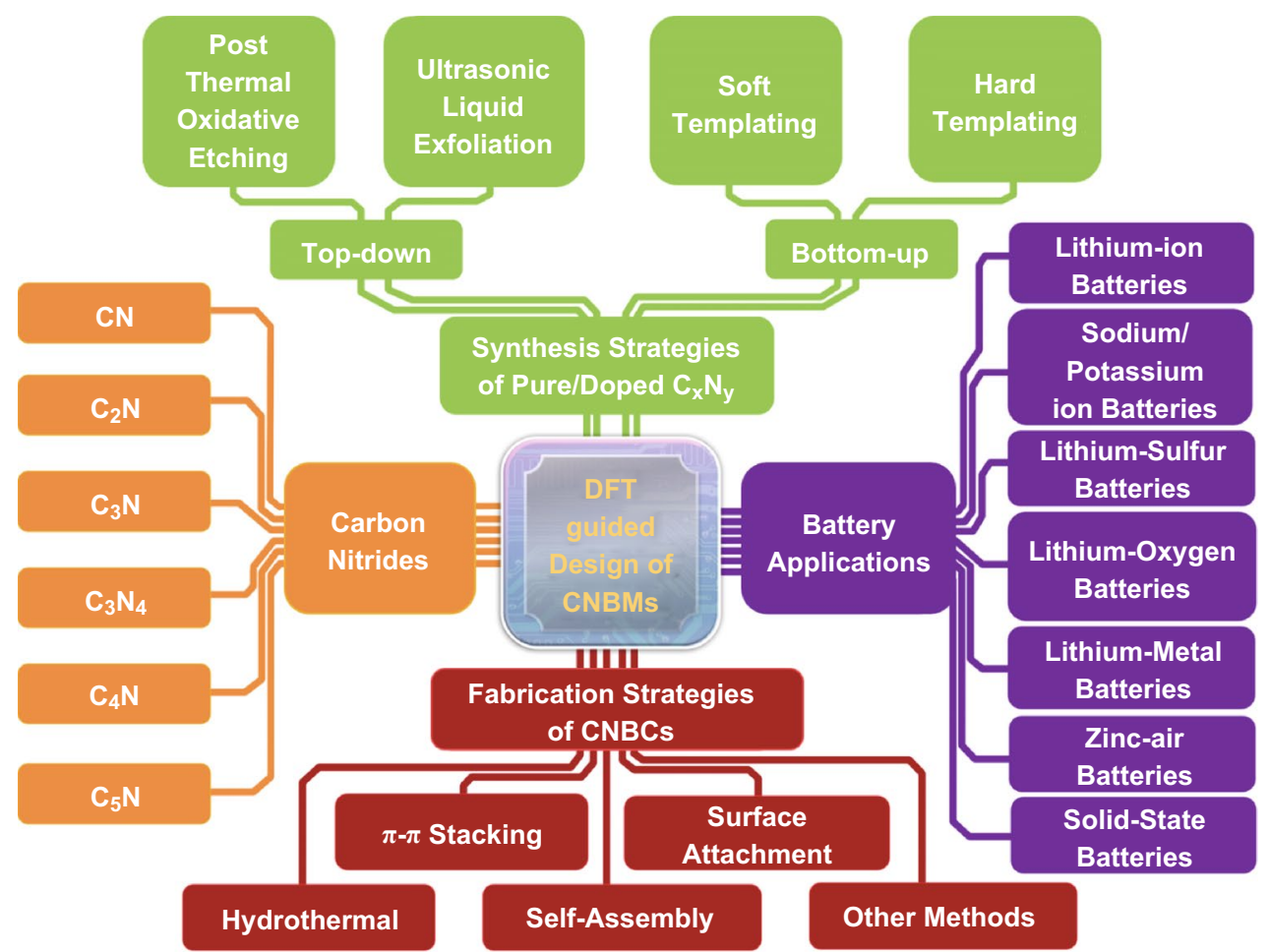

Fig. 1 Overview of the main topics of this work, including DFT-guided design (symbolized by the "CPU" at the center), the molecular configuration of carbon nitrides (yellow block), the synthesis strategies of pure/doped carbon nitrides (green block), the fabrication strategies of CNBCs (red block) and the battery applications of CNBMs (purple block). (Color figure online)

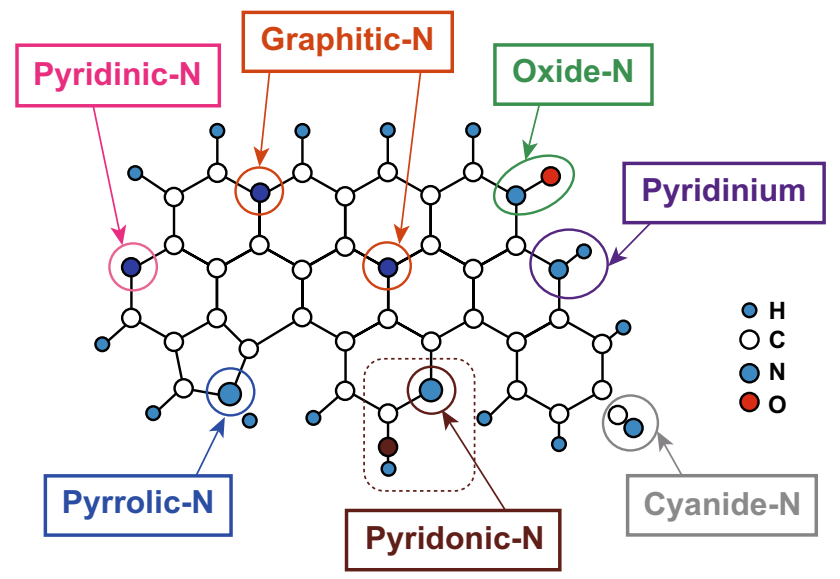

Fig. 2 Common forms of nitrogen species in nitrogen-doped carbon materials. Reproduced with permission from Ref. [12]. Copyright permissions from Wiley-VCH. (Color figure online)

[14], but they all exhibit different structural frameworks and $\mathrm{C} / \mathrm{N}$ ratio. In this section of the review, we summarize the crystalline structure, surface functionalities, and electronic properties of different carbon nitrides, including pyridinic nitrogen-based carbon nitrides $\left(\mathrm{CN}, \mathrm{C}_{2} \mathrm{~N}\right.$, and $\left.\mathrm{C}_{3} \mathrm{~N}_{4}\right)$ and graphitic nitrogen-based carbon nitrides $\left(\mathrm{C}_{3} \mathrm{~N}, \mathrm{C}_{4} \mathrm{~N}\right.$, and $\mathrm{C}_{5} \mathrm{~N}$ ) (Fig. 3).

\subsubsection{Pyridinic Nitrogen-Based Carbon Nitrides (CN, $\left.\mathrm{C}_{2} \mathrm{~N}, \mathrm{C}_{3} \mathrm{~N}_{4}\right)$}

Pyridinic-N is one of the edge site nitrogen species in an $\mathrm{N}$-doped carbon material or carbon nitride. It is bonded to two carbon atoms and supplies one p electron to the $\pi-\pi$ conjugated system of carbon [12]. Due to the co-ordination of pyridinic- $\mathrm{N}$ to 2 carbon atoms, it donates 4 electrons to the $s p^{2}$ of each carbon atom along with a lone pair. Because of its superior electronegativity, it is able to pull $\pi$-electrons from the conjugated system of carbon, thereby making it negatively charged $\mathrm{N}$-atom. When the $\pi$-conjugated system of carbon is broken (the aromaticity), a non-bonding $p_{z}$ orbital is formed, and this orbital can also be observed around defected carbon materials. Carbon materials that contain pyridinic- $\mathrm{N}$ can function as Lewis base because the 


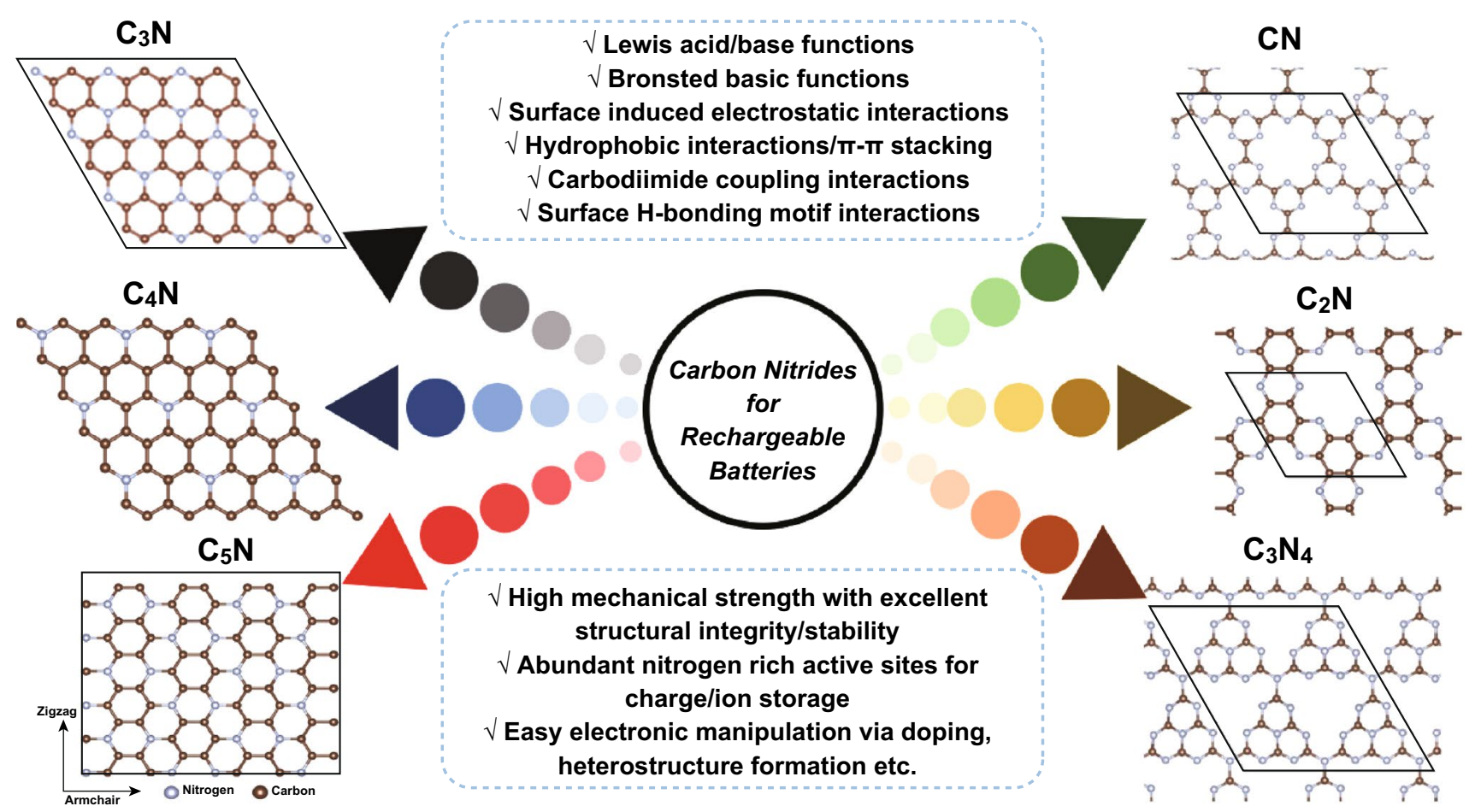

Fig. 3 Geometric structures of the pyridinic and graphitic-N-based carbon nitrides reported for rechargeable batteries and their surface functionalities. The brown spheres represent carbon atoms, and the light blue one represents nitrogen atoms in the $2 \mathrm{D}$ carbon nitrides structures. (Color figure online)

pyridinic-N exhibits a negative charge on surrounding carbon atom, which makes them positively charged with a lone pair of electrons as a result of the non-bonding $p_{z}$ orbital [12]. The pyridinic-N-based carbon nitrides in this category include $\mathrm{CN}, \mathrm{C}_{2} \mathrm{~N}$, and $\mathrm{C}_{3} \mathrm{~N}_{4}$.

2.1.1.1 $\mathrm{CN}$ CN exists in different compositions such as $\mathrm{C}_{2} \mathrm{~N}_{2}, \mathrm{C}_{3} \mathrm{~N}_{3}$, and $\mathrm{C}_{4} \mathrm{~N}_{4}$, and the structure of these carbon nitride materials possesses round and uniform pores, six pyridinic nitrogens in each unit cell and a bandgap of $\sim 1.5$ $1.6 \mathrm{eV}$ (Fig. 4a, b) [15]. Most of the carbon nitrides contain both graphitic and pyridinic nitrogen except for $\mathrm{CN}$. Due to its rich pyridinic nitrogen structure and absence of graphitic nitrogen, $\mathrm{CN}$ exhibits high structural stability, better conductivity and does not experience loss of crystallinity when it interacts with alkali metal ions like $\mathrm{Li}^{+}$.

2.1.1.2 $\mathrm{C}_{2} \mathrm{~N}$ The structure of $\mathrm{C}_{2} \mathrm{~N}$ exhibits $s p^{2}$ hybridization, and it is filled with uniformly sized holes and one large hole at the center, which is due to the six-member nitrogencontaining ring (Fig. 4c). Like the structure of graphene, it possesses several benzene rings that are bridged by pyrazine rings, which have two nitrogen atoms opposite to each other [16]. Also, unlike graphene, which has a fully conjugated $\pi$-electron structure, the presence of nitrogen in the structure of $\mathrm{C}_{2} \mathrm{~N}$ makes the $\pi$-electronic structure of its benzene rings isolated. Therefore, it has a flat band and exists as a semiconductor with a bandgap of $1.96 \mathrm{eV}$ (Fig. 4d). Due to its wider structure and the abundance of several benzene and pyrazine rings, it is expected that it will possess several active sites for alkali metal ion storage. Moreover, the defect sites and higher nitrogen population of $\mathrm{C}_{2} \mathrm{~N}$ suggest that it will exhibit superior conductivity to boron nitride (BN) [17].

2.1.1.3 $C_{3} N_{4} \mathrm{C}_{3} \mathrm{~N}_{4}$ carbon nitride is the most reported member of the carbon nitride family. It is composed of consistently repeated tri-s-triazine units having planar $s p^{2}$-hybridized conjugation structures held together by van de Waals forces. It often occurs as bulk $\mathrm{C}_{3} \mathrm{~N}_{4}$, which has a relatively low indirect bandgap of $\sim 2.7 \mathrm{eV}$ and an interplanar distance of $0.324 \mathrm{~nm}$ and can be functionalized to obtain other architectures such as the monolayer 2D sheet (Fig. 4e) [18]. This indirect bandgap of $\mathrm{C}_{3} \mathrm{~N}_{4}$ highly has spurred massive interest in its application for 

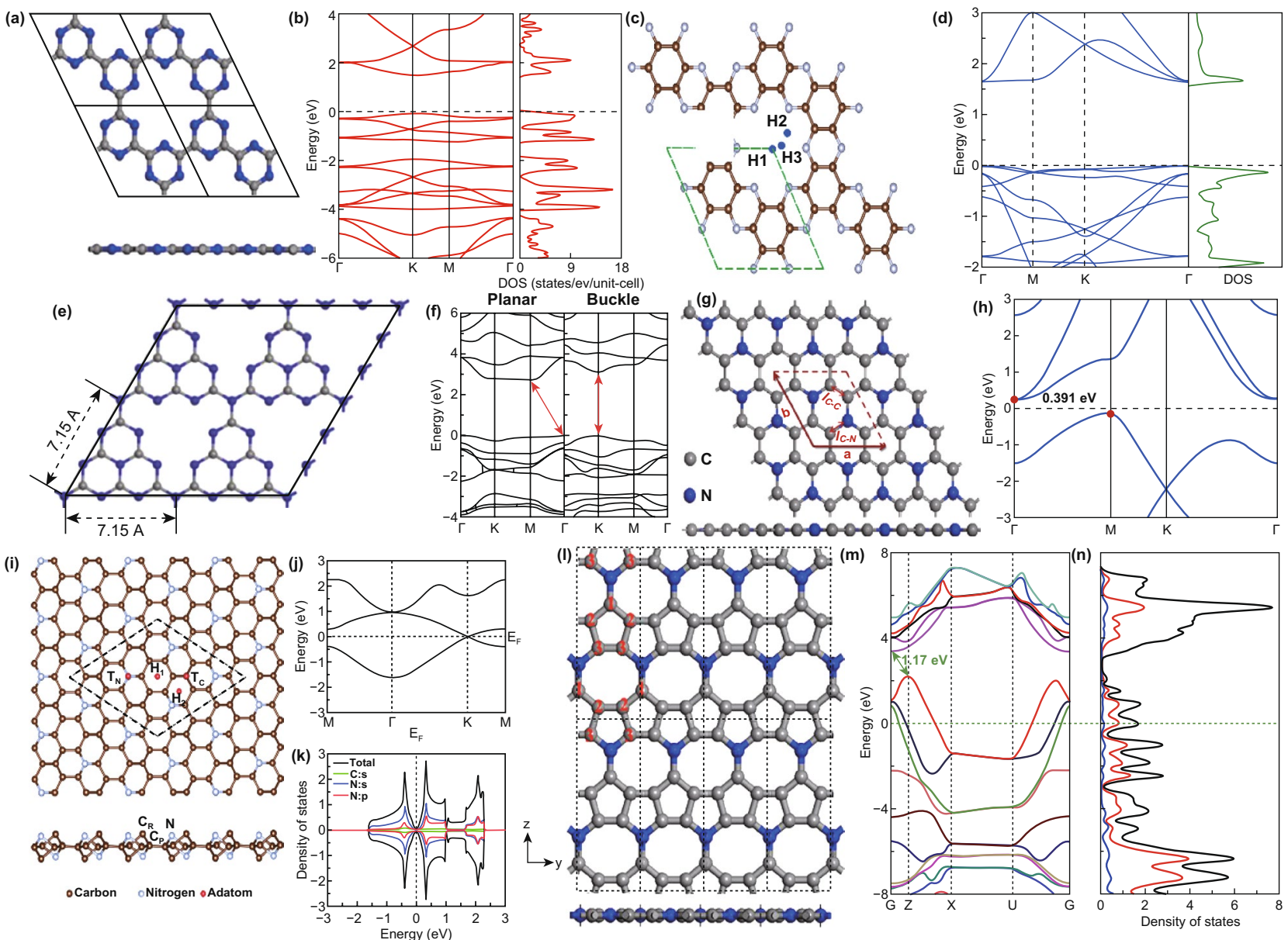

Fig. 4 a Top view and side view of the supercell $(2 \times 2)$ g- $\mathrm{C}_{3} \mathrm{~N}_{3}$. b Band structure and total density of state for $1 \times 1$ g-C $\mathrm{C}_{3} \mathrm{~N}_{3}$. Reproduced with permission from Ref. [15]. c Relaxed structure of $2 \times 2 \mathrm{C}_{2} \mathrm{~N}$ monolayer, H1, H2, and $\mathrm{H} 3$ are possible binding sites for transition metal atom doping on the $\mathrm{C}_{2} \mathrm{~N}$. d Band structure and density of states of $\mathrm{C}_{2} \mathrm{~N}$ monolayer. Reproduced with permission from Ref. [28]. e Schematic structure of monolayer g- $\mathrm{C}_{3} \mathrm{~N}_{4}$. Reproduced with permission from Ref. [18]. f Calculated band structures of monolayer g- $\mathrm{C}_{3} \mathrm{~N}_{4}$ with planar or buckled topology. Reproduced with permission from Ref. [20]. $\mathbf{g}$ Optimized structure and $\mathbf{h}$ band structure of $\mathrm{C}_{3} \mathrm{~N}$ monolayer. The unit cell is shown by the red dashed line. Reproduced with permission from Ref. [29]. i Top and side view of the atomic structure of monolayer $\mathrm{C}_{4} \mathrm{~N}$. The black dashed lines show the $3 \times 3 \times 1$ supercell of monolayer $\mathrm{C}_{4} \mathrm{~N}$. Four adsorption sites were considered $\left(\mathrm{H}_{1}, \mathrm{H}_{2}, \mathrm{~T}_{\mathrm{C}}, \mathrm{T}_{\mathrm{N}}\right)$. $\mathbf{j}$ Electronic band structures and $\mathrm{k}$ PDOS of the unit cell of a pristine $\mathrm{C}_{4} \mathrm{~N}$ monolayer. Reproduced with permission from Ref. [30]. 1 Top (upper) and side (lower) view of the atomic structure of $\mathrm{C}_{5} \mathrm{~N}$ monolayer. The gray and blue balls represent $\mathrm{C}$ atoms and $\mathrm{N}$ atoms, respectively. $\mathrm{m}$ Band structure and $\mathrm{n}$ density of states (DOS) of $\mathrm{C}_{5} \mathrm{~N}$ monolayer obtained from HSE06 calculations. The black, red, and blue lines denote the total DOS of $\mathrm{C}_{5} \mathrm{~N}$, the partial DOS of $\mathrm{C}$ atoms, and the partial DOS of $\mathrm{N}$ atoms, respectively. Reproduced with permission from Ref. [27]. Copyright permissions from Elsevier, Royal Society of Chemistry and Wiley-VCH. (Color figure online)

several applications such as photocatalysis, oxygen evolution, reduction reactions, sensing devices, etc. However, the semiconductor property of bulk $\mathrm{C}_{3} \mathrm{~N}_{4}$ limits the electronic conductivity for application in electronic devices [19]. Under buckling, the indirect bandgap of bulk $\mathrm{C}_{3} \mathrm{~N}_{4}$ can be tuned into a direct bandgap material with superior electronic conductivity (Fig. 4f) [20]. This ability to easily modify the electronic and structural properties of $\mathrm{C}_{3} \mathrm{~N}_{4}$ makes it one of the most preferred and widely applied carbon nitride structures [21]. 


\subsubsection{Graphitic Nitrogen-Based Carbon Nitrides $\left(C_{3} N\right.$, $\mathrm{C}_{4} \mathrm{~N}$, and $\mathrm{C}_{5} \mathrm{~N}$ )}

Graphitic nitrogen is one of the most widely known forms of nitrogen. It has a nitrogen bonded to three carbon atoms, and it is the nitrogen-doped into the basal graphitic carbon plane of the material. Due to its superior negativity in comparison with carbon, it is possible for graphitic nitrogen to induce a positive charge on adjacent carbon, thereby making it readily active site for attraction to negatively charged species [22]. This makes it a commonly desired form of nitrogen doping, just like pyridinic nitrogen. The graphitic-N-based carbon nitrides, which we shall discuss in this review, include $\mathrm{C}_{3} \mathrm{~N}, \mathrm{C}_{4} \mathrm{~N}$, and $\mathrm{C}_{5} \mathrm{~N}$.

2.1.2.1 $C_{3} N$ The structure of $\mathrm{C}_{3} \mathrm{~N}$ contains well-defined homogenous rings with no large holes. It is a $2 \mathrm{D}$ honeycomb lattice configuration that displays a $\mathrm{D}_{6 \mathrm{~h}}$-symmetry that facilitates high structural stability and superior thermal conductivity (Fig. 4g). It is a semiconductor which displays a unique molecular orbital with a low unoccupied molecular orbital gap $(\sim 2.7 \mathrm{eV})$ and an indirect bandgap of $0.39 \mathrm{eV}$ (Fig. 4h) [23].

2.1.2.2 $C_{4} N$ Compared to the atomic structure of another carbon nitride, the $\mathrm{C}_{4} \mathrm{~N}$ structure is filled with $s p^{3}$ hybridized species and due to the presence of $4 p_{z}$ atomic orbitals in the projected electron density of states (PDOS), it exhibits a Dirac cone shape in its band structure like that of graphene (Fig. 4i, j). It is often called the dumbbell (DB) $\mathrm{C}_{4} \mathrm{~N}$ and depending on the positions of the raised $\mathrm{C} / \mathrm{N}$ atoms in its structure, two structural configurations exist, namely the $\mathrm{DB} \mathrm{C}_{4} \mathrm{~N}-\mathrm{I}$ and the $\mathrm{DB} \mathrm{C}_{4} \mathrm{~N}$-II. The former refers to a $\mathrm{C}_{4} \mathrm{~N}$ monolayer structure in which the raised $\mathrm{C} / \mathrm{N}$ atoms are located on the same side, while the latter is a $\mathrm{C}_{4} \mathrm{~N}$ monolayer structure where $\mathrm{C} / \mathrm{N}$ atoms are on opposite sides $[24,25]$. These two configurations of $\mathrm{C}_{4} \mathrm{~N}$ are semiconductors in nature and display a narrow and zero bandgap (Fig. 4k); however, this property can be tuned easily [24, 26].

2.1.2.3 $\mathrm{C}_{5} \mathrm{~N} \mathrm{C}_{5} \mathrm{~N}$ is the most recently reported graphitic$\mathrm{N}$-based carbon nitrides; like $\mathrm{C}_{4} \mathrm{~N}$, the atomic structure of $\mathrm{C}_{5} \mathrm{~N}$ is filled with $s p^{3}$ hybridized carbon atoms; however, it contains two cyclic rings of different sizes (Fig. 4l). A 5-membered carbon ring and an eight-membered carbon ring with two nitrogen atoms are opposite to each other, and these rings are side-by-side to each other (see the atomic structure of $\mathrm{C}_{5} \mathrm{~N}$ in Fig. $4 \mathrm{k}$ ). The $\mathrm{C}_{5} \mathrm{~N}$ structure has some interesting features such as high chemical, mechanical and thermodynamic stability. Also, analysis of the band structure shows that the Fermi level is located below the valence-band maximum, which suggests it will be metallic and display superior conductivity than other carbon nitrides (Fig. 4m, n) [27].

\subsection{Doped Carbon Nitrides}

It has been proven that the metal ion storage capacity of an electrode material such as carbon nitride is significantly dependent on the electronic property. Most carbon nitrides are semiconductors, the electronic density of states (DOS) of the majority of the carbon nitrides possess a lone pair orbital of nitrogen at their Fermi level, and this leads to a large effective mass for hole/electron and results in poor electronic conductivity [19]. Therefore, doping is important for carbon nitride structures. Heteroatoms of elements at the top end of the periodic table such as sulfur, nitrogen, boron, and phosphorus, display narrow bandgap and lower high occupied molecular orbital, which signifies superior electronic conductivity. Therefore, replacing some of the carbon atoms in the crystalline structure of carbon nitrides with metallic or non-metallic atoms can boost their electronic conductivity and electron mobility. Doping also creates surface defects on the carbon nitride structure, and this is beneficial for effective charge transport.

Three heteroatoms are commonly used to dope carbon nitrides. These are carbon, nitrogen, sulfur, and phosphorus. $\mathrm{C}$ doping in carbon nitrides can facilitate the formation of delocalized $\pi$-bonds, which can result in $n-\pi^{*}$ electronic transition due to interaction with inherent nitrogen, and this will boost the electronic conductivity and charge transfer. $\mathrm{N}$ and $\mathrm{S}$ doping have proven to enlarge the interlayer distance of carbon nitrides; this facilitates the adsorption of metal ions and improves the conductivity. Cha et al. reported S-doped mesoporous $\mathrm{CN}$ carbon nitride (Fig. 5a shows the optimized structure), and from the electron density profile presented in Fig. 5b, it is obvious that effective charge distribution can be achieved at S-doped sites [31]. Boron (B) and phosphorus (P) doping can decrease the indirect bandgap of semiconductor carbon nitrides and make them metallic. Molaei et al. studied the effect of doping $\mathrm{C}_{3} \mathrm{~N}_{4}$ with phosphorus by replacing some of the $\mathrm{N}$ atoms with $\mathrm{P}$ atoms (Fig. 5c), and the DOS 


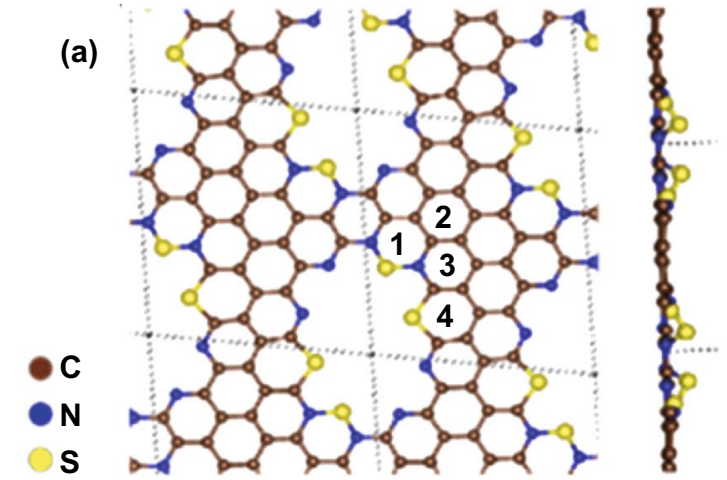

(b)
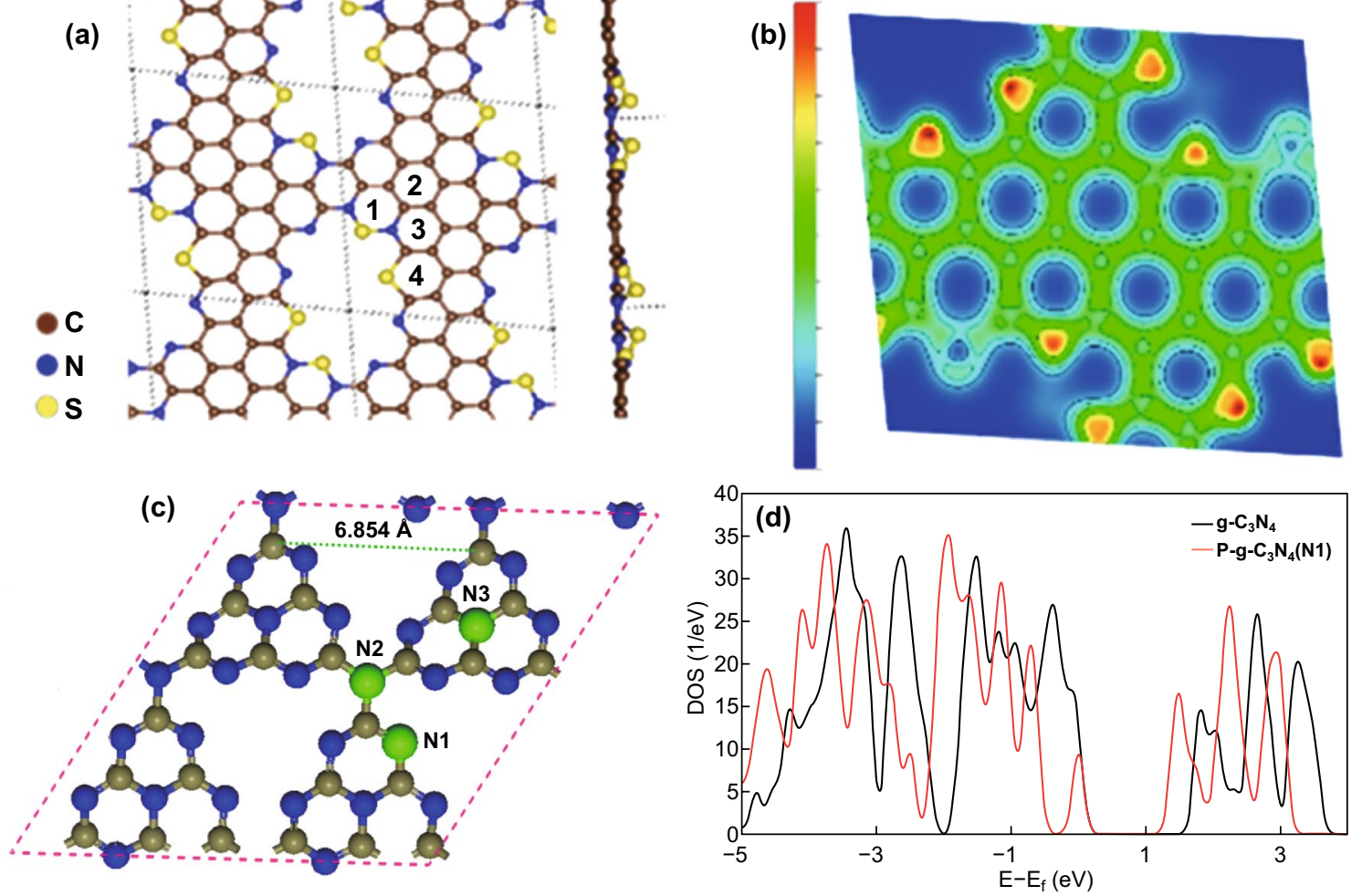

Fig. 5 a Optimized atomic structure of S-doped mesoporous CN (S-MCN). b Charge density profile of S-MCN, blue color-lowest electron density $(0 \%)$, and red color-highest electron density (100\%). Reproduced with permission from Ref. [31]. c Optimized structure g- $\mathrm{C}_{3} \mathrm{~N}_{4}$ monolayer, showing possible P-doping sites. $\mathbf{d}$ DOS plots of P-doped $\mathrm{g}_{-} \mathrm{C}_{3} \mathrm{~N}_{4}$ for P substitution at N1 and N2 sites. Reproduced with permission from Ref. [32]. Copyright permissions from American Chemical Society and Springer Nature. (Color figure online)

result shown in Fig. 5d confirms a shift of the Fermi level toward the conduction band. This suggests a narrowed band gap and enhanced electronic conductivity compared to pure $\mathrm{C}_{3} \mathrm{~N}_{4}$ [32]. In summary, heteroatom doping of carbon nitrides is beneficial for boosting their electrical conductivity, improving charge transfer, enlarging their interlayer distance, and boosting metal ion storage.

\subsection{CNBCs}

Although doping is an effective way of modulating the electronic conductivity of carbon nitrides, they are still limited by poor reversible capacity due to ineffective metal ion storage mechanisms and inadequate surface area. Most carbon nitrides are not able to achieve the desired performance in battery testing because the adsorption energy may be too strong for effective adsorption and desorption of metal ions or the diffusion barrier may be too high for easy metal ion transport. Also, apart from poor electronic conductivity, pure carbon nitrides are characterized by smaller surface area, which provides inadequate coverage for metal ion adsorption. CNBCs can solve these problems because combining pure carbon nitride with highly conductive materials like reduced graphene oxide ( $\mathrm{rGO}$ ) will produce a material with improved electronic conductivity and larger surface area. Moreover, the formation of CNBCs with high theoretical capacity metal oxides such as $\mathrm{Fe}_{2} \mathrm{O}_{3}$ will provide an anode material with an improved reversible capacity [33]. CNBCs can also be formed by combining pure carbon nitride with metal chalcogenides, perovskites, etc., for different metalion batteries. Hence, we summarize that an effective way to resolve the problems of poor reversible capacity and limited surface area is through CNBCs. 


\section{DFT-Guided Studies of CNBMs for Energy Storage Devices}

After the first discovery/synthesis of tri-s-triazine-based carbon nitride by Berzelius in 1834, the prediction and synthesis of beta- $\mathrm{C}_{3} \mathrm{~N}_{4}$ in 1993, the discovery of other carbon nitride structures have largely depended on theoretical first-principle simulations. First-principle calculations allow researchers to calculate or predict the structures and properties of material before its synthesis. It can also be used to resolve the discrepancy between experimental measurements and theoretical calculations by considering various possible alkali-metal atom diffusion kinetics, including diffusions in the bulk structure, on the surface, in the defect rich sites, etc. [1, 34]. This prevents random experimental tests or synthesis, thereby facilitating materials discovery. Furthermore, modification strategies for improving the properties of prospective materials can be easily explored through first-principle calculations. DFT is one of the most common computational simulation methods. It is a very powerful tool used to predict different electrochemical parameters of electrode materials. DFT calculations can be used to determine the alkali-metal atom insertion voltage of electrode materials, calculate the migration energy barriers of the alkalimetal atom, and directly visualize the transport pathways and dynamics $[35,36]$. In addition, the theoretical capacity of a potential electrode material can be predicted from DFT calculations by investigating the maximum metal atom loading on its structure. The adsorption energy of important molecules on the structure of electrode materials can also be calculated; for example, the adsorption of polysulfides on $\mathrm{Li}-\mathrm{S}$ cathode materials. Crystal and surface defects are important properties of an electrode material because they impact the alkali-metal atom transport mechanism and pathways, and their effect can also be studied through first-principle calculations. Moreover, information on the intrinsic electronic conductivity and bandgap can be directly inferred from the calculated electronic density of states by observing the Fermi level, conduction, and valence bands. The important role of DFT calculations in CNBMs for energy storage devices includes the DFT-guided synthesis and the DFT-predicted electrochemical properties. In terms of DFT-guided synthesis, DFT studies can determine important synthesis parameters such as the formation energy, exfoliation energy, and cohesive energy of a CNBM. These are criteria that indicate the ease/feasibility of synthesizing a CNBM experimentally. DFT calculations can also provide an atomistic understanding of the interaction between the $\mathrm{C} / \mathrm{N}$ and the adsorbed metal atom, which will reveal the structural limitations of the CNBMs and guide the synthesis of superior material. DFT studies also play a significant role in predicting fundamental electrochemical properties such as the bandgap, metal atom adsorption energy, open-circuit potential, charge transport kinetics, and theoretical capacity of the CNBMs. These parameters forecast the prospect of CNBMs for energy storage devices and reveal potential limitations that must be considered and improved upon. The electrochemical properties that can be predicted from DFT are summarized in Fig. 6.

\subsection{Theoretical Calculations on CNBMs for Energy Storage Devices}

Density functional theory calculations are one of the most useful tools for discovery and electrochemical investigation of different carbon nitrides for rechargeable batteries [41]. In this section, we discuss different carbon nitrides that have been studied through DFT.

\subsubsection{Pure Carbon Nitrides}

Through DFT calculations, it was predicted that $\mathrm{C}_{3} \mathrm{~N}_{4}$ carbon nitride could deliver a theoretical capacity of up to $524 \mathrm{mAh} \mathrm{g}^{-1}\left(\mathrm{Li}_{2} \mathrm{C}_{3} \mathrm{~N}_{4}\right)$ [42], and this capacity has not been achieved in battery testing. Mao et al. [43], Veith et al. [44], and Hankel et al. [45] showed that this poor performance was due to the high content of graphitic nitrogen in its structure which resulted in ineffective intercalation. We reported the first $\mathrm{C}_{3} \mathrm{~N}_{4}$ with reduced graphitic-N and increased pyridinic- $\mathrm{N}$ for LIBs, and our DFT calculations showed that unlike bulk/sheet $\mathrm{C}_{3} \mathrm{~N}_{4}$ which adsorbs $\mathrm{Li}$ atom in the triangular pore at high energy of $\sim 4 \mathrm{eV}$, a $1 \mathrm{D}-\mathrm{C}_{3} \mathrm{~N}_{4}$ fiber possesses lower Li binding energy $(2.61 \mathrm{eV})$ at its edges. Hence, it can effectively adsorb/desorb Li atoms (Fig. 7a, b) [46]. Hui Pan reported a first-principle study on $\mathrm{C}_{3} \mathrm{~N}_{4}$ carbon nitride nanotubes for LIBs and predicted that it could store $\mathrm{Li}$ atoms internally and externally due to its porous structure, which might make it better than other dimensions of carbon nitride [47]. 


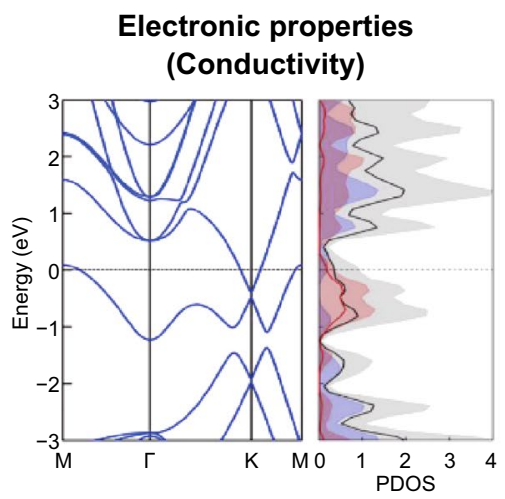

\section{Voltage profile (Open Circuit Potential)}

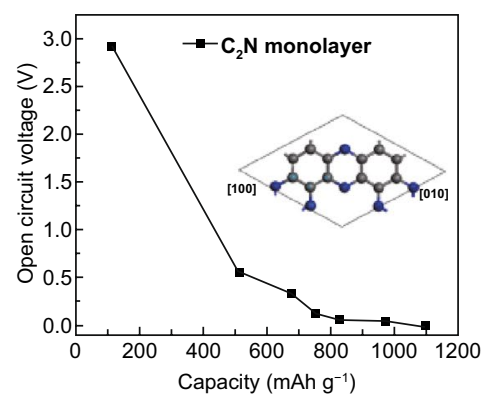

Charge density distribution (Charge transfer)

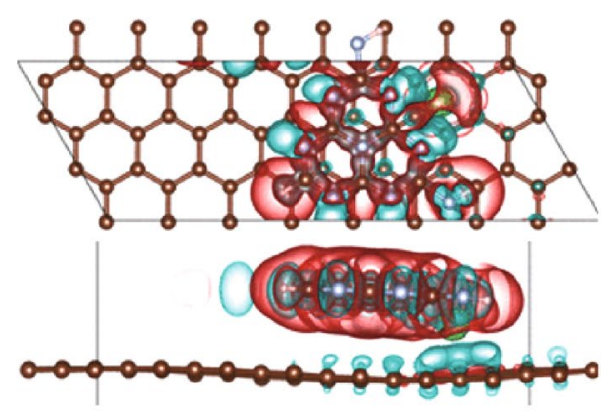

\section{Battery properties predicted from DFT}

Metal-atom transport (Diffusion Kinetics)

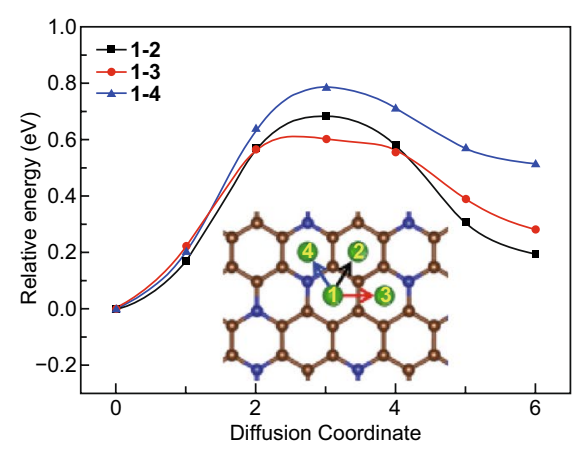

Polysulfide Binding (Adsorption Kinetics)

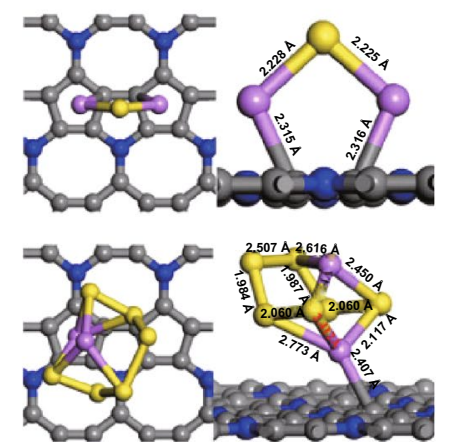

Metal-atom Storage (Theoretical Capacity)

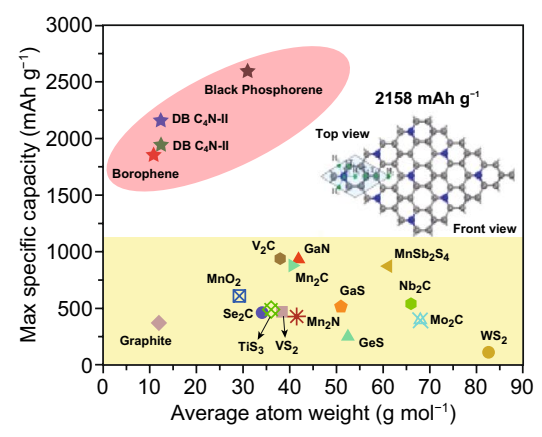

Fig. 6 Electrochemical properties of carbon nitrides can be predicted from DFT calculations. Reproduced with permission from [27, 37-40]. Copyright permissions from Elsevier, American Chemical Society, Wiley-VCH, and IOP Publishing. (Color figure online)

Other carbon nitride structures have also been studied for LIBs through DFT. For example, Hankel et al. showed that although g-CN can deliver a high capacity of $454 \mathrm{mAh} \mathrm{g}^{-1}$. Its high Li binding energy of $>3 \mathrm{eV}$ leads to ineffective intercalation/deintercalation and limits its prospects for LIBs [48]. The study of Hussain et al. on $\mathrm{C}_{2} \mathrm{~N}-h 2 \mathrm{D}$ showed that despite the pyridinic nitrogen, which facilitates Li storage, the high initial Li adsorption energy would result in poor battery performance [16]. By using a "pair of particle (metals) model," Wu et al. [49] carried out a DFT study on $\mathrm{C}_{2} \mathrm{~N}$ for LIBs and SIBs to show that $\mathrm{C}_{2} \mathrm{~N}$ monolayer can achieve a capacity of 2939 and $2469 \mathrm{mAh} \mathrm{g}^{-1}$ for LIBs and SIBs with low diffusion barrier and an OCV of $0.45 \mathrm{~V}$ [16]. Liu et al. carried out a DFT study on different $\mathrm{C}_{3} \mathrm{~N}$ compositions $\left(\mathrm{C}_{3} \mathrm{~N}, \mathrm{C}_{2.67} \mathrm{~N}\right.$, and $\left.\mathrm{C}_{3.33} \mathrm{~N}\right)$ and showed that the drop in capacity experience by $\mathrm{Xu}$ et al. [50] was due to ineffective intercalation of $\mathrm{Li}$. They concluded that $\mathrm{C}_{3.33} \mathrm{~N}$ is the preferred $\mathrm{C}_{3} \mathrm{~N}$ composition, and it delivered a reversible capacity of $840.35 \mathrm{mAh} \mathrm{g}^{-1}$ (Fig. 7c), operated at a low open-circuit potential of $0.12 \mathrm{~V}$, and displayed superior electronic conductivity [40]. Guo et al. proposed other $\mathrm{C}_{3} \mathrm{~N}$ allotropes $\left(\mathrm{C}_{3} \mathrm{~N}-\mathrm{S} 1, \mathrm{C}_{3} \mathrm{~N}-\mathrm{S} 2\right.$, and $\left.\mathrm{C}_{3} \mathrm{~N}-\mathrm{S} 3\right)$ with unique electronic properties, and the $\mathrm{C}_{3} \mathrm{~N}-\mathrm{S} 2$ structure displayed the most feasible Li diffusion pathway with lower diffusion barrier $(0.14 \mathrm{eV})$ for LIBs (Fig. 7d, e) [51]. Yang et al. also reported the first-principle study of two structural configurations of $\mathrm{DB} \mathrm{C}_{4} \mathrm{~N}$ as LIBs anode for LIBs, and they predicted that $\mathrm{DB} \mathrm{C}_{4} \mathrm{~N}-\mathrm{I}$ and $\mathrm{DB} \mathrm{C}_{4} \mathrm{~N}-\mathrm{II}$ could deliver high theoretical capacities of $1942 \mathrm{mAh} \mathrm{g}^{-1}\left(\mathrm{DB} \mathrm{C}_{4} \mathrm{~N}-\mathrm{I}\right)$ and $2158 \mathrm{mAh} \mathrm{g}^{-1}$ (DB C 4 N-II) [52].

DFT studies of pure carbon nitrides for large-sized metal ion batteries have also been reported. For instance, Weng et al. showed that pure $\mathrm{C}_{3} \mathrm{~N}_{4}$ nanosheet displays high adsorption energy for Na-atom, but it shows an exceedingly high diffusion barrier, which makes it fail as a SIBs anode [53]. Moreover, through DFT we showed that thanks to the high pyridinic-N of 
(a)

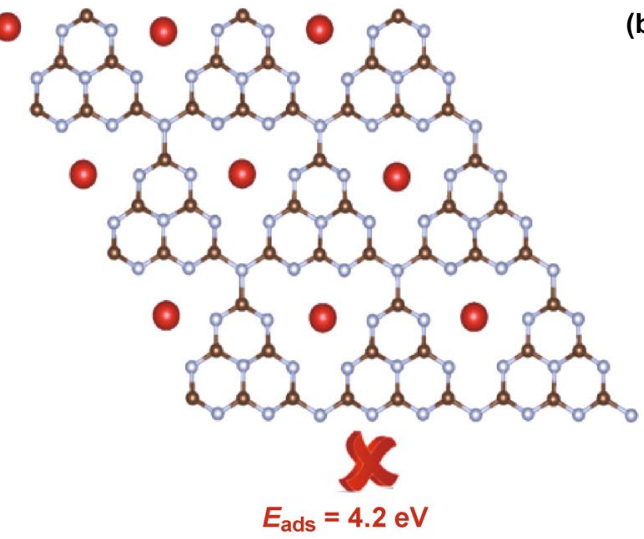

(b)

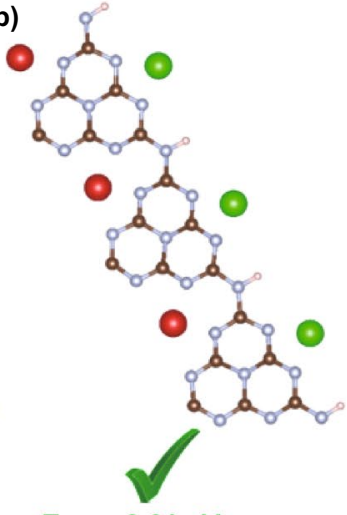

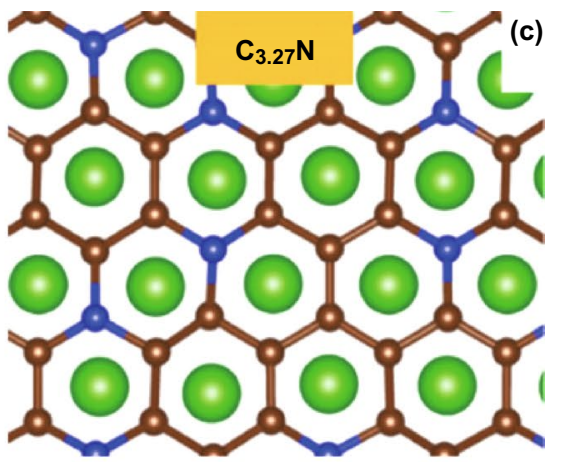

$E_{\mathrm{ads}}=2.61 \mathrm{eV}$

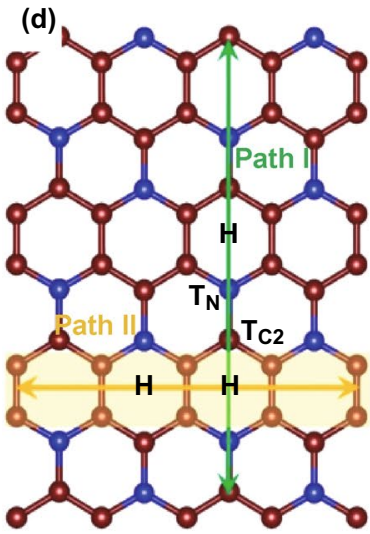

(e)
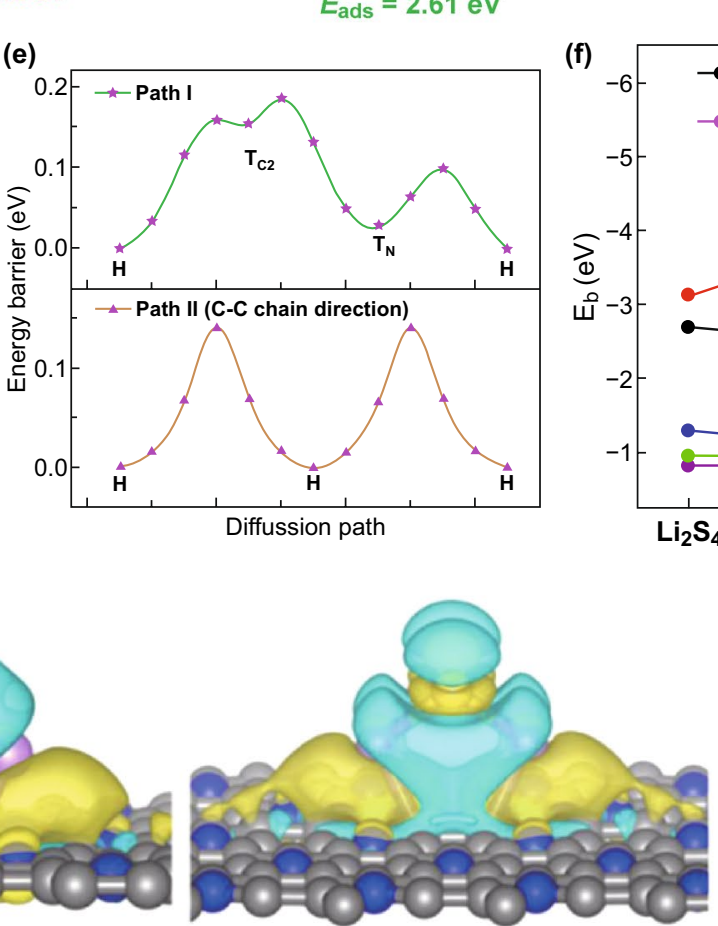

Capacity: $840.35 \mathrm{mAh} \mathrm{g}^{-1}$
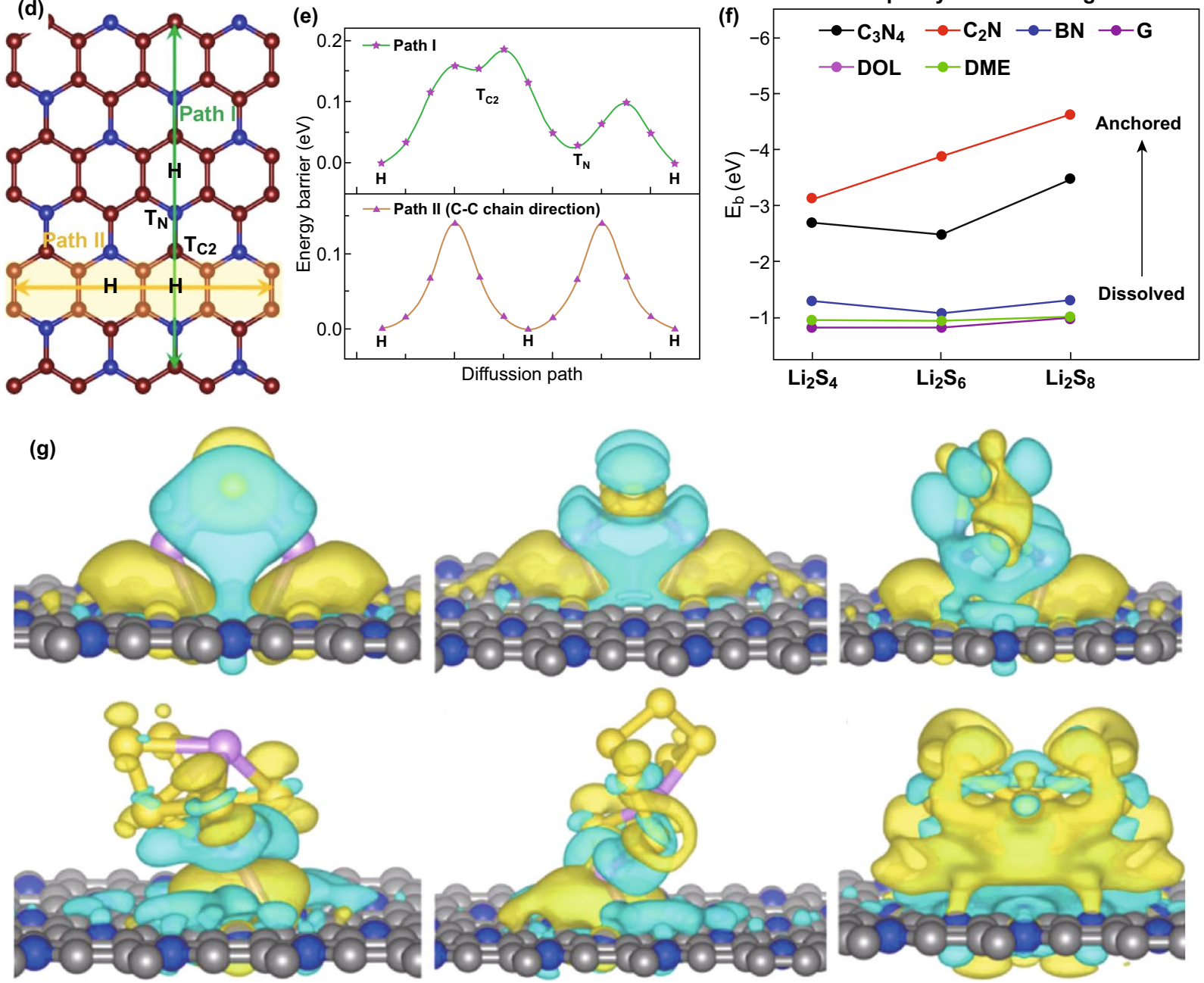

Fig. 7 Reversible Li active sites in a $2 \mathrm{D}-\mathrm{C}_{3} \mathrm{~N}_{4}$ sheet, and b $1 \mathrm{D}-\mathrm{C}_{3} \mathrm{~N}_{4}$ fiber. Green means reversible Li atoms and red means non-reversible Li atoms. $\mathbf{c}$ Top and side view of stable intercalation structures of $n \mathrm{Li}$ ions into $\mathrm{C}_{3} \mathrm{~N}$. Reproduced with permission from Ref. [40]. d Diffusion paths and e corresponding energy barriers of Li migration in $\mathrm{C}_{3} \mathrm{~N}-\mathrm{S} 2$. Reproduced with permission from Ref. [51]. f Binding energy of Li $\mathrm{S}_{4} /$ $\mathrm{Li}_{2} \mathrm{~S}_{6} / \mathrm{Li}_{2} \mathrm{~S}_{8}$ interacting with $\mathrm{G}, \mathrm{BN}, \mathrm{C}_{2} \mathrm{~N}, \mathrm{C}_{3} \mathrm{~N}_{4}$ and DOL/DME solvent, respectively. Reproduced with permission from Ref. [17]. $\mathrm{g}$ Isosurfaces of charge density difference of $\mathrm{Li}_{2} \mathrm{~S}, \mathrm{Li}_{2} \mathrm{~S}_{2}, \mathrm{Li}_{2} \mathrm{~S}_{4}, \mathrm{Li}_{2} \mathrm{~S}_{6}, \mathrm{Li}_{2} \mathrm{~S}_{8}$, and $\mathrm{S}_{8}$ adsorbed on the surface of $\mathrm{C}_{5} \mathrm{~N}$ with the isovalue of $0.003 \mathrm{~A}^{-3}$. Blue wireframes denote loss of electrons and yellow wireframes denote gain of electrons. Reproduced with permission from Ref. [27]. Copyright permissions from American Chemical Society, Elsevier and Wiley-VCH. (Color figure online) 
$1 \mathrm{D}-\mathrm{C}_{3} \mathrm{~N}_{4}$ fiber it exhibits a high affinity for potassium ions, but it suffers from a rather high K-diffusion barrier which limits effective ion transport [54]. Bhuriyal et al. also reported the first-principle study of $\mathrm{C}_{3} \mathrm{~N}$ monolayer as a promising anode material for SIBs and PIBs, and they showed that multilayer adsorption of the metal atoms generated a high capacity of $1072 \mathrm{mAh} \mathrm{g}^{-1}$ and low diffusion barrier of 0.03 and $0.07 \mathrm{eV}$ for $\mathrm{Na}$ and K-ion [55]. Xu et al. showed that metal ion ( $\mathrm{Li}$, $\mathrm{Na}$, and $\mathrm{K}$ ) adsorption on $\mathrm{C}_{4} \mathrm{~N}$ is an effective way to open the zero bandgap and modulate the electronic property because the adsorbed metal ion transfers charges to the surface of DB $\mathrm{C}_{4} \mathrm{~N}[30]$.

Thanks to the nitrogen-rich structure, carbon nitrides have also been studied for $\mathrm{Li}-\mathrm{S}$ and other battery systems. $\mathrm{Li}$ et al. reported that due to the accumulation of charges at the $\mathrm{N}-\mathrm{N}$ bond of the $\mathrm{C}_{4} \mathrm{~N}_{4}$ structure, it demonstrates superior lithium polysulfide species (LIPSs) anchorage than commercial electrolyte solvent molecules (DOL and DME) [56]. Zheng and co-workers compared the LIPSs anchoring property of graphene, boron nitride $(\mathrm{BN}), \mathrm{C}_{2} \mathrm{~N}$, and $\mathrm{C}_{3} \mathrm{~N}_{4}$ with commercial solvents and showed that $\mathrm{C}_{2} \mathrm{~N}$ and $\mathrm{C}_{3} \mathrm{~N}_{4}$ were the most effective due to their stronger binding energy (Fig. 7f) surface interaction with LiPSs via the Li-N/C-S bonds formed during their interaction [17]. Liang et al. also showed that interaction between LIPSs and polymeric $\mathrm{C}_{3} \mathrm{~N}_{4}$ (p- $\mathrm{C}_{3} \mathrm{~N}_{4}$ ) exhibits strong ionic bonding, electrostatic, and $\mathrm{vdW}$ interactions which are beneficial for altering the bonding and spatial configuration of LIPSs which then modifies their redox kinetics [57]. Meng et al. also reported that the abundant nitrogen species on the surface of $\mathrm{C}_{3} \mathrm{~N}_{4}$ nanosheet is able to facilitate LiPSs anchoring by a surface chemical adsorption mechanism due to the formation of a Li-N bond [58]. Wang et al. reported a first-principle study on the application of $\mathrm{C}_{5} \mathrm{~N}$ as a LIPSs host. The isosurfaces of charge density difference presented in Fig. $7 \mathrm{~g}$ showed that it exhibits an effective physical/chemical adsorption property, which enables LIPSs anchoring and charge transfer to its surface [27]. Carbon nitrides have also been explored for metal-air batteries because of their unique properties. For example, Shinde et al. reported the prospect of $\mathrm{C}_{2} \mathrm{~N}$ for zinc-air (Zn-Air) batteries and showed that the open holey structure of $\mathrm{C}_{2} \mathrm{~N}$ enabled reversible oxygen reactions and improved the electronic conductivity [59]. Je et al. also carried out first-principle calculations on heptazine and triazine sourced $\mathrm{C}_{3} \mathrm{~N}_{4}$ for non-aqueous Li-O $\mathrm{O}_{2}$ battery, and the results showed that triazine was better because it delivered a higher overpotential. Interaction of $\mathrm{C}_{3} \mathrm{~N}_{4}$ with $\mathrm{LiO}_{2}$ resulted in the formation of a Li-N bonding, which is dependent on the ratio of $\mathrm{N}$ in the material and greatly influences their overpotential [60].

\subsubsection{Doped Carbon Nitrides}

Theoretical study on doped carbon nitrides of different atomic compositions has been reported. For example, Nong et al. considered the effect of non-metal doping (boron, oxygen, and sulfur) and the impact of strain on the Li storage capacity and $\mathrm{Li}$ absorptivity of $\mathrm{C}_{3} \mathrm{~N}$. They reported that oxygen-doped $\mathrm{C}_{3} \mathrm{~N}\left(\mathrm{O}_{\mathrm{N}}-\mathrm{C}_{3} \mathrm{~N}\right)$ was the preferred dopant, it operated at $0.02 \mathrm{~V}$ and delivered a higher theoretical capacity of $534.42 \mathrm{mAh} \mathrm{g}^{-1}$ although it exhibited a high Li diffusion barrier of $0.78 \mathrm{eV}$, and this could be lowered by applying strain to the $\mathrm{C}_{3} \mathrm{~N}$ structure [61]. Tian et al. also studied the effect of boron doping on the performance of $\mathrm{C}_{3} \mathrm{~N}$ for alkali metal ion battery ( $\mathrm{Li}, \mathrm{Na}$, and $\mathrm{K})$ and showed that $\mathrm{B}_{4}$-doped $\mathrm{C}_{3} \mathrm{~N}$ displays superior capacity, cycle, and thermal stability than pristine $\mathrm{C}_{3} \mathrm{~N}$ [29]. Cha et al. showed that $\mathrm{CN}$ possesses a high Na adsorption energy, which can foster attraction of $\mathrm{Na}$ atoms into its structure for SIBs batteries [31]. Although Weng et al. [62] proved that $\mathrm{C}_{3} \mathrm{~N}_{4}$ displays a very high Naadsorption energy which limits its application for SIBs, the report of Molaei et al. on P-doped $\mathrm{C}_{3} \mathrm{~N}_{4}$ showed that phosphorus doping is an effective way to decrease the high $\mathrm{Na}$ adsorption energy and diffusion barrier in $\mathrm{C}_{3} \mathrm{~N}_{4}$ (Fig. 8a-d). The more P-atoms introduced into the structure of $\mathrm{C}_{3} \mathrm{~N}_{4}$, the lower these energies [32]. Moreover, the work of Cha et al. [31] on Si-doped CN suggests that S-doping of carbon nitrides can successfully enlarge their interlayer distance for such large-sized metal-ion battery applications.

Doped carbon nitrides have also been studied for $\mathrm{Li}-\mathrm{S}$ battery, Lin et al. studied the effect of transition metal doping $\left(\mathrm{Mn}, \mathrm{Fe}, \mathrm{Co}, \mathrm{Ni}\right.$, and $\mathrm{Cu}$ ) in $\mathrm{C}_{2} \mathrm{~N}$ for improved immobilization of polysulfides in $\mathrm{Li}-\mathrm{S}$ batteries, their results showed that a Lewis acid-base interaction which boosted LiPSs anchoring was established, and a significant charge was transferred from the transition metal dopant to the $\mathrm{C}_{2} \mathrm{~N}$ monolayer with $\mathrm{Co} @ \mathrm{C}_{2} \mathrm{~N}$ transferring the most in line with its superior adsorption energy (Fig. 8e, f) [28]. Zhao and co-workers reported confined single-atom $\mathrm{Pt}$ in holey g- $\mathrm{C}_{3} \mathrm{~N}_{4}$, and DFT calculations showed that incorporation of single-atom $\mathrm{Pt}$ in holey g- $\mathrm{C}_{3} \mathrm{~N}_{4}$ leads to improved electrical 

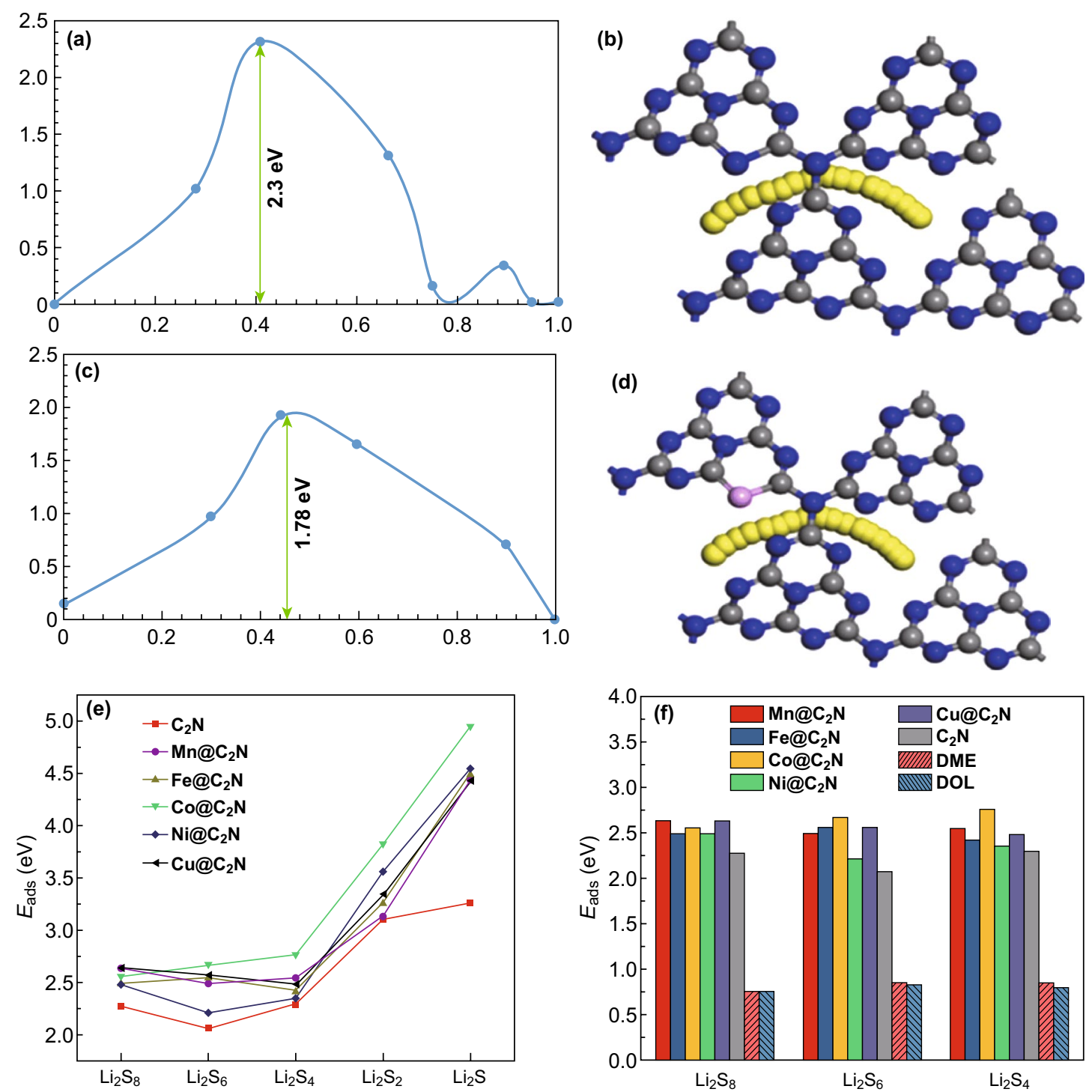

Fig. 8 a Energy barrier for Na diffusion through $\mathrm{g}_{-} \mathrm{C}_{3} \mathrm{~N}_{4}$, b corresponding Na diffusion path. c Energy barriers for Na diffusion through P-g$\mathrm{C}_{3} \mathrm{~N}_{4}$, d corresponding $\mathrm{Na}$ diffusion path. Reproduced with permission from Ref. [32]. e Adsorption energies of LiPSs on transition metal embedded $\mathrm{C}_{2} \mathrm{~N}$ monolayers. f Adsorption energies of long-chain LiPSs with transition metal embedded $\mathrm{C}_{2} \mathrm{~N}, 1,2$-dimethoxyethane (DME) and 1,3-dioxolane (DOL). Reproduced with permission from Ref. [28]. Copyright permissions from Springer Nature and Elsevier. (Color figure online)

conductivity and a more stable structure with efficient electron and ionic transfer [63].

\subsubsection{CNBCs}

CNBCs with superior electronic conductivity and higher capacity have also been studied through DFT. For example, Wang et al. reported a DFT study of $\mathrm{C}_{3} \mathrm{~N} /$ graphene heterostructure for LIBs and proved that the electrical conductivity and structural stability can be significantly improved. The heterostructure recorded a high theoretical capacity of $1079 \mathrm{mAh} \mathrm{g}^{-1}$, a low Li diffusion barrier of $0.28 \mathrm{eV}$ at the interlayer (Fig. 9a), and operated at a low open-circuit voltage of $0.13 \mathrm{~V}$ [37]. Ding et al. reported the first-principle study of $\mathrm{C}_{2} \mathrm{~N} /$ graphene bilayer for LIBs, and by using molecular dynamic (MD) simulations, they predicted that Li storage follows a two-step process, i.e., migration through the $z$-direction via the large hole in the center of the $\mathrm{C}_{2} \mathrm{~N}$ 

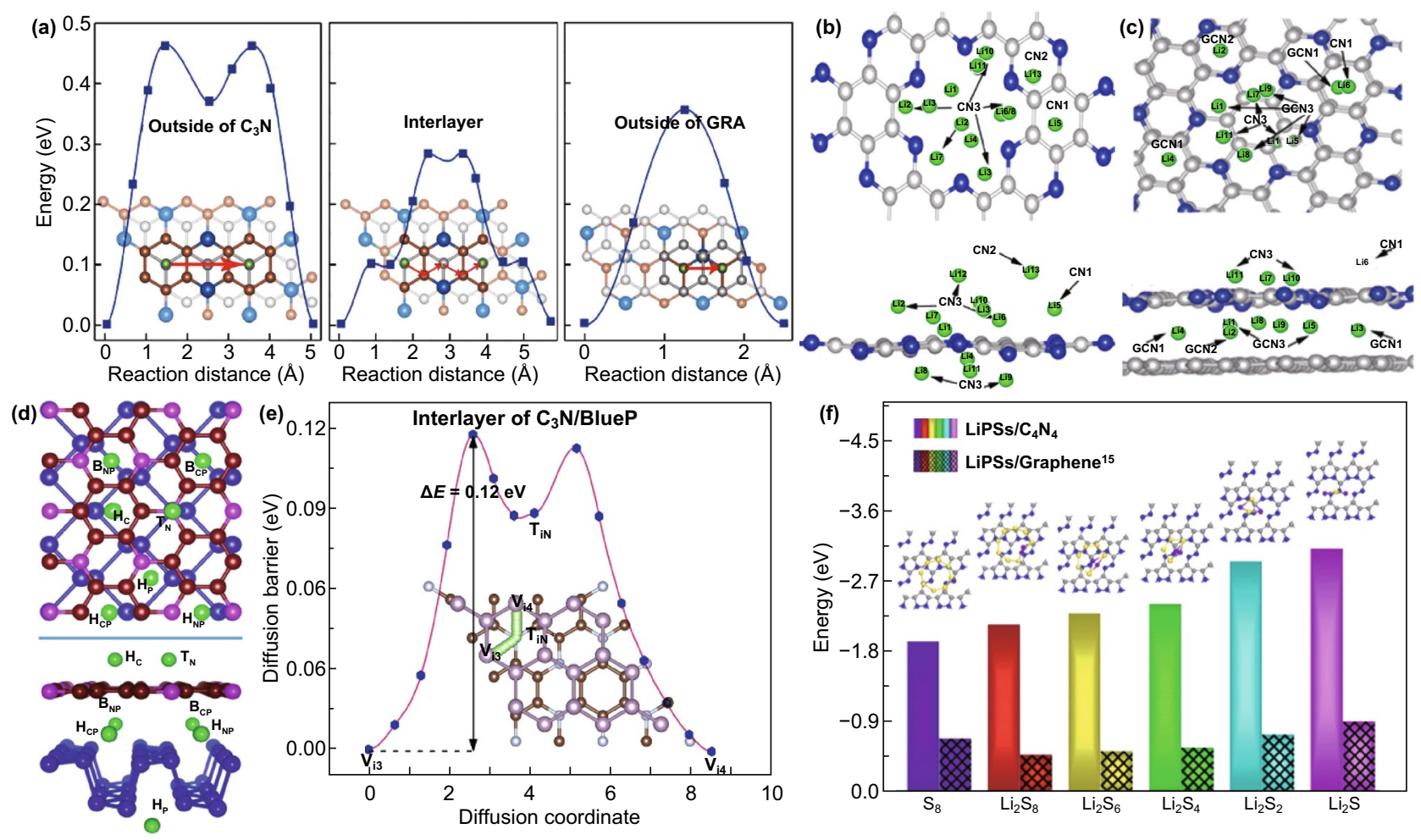

Fig. 9 a Energy profiles for Li atom diffusion on $\mathrm{C}_{3} \mathrm{~N} / \mathrm{GRA}$, along with the corresponding pathways denoted as red arrows. Carbon atoms from graphene-gray balls, carbon atoms from $\mathrm{C}_{3} \mathrm{~N}$-orange balls, nitrogen atoms-blue and lithium atoms-green. Reproduced with permission from Ref. [37]. b Top and side views of $\mathrm{Li}_{13}-\mathrm{C}_{2} \mathrm{~N}$ structure; $\mathbf{c}$ top and side views of the $\mathrm{Li}_{11}-\mathrm{C}_{2} \mathrm{~N} /$ graphene bilayer. Different adsorption sites are indicated as CN1, CN2, CN3, GCN1, GCN2, and GCN3 for both structures. Reproduced with permission from Ref. [38]. d Top and side views of the Li adsorption site on the $\mathrm{C}_{3} \mathrm{~N} / \mathrm{P}$ heterostructure $\left(\mathrm{Li} / \mathrm{C}_{3} \mathrm{~N} / \mathrm{P}, \mathrm{C}_{3} \mathrm{~N} / \mathrm{Li} / \mathrm{P}\right.$, and $\left.\mathrm{C}_{3} \mathrm{~N} / \mathrm{P} / \mathrm{Li}\right)$. $\mathrm{HC}$ and $\mathrm{TN}$ sites are on the outer surface of $\mathrm{C}_{3} \mathrm{~N}$, and $\mathrm{HP}$ site is on the outer surface of phosphorene, HCP, HNP, BCP, and BNP sites are in the interlayer of the $\mathrm{C}_{3} \mathrm{~N} / \mathrm{P}$ heterostructure. Reproduced with permission from Ref. [64]. e Lithium migration pathway and corresponding energy profile through Path II of the interlayer of $\mathrm{C}_{3} \mathrm{~N} / \mathrm{Blue}$ $\mathrm{P}$ heterostructure. Reproduced with permission from Ref. [65]. f Adsorption energy for $\mathrm{S}_{8}$ cluster and LiPSs on $\mathrm{C}_{4} \mathrm{~N}_{4}$ monolayer (bars without patterns) and graphene (bars with patterns), respectively. The insets on the pillars show $\mathrm{S}_{8}$ or $\mathrm{Li}_{2} \mathrm{Sn} / \mathrm{C}_{4} \mathrm{~N}_{4}$ structures generated by the principle of minimum energy. Reproduced with permission from Ref. [56]. Copyright permissions from Elsevier, American Chemical Society and Royal Society of Chemistry. (Color figure online)

structure and on to the surface of the $\mathrm{C}_{2} \mathrm{~N}$ membrane. The structures of different compositions of the bilayer heterostructures are presented in Fig. 9b, c. [38]. Guo et al. [64] and Lin et al. [65] also reported a DFT study on $\mathrm{C}_{3} \mathrm{~N} /$ phosphorene heterostructure for LIBs, while Bao et al. explored its potential for $\mathrm{Li} / \mathrm{Na}$ battery. The three reports concluded that the design of such $\mathrm{C}_{3} \mathrm{~N} /$ phosphorene heterostructure would not only address the issues of phosphorene but also alleviate the problems of $\mathrm{C}_{3} \mathrm{~N}$ for $\mathrm{Li} / \mathrm{Na}$ storage. Storage of $\mathrm{Li}$-ions occurred at the outer surface and interlayer of the heterostructure (Fig. 9d, e) [66].

DFT reports on CNBCs for $\mathrm{Li}-\mathrm{S}$ batteries have also been widely reported. For instance, Liao and co-workers showed that the anchoring ability of $\mathrm{C}_{3} \mathrm{~N}_{4}$ could be exploited in CNBCs [67]. Fan et al. also reported a carbon black blended $\mathrm{g}-\mathrm{C}_{3} \mathrm{~N}_{4}$ (g-C-coated) for Li-S battery and showed that two bonds ( $\mathrm{C}-\mathrm{S}$ and $\mathrm{N}-\mathrm{Li}$ ) are formed as a result of its interaction with LIPSs. These bonds inhibit the migration of LiPSs because it effectively binds to the LiPSs [68]. The work of $\mathrm{Li}$ et al. on porous $\mathrm{C}_{4} \mathrm{~N}_{4}$ monolayer and $\mathrm{C}_{4} \mathrm{~N}_{4} /$ graphene composite for Li-S battery reported that LIPSs adsorption occurred by a chemisorption process and addition of graphene enhanced this process (Fig. 9f) [56]. Chen et al. studied the effect of transition metal ( $\mathrm{Fe}, \mathrm{Ni}, \mathrm{Cu}$, and $\mathrm{Co}$ )-doped $\mathrm{g}-\mathrm{C}_{3} \mathrm{~N}_{4} / \mathrm{C}$ composite for Li-S battery and showed that this would increase the electron mobility, while $\mathrm{g}-\mathrm{C}_{3} \mathrm{~N}_{4}$ will prevent polysulfide dissolution by anchoring LiPSs species [69]. In summary, DFT has been very key in the synthesis and electrochemical study of carbon nitrides for metal-ion 
Table 1 Comparison of the DFT predicted parameters of pure carbon nitrides with commercial graphite for energy storage devices

\begin{tabular}{|c|c|c|c|c|c|}
\hline Materials & Conductivity & Capacity $\left(\mathrm{mAh} \mathrm{g}^{-1}\right)$ & Adsorption energy (eV) & Diffusion barrier $(\mathrm{eV})$ & $\overline{\text { Operating voltage }(\mathrm{V})}$ \\
\hline Graphite & Metallic & $\begin{array}{l}372 \text { (LIBs) } \\
31 \text { (SIBs) [70] } \\
279 \text { (PIBs) [71] }\end{array}$ & $\begin{array}{l}1.1-1.29(\mathrm{LIBs})[72] \\
-0.67(\mathrm{SIBs})[73] \\
-0.44 \text { to } 2.0(\mathrm{PIBs})[74]\end{array}$ & $\begin{array}{l}0.22 \text { (LIBs) [75] } \\
0.09-0.35 \text { (SIBs) [76] } \\
0.039 \text { (PIBs) [77] }\end{array}$ & $\begin{array}{l}0-0.5 \text { (LIBs) [78] } \\
0.3 \text { (SIBs) [79] } \\
\sim 0.24 \text { (PIBs) [80] }\end{array}$ \\
\hline $\mathrm{CN}$ & Semi-conductor & 454 (LIBs) [48] & -5.03 (LIBs) [48] & $\sim 3$ (LIBs) [45] & $\sim 0.6$ (LIBs) [81] \\
\hline $\mathrm{C}_{2} \mathrm{~N}$ & Semi-conductor & $\begin{array}{l}2939 \text { (LIBs) [49] } \\
2469 \text { (SIBs) [49] }\end{array}$ & $\begin{array}{l}-3.437 \text { (LIBs) [49] } \\
-2.868 \text { (SIBs) [49] }\end{array}$ & $\begin{array}{l}0.409 \text { (LIBs) [49] } \\
0.116 \text { (SIBs) [49] }\end{array}$ & $\begin{array}{l}0.452 \text { (LIBs) [49] } \\
0.458 \text { (SIBs) [49] }\end{array}$ \\
\hline $\mathrm{C}_{3} \mathrm{~N}$ & Semi-conductor & $\begin{array}{l}837.06 \text { (LIBs) [40] } \\
1072 \text { (SIBs) [55] } \\
1072 \text { (PIBs) [55] }\end{array}$ & $\begin{array}{l}-0.01 \text { (LIBs) [40] } \\
-1.806 \text { (SIBs) [55] } \\
-2.230 \text { (PIBs) [55] }\end{array}$ & $\begin{array}{l}0.8 \text { (LIBs) [40] } \\
0.03 \text { (SIBs) [55] } \\
0.07 \text { (PIBs) [55] }\end{array}$ & $\begin{array}{l}0.15 \text { (LIBs) [40] } \\
0.13 \text { (SIBs) [55] } \\
0.26 \text { (PIBs) [55] }\end{array}$ \\
\hline $\mathrm{C}_{3} \mathrm{~N}_{4}$ & Semi-conductor & 524 (LIBs) [44] & $-4.56(\mathrm{LIBs})[45]$ & $\sim 1.8$ (LIBs) [47] & 0.8 (LIBs) [44] \\
\hline $\mathrm{C}_{4} \mathrm{~N}$ & Semi-conductor & $\begin{array}{l}\text { I-1942 (LIBs) [52] } \\
\text { II -2158 (LIBs) [52] }\end{array}$ & $\begin{array}{l}\mathrm{I}-1.3 \text { (LIBs) } \\
\mathrm{II}-0.93 \text { (LIBs) [52] }\end{array}$ & $\begin{array}{l}\mathrm{I}-0.26[52] \\
\mathrm{II}-0.21[52]\end{array}$ & $\begin{array}{l}\mathrm{I}-0.60[52] \\
\mathrm{II}-0.68[52]\end{array}$ \\
\hline $\mathrm{C}_{5} \mathrm{~N}$ & Metallic & N/A & N/A & N/A & N/A \\
\hline
\end{tabular}

batteries. Table 1 compares the DFT predicted parameters of carbon nitrides with commercial graphite anode for energy storage devices. From this table, it is obvious that most of the carbon nitrides can function as anode materials with superior theoretical capacity compared to graphite. These electrochemical properties have inspired researchers into the synthesis and fabrication of pure and doped carbon nitrides as well as CNBCs for energy storage devices.

\section{Synthesis Strategies of Pure and Doped Carbon Nitrides}

The conclusions obtained from DFT studies showed that the poor performance of most CNBMs can be traced to high metal atom adsorption energy due to excess graphitic$\mathrm{N}$, which leads to irreversible intercalation/deintercalation, poor conductivity, and low charge transfer mobility, as well as inferior structural stability after metal atom adsorption. DFT calculations showed that these problems could be overcome by regulating the ratio of $\mathrm{C} / \mathrm{N}$ in the structure and prioritizing pyridinic-N, heteroatom doping,
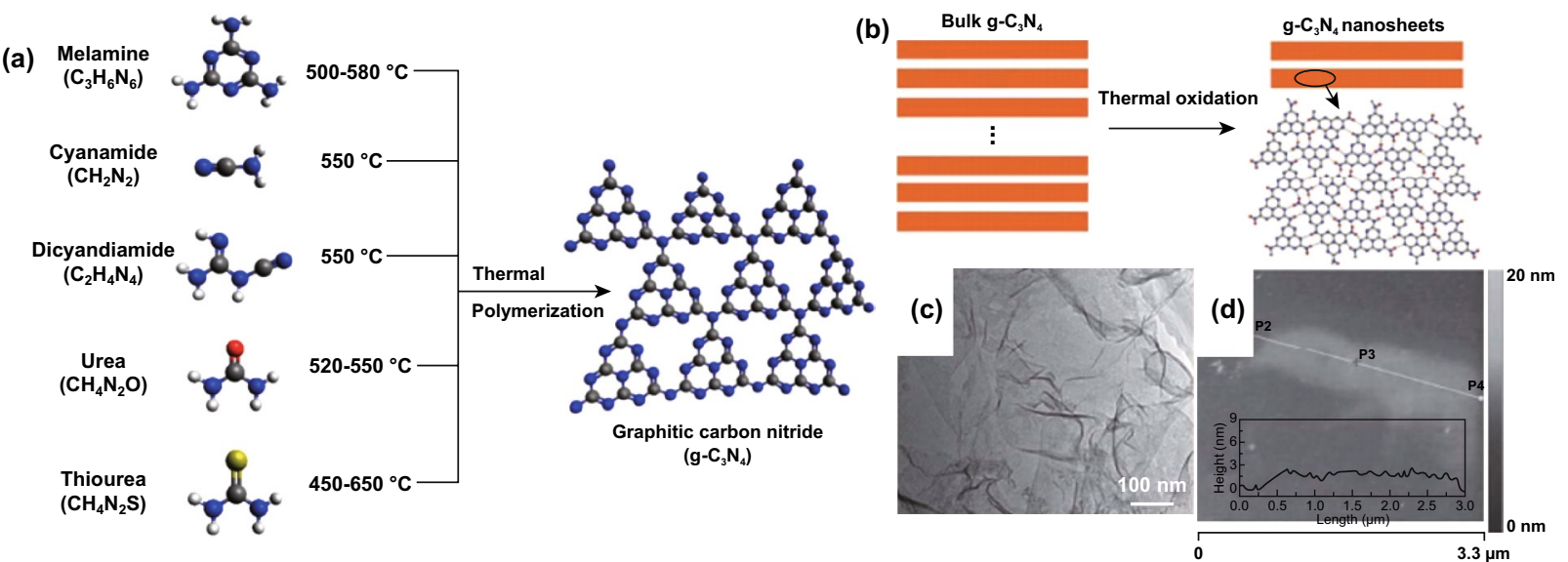

Fig. 10 a Schematic illustration of one of the top-down synthesis approach (thermal polymerization) for $g$ - $\mathrm{C}_{3} \mathrm{~N}_{4}$ using different precursors. Black balls—carbon $(\mathrm{C})$, blue balls—nitrogen $(\mathrm{N})$, white balls—hydrogen $(\mathrm{H})$, red balls—oxygen $(\mathrm{O})$, and yellow balls—sulfur (S), respectively. Reproduced with permission from Ref. [84]. b Schematic of the synthesis of g- $_{3} \mathrm{~N}_{4}$ nanosheets from bulk g- $\mathrm{C}_{3} \mathrm{~N}_{4}$. In the atomic model, carbon atoms - gray balls, nitrogen atoms-blue balls and hydrogen atoms-red. c TEM image of $g-\mathrm{C}_{3} \mathrm{~N}_{4}$ nanosheets. d Tapping-mode AFM image of a single $\mathrm{g}_{-} \mathrm{C}_{3} \mathrm{~N}_{4}$ nanosheet deposited on the silicon wafer substrate. The inset is the height curve determined along the line between P1 and P4. Reproduced with permission from Ref. [88]. Copyright permissions from American Chemical Society and Wiley-VCH. (Color figure online) 
and CNBCs design with other superior electrode materials. Inspired by these DFT conclusions, several researchers have modified the general experimental synthesis strategies to obtain CNMBs that exhibit the desired structural/ electronic properties. Such modified experimental synthesis strategies that are motivated by the findings in DFT studies can be considered DFT-guided synthetic protocols. In this section, we summarize some significant DFTguided synthesis strategies for CNBMs, including pure/ doped carbon nitrides as well as CNBCs.

\subsection{Top-Down Strategy}

Carbon nitrides generally occur in the bulk state, and this form of carbon nitride is obtained via thermal decomposition of N-rich amine compounds such as melamine [82] (Fig. 10a). However, bulk carbon nitride suffers from the poor conductivity, limited surface area, and sluggish reaction kinetics [83, 84]. Bulk carbon nitride also contains excess graphitic-N which is proven to limit the performance of carbon nitrides in rechargeable batteries according to DFT conclusions. One way to regulate the $\mathrm{C} / \mathrm{N}$ ratio and decrease the graphitic-N is by converting bulk carbon nitride to nanosheets and other morphologies. This can be achieved through the top-down strategy which is grouped into postthermal oxidative etching and ultrasonic liquid exfoliation.

\subsubsection{Thermal Oxidation}

As the name implies, this method involves the heat treatment of bulk carbon nitride at high temperature and it is an effective way to break the van der Waals forces which hold the layer of carbon nitride together. This process produces a sheet-like carbon nitride with large surface area, surface defects and adjusted layer thickness [22, 85]. As depicted in Fig. $10 \mathrm{~b}$, bulk $\mathrm{g}-\mathrm{C}_{3} \mathrm{~N}_{4}$ can be converted to $\mathrm{g}-\mathrm{C}_{3} \mathrm{~N}_{4}$ nanosheets via thermal oxidation and Fig. 10c, $d$ shows that the layer thickness can also be regulated. Guo et al. reported the synthesis of graphite/sheet-like carbon nitride (CN) as well as nanotube, nanoribbon, and microsphere morphologies via thermal treatment $[86,87] .2 \mathrm{D}-\mathrm{C}_{3} \mathrm{~N}$ carbon nitride with a needle-like morphology was also synthesized by via a direct solid-state reaction [23].

\subsubsection{Ultrasonic Liquid Exfoliation}

Another effective strategy to convert bulk multilayered carbon nitrides to few/single layer carbon nitrides is through the intercalation of solvent molecules through the bulk structure, thereby resulting in delamination (Fig. 11a). This liquid exfoliation process is effective for synthesizing nanosheets or flakes of carbon nitrides (Fig. 11b, c). Mahmood et al. reported the synthesis of two-dimensional $\mathrm{C}_{2} \mathrm{~N}$ carbon nitride by a top-down (facile wet-chemical
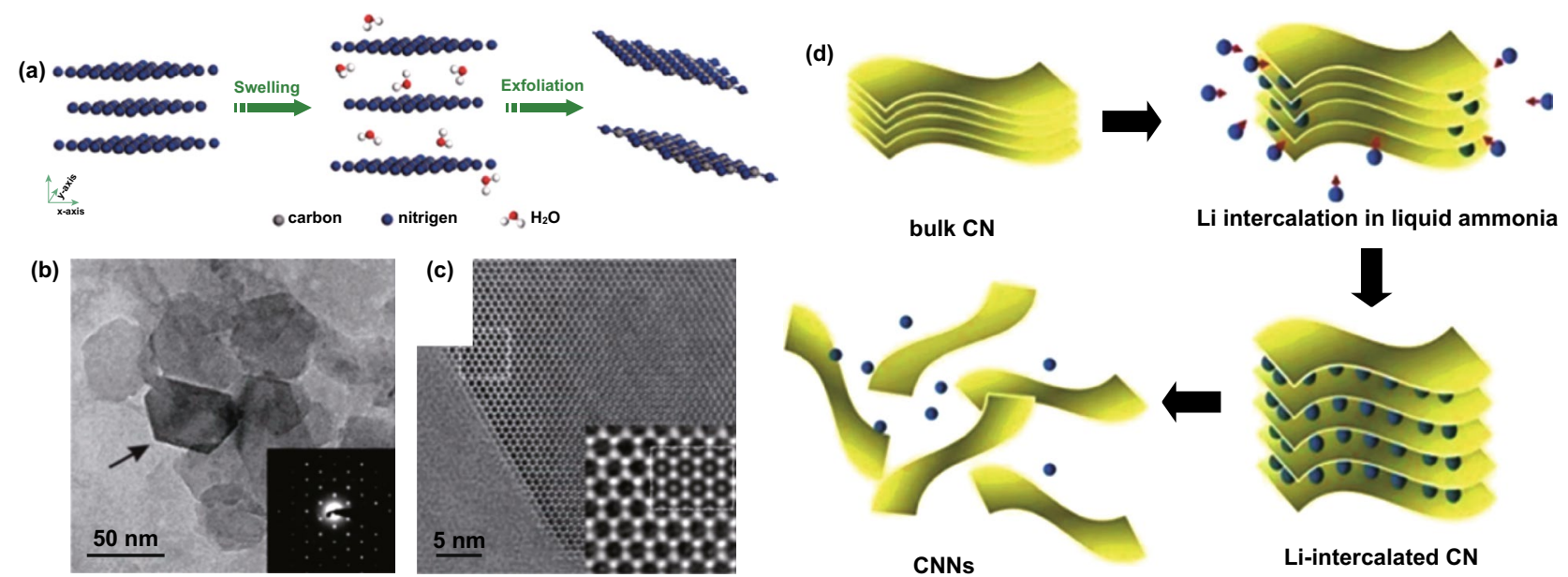

Fig. 11 a Schematic illustration of liquid-exfoliation process from bulk g- $\mathrm{C}_{3} \mathrm{~N}_{4}$ to ultrathin nanosheets. Reproduced with permission from Ref. [90]. b TEM image of exfoliated ultrathin nanosheets, $\mathbf{c}$ higher magnification of a carbon nitride nanosheet edge viewed along [001]. Reproduced with permission from Ref. [91] d Schematic diagram of the lithiation and exfoliation of g- $\mathrm{C}_{3} \mathrm{~N}_{4}$ nanosheets from bulk g- $\mathrm{C}_{3} \mathrm{~N}_{4}$. Reproduced with permission from Ref. [92]. Copyright permissions from American Chemical Society. (Color figure online) 
reaction) approach [89]. This process can also be achieved through lithiation exfoliation which uses Li ions as exfoliant to penetrate the layers of bulk carbon nitride and separate them to individual nanosheets (Fig. 11d).

\subsection{Bottom-Up Strategy}

The bottom-up strategy or template-aided synthesis is divided into soft and hard templating method.

\subsubsection{Hard Templating}

Templates are often used as morphology directing agents during the synthesis of unique carbon nitride morphologies. Hard templates such as silica [93-95], anodic alumina oxide [96], and carbon [97] are often reported for synthesizing CNBMs. For instance, DFT studies showed that by increasing the $\mathrm{N}$ content in $\mathrm{C}_{3} \mathrm{~N}_{4}$ to $\mathrm{C}_{3} \mathrm{~N}_{5}$ the electrochemical properties can be improved. Recently, Kim et al. reported the synthesis of a graphene-like mesoporous carbon nitride $\mathrm{C}_{3} \mathrm{~N}_{5}$ with superior electronic properties by using KIT-6 as a hard template [98]. Moreover, their DFT/electrochemical study showed that such composite can deliver excellent performance for energy storage devices [34]. The $\mathrm{C}_{3} \mathrm{~N}_{5}$ sample showed outstanding interesting electrochemical properties, and it was combined with graphene oxide to form a composite (MCN-11). Figure 12a shows a scheme of the synthesis procedure of the $\mathrm{C}_{3} \mathrm{~N}_{5}$ and the hybrid.

\subsubsection{Soft Templating}

Templating materials which demonstrate self-assembling properties have also been employed for synthesizing carbon nitrides by using ionic liquids [99, 100], surfactants [101-103], and amphiphilic block polymers [102, 104]. Yong et al. reported the synthesis of a nanoporous carbon nitride by using ionic liquid as soft templates (Fig. 12b-e), and such carbon nitride structure demonstrated superior conductivity to bulk material [101]. In summary, by using the conclusions of DFT studies as a guide, the general experimental synthesis approach of carbon nitrides can be optimized to achieve carbon nitrides with regulated $\mathrm{C} / \mathrm{N}$ ratio, increased pyridinic-N, superior structural stability, and conductivity for improved performance.

\subsection{Fabrication Strategies of Doped Carbon Nitrides}

The DFT study of Molaei et al. [32] proved that heteroatom doping of carbon nitride will boost the electronic conductivity and improve metal atom storage, and the DFT conclusion of this work motivated the Vinu group to report the synthesis of rod-like sulfur-doped mesoporous CN (S-CN) by a templating method (Fig. 13a) [31]. Phosphorus-doped mesoporous carbon nitride (P-MCN) was also synthesized via a simple template approach [105]. A schematic of the template synthesis method for heteroatom-doped mesoporous carbon nitrides is presented in Fig. 13b. To summarize, doped carbon nitrides can be synthesized through a combination of some top-down and bottom-up approaches (a)
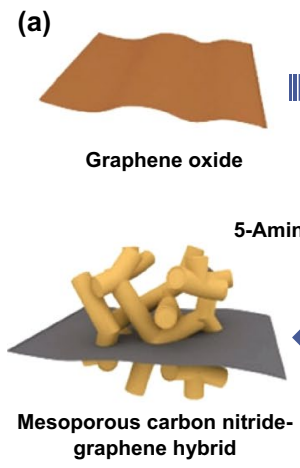

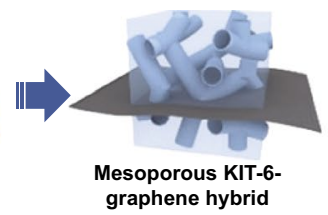

Amino-1H-tetrazole

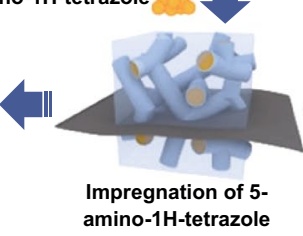

(b) Silica nanospheres (SNSs: $20-80 \mathrm{~nm}$ )

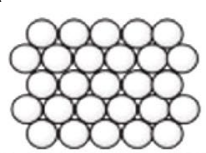

(c)

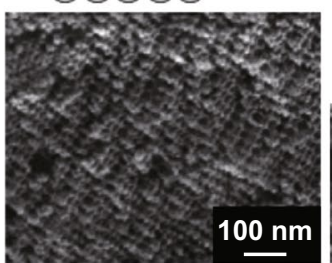

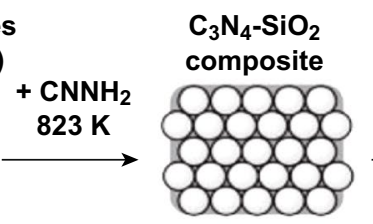

(d)

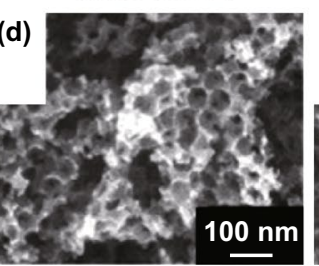

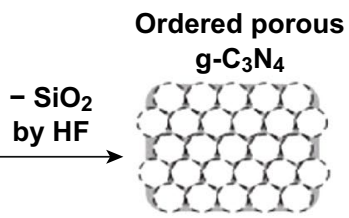

(e)

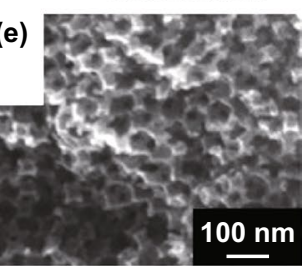

Fig. 12 a Schematic representation of the synthesis protocol for synthesizing the mesoporous $\mathrm{C}_{3} \mathrm{~N}_{5}$ and its graphene hybrid. Reproduced with permission from Ref. [98]. b Schematic illustration of the synthesis of ordered porous $\mathrm{g}-\mathrm{C}_{3} \mathrm{~N}_{4}$ by using close-packed silica nanospheres (SNSs) as the primary template. $\mathbf{c}-\mathbf{e}$ FE-SEM images of porous $\mathrm{g}-\mathrm{C}_{3} \mathrm{~N}_{4}$ at different resolutions. Reproduced with permission from Ref. [93]. Copyright permissions from Wiley-VCH and Royal Society of Chemistry. (Color figure online) 
(a)

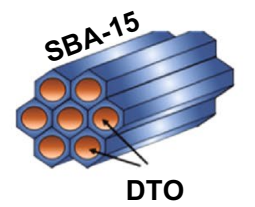

1) Carbonization at $500 / 600 / 700{ }^{\circ} \mathrm{C}$

2) Etching SBA-15
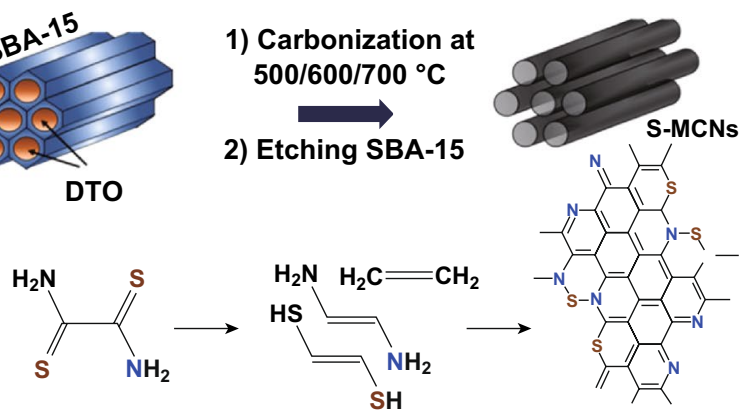

(b)
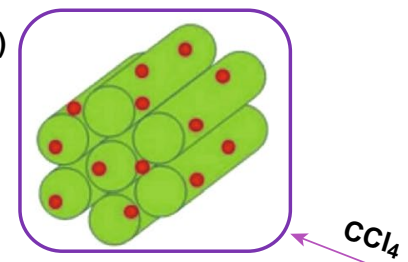

MCN-1

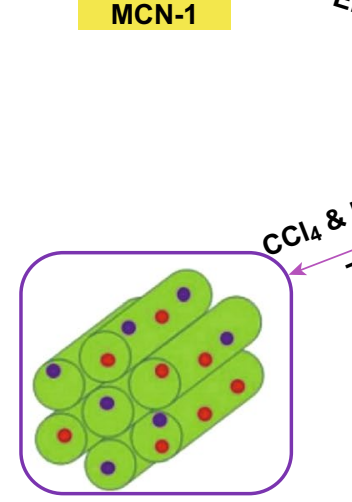

P-MCN-1
- Nitrogen

- Boron

- Phosphorus

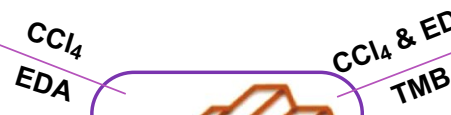

\& ED

TEP

SBA-15

$\mathrm{CCl}_{4}=$ Carbon Tetrachloride

$\mathrm{EDA}=$ Ethylenediamine

TMB $=$ Trimethyl Borate

TEP = Trimethyl Phosphate
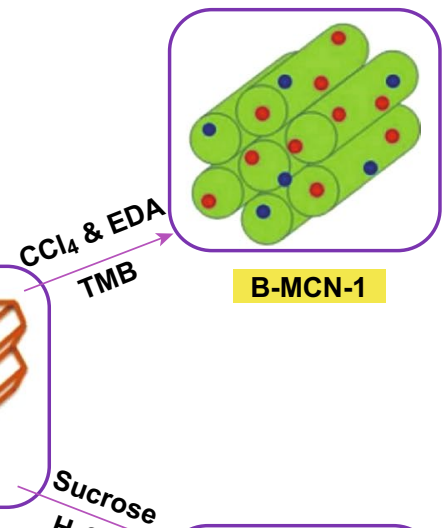

B-MCN-1

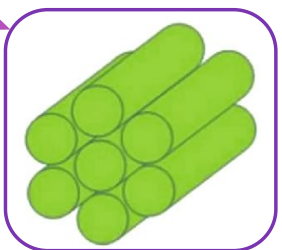

CMK-3

Fig. 13 a Schematic of the synthesis procedure of S-MCN [31]. b Schematic of the template synthesis method for heteroatom-doped mesoporous carbon nitrides. Reproduced with permission from Ref. [105]. Copyright permission from American Chemical Society. (Color figure online)

which often involves the use of a salt of the heteroatom or a surfactant.

\section{Fabrication Strategies for CNBCs}

DFT studies have proved that CNBCs design is another effective way to resolve the challenges of carbon nitrides because such CNBCs will demonstrate superior conductivity, better structural stability, and enhanced charge transfer. Therefore, in this section, we highlight some recent CNBCs that have been synthesized through commonly reported experimental synthesis strategies but inspired by the conclusions of DFT studies.

\subsection{Hydrothermal Method}

Hydrothermal method involves the controlled synthesis of a composite in a tightly sealed vessel under high temperature and pressure $[106,107]$. Although $2 \mathrm{D}-\mathrm{C}_{3} \mathrm{~N}_{4}$ is widely reported for designing CNBCs, our DFT studies showed that $1 \mathrm{D}-\mathrm{C}_{3} \mathrm{~N}_{4}$ exhibits superior structural stability and metal storage capability than $2 \mathrm{D}-\mathrm{C}_{3} \mathrm{~N}_{4}$ [40]. Moreover, our comparative DFT study between $1 \mathrm{D} / 2 \mathrm{D} \mathrm{C}_{3} \mathrm{~N}_{4} /$ graphene and $1 \mathrm{D} / 2 \mathrm{D}$ $\mathrm{C}_{3} \mathrm{~N}_{4}$ /graphene showed that $1 \mathrm{D} / 2 \mathrm{D}$ will perform better [38]. These DFT conclusions motivated us to combine $1 \mathrm{D}-\mathrm{C}_{3} \mathrm{~N}_{4}$ with 2D-rGO for energy storage devices. Therefore, we reported the synthesis of a $1 \mathrm{D} / 2 \mathrm{D} \mathrm{C}_{3} \mathrm{~N}_{4} / \mathrm{rGO}$ composite via 
(a)

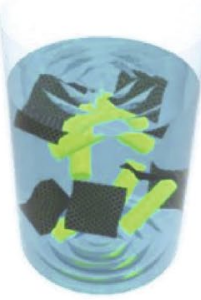

Sonication

[BMIM]PF

(b)

$$
\mathrm{Co}\left(\mathrm{CH}_{3} \mathrm{COO}\right)_{2}
$$

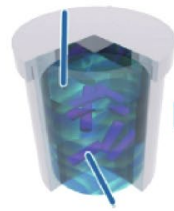

$\mathrm{C}_{3} \mathrm{~N}_{4}$ fibre

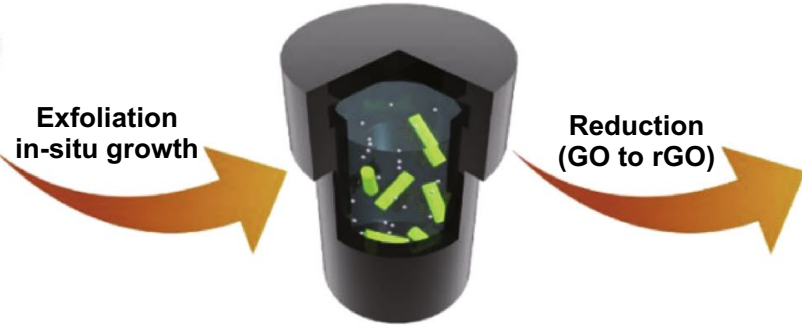

Hydrothermal reaction

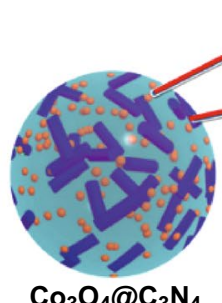

$\mathrm{Co}_{3} \mathrm{O}_{4} @ \mathrm{C}_{3} \mathrm{~N}_{4}$

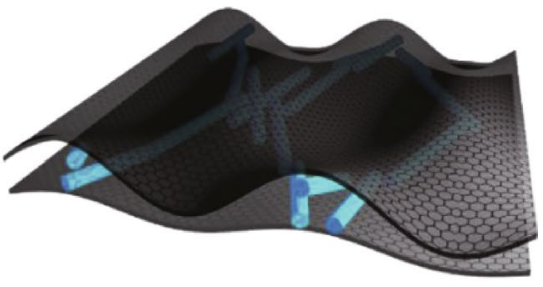

1D/2D C $\mathrm{N}_{3} \mathrm{~N}_{4} / \mathrm{rGO}$ composite

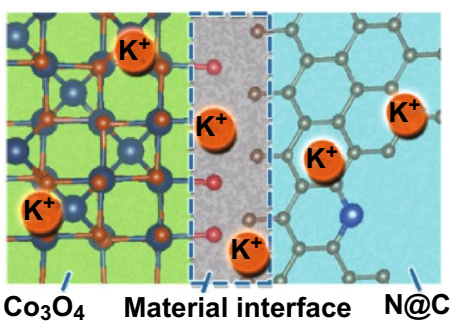

Fig. 14 a Schematic illustration of the synthesis of $1 \mathrm{D} / 2 \mathrm{D} \mathrm{C}_{3} \mathrm{~N}_{4} / \mathrm{rGO}$ composite via a hydrothermal/freeze-drying method. Reproduced with permission from Ref. [54]. b Scheme illustrating suggested potassiation and depotassiation mechanism of the $\mathrm{Co}_{3} \mathrm{O}_{4} @ \mathrm{~N}-\mathrm{C}$ electrode. Reproduced with permission from Ref. [108]. Copyright permission from Elsevier and American Chemical Society. (Color figure online)

a freeze-drying-assisted hydrothermal approach by deploying the $\pi-\pi$ interaction between $\mathrm{C}_{3} \mathrm{~N}_{4}$ and graphene [54]. Figure 14a shows the synthesis scheme of the composite. Guided by the result of our DFT calculations, we also reported the design of a composite of $\mathrm{Co}_{3} \mathrm{O}_{4} @ \mathrm{~N}-\mathrm{C}$ derived from $1 \mathrm{D}-\mathrm{C}_{3} \mathrm{~N}_{4}$ via an ionic liquid-assisted solvothermal method [108]. Scheme illustration of the synthesis strategy is depicted in Fig. 14b.

\subsection{Self-Assembly Method}

Due to their amphoteric nature, carbon nitrides possess tunable surface functional groups and surface charges which enable surface attachment with other functional materials such as graphene and other functional 2D materials [130]. Such structural interaction has been identified through the molecular dynamic simulation and DFT studies of Ding et al. and Wang et al. The heterostructure will display superior electronic conductivity and structural stability than the pure carbon nitride. This concept is employed in selfassembly synthesis of $\mathrm{C}_{3} \mathrm{~N}_{4}$ and other CNBMs. Figure 15 shows a detailed schematic of the self-assembly approach for a surface modified $\mathrm{C}_{3} \mathrm{~N}_{4}(\mathrm{pCN})$ with graphene oxide and reduced graphene oxide to achieve a $\mathrm{GO} / \mathrm{pCN}$ and $\mathrm{rGO} / \mathrm{pCN}$ composite, respectively [109].

\subsection{Other Composite Fabrication Strategies}

CNBCs can also be designed by some other unique methods, and Fu et al. designed a 2D-2D g- $\mathrm{C}_{3} \mathrm{~N}_{4}-\mathrm{rGO}$ hybrid via an in situ chemical method by initiating a nucleophilic reaction between epoxy groups on the surface of $\mathrm{GO}$ and amine/amide groups on dicyanamide- $\mathrm{C}_{2} \mathrm{H}_{4} \mathrm{~N}_{4}$. The synthesis method is depicted in Fig. 16a, and through this approach, the problem of poor electrical conductivity, aggregation, and restacking was resolved [110]. Similarly, $\mathrm{Li}$ et al. reported the design of a $\mathrm{Zn}_{2} \mathrm{GeO}_{4} / \mathrm{g}-\mathrm{C}_{3} \mathrm{~N}_{4}$ composite by growing $\mathrm{Zn}_{2} \mathrm{GeO}_{4} \mathrm{NPs}$ in-between the layers of $\mathrm{g}_{-} \mathrm{C}_{3} \mathrm{~N}_{4}$ via a solution approach to inhibit agglomeration of $\mathrm{Zn}_{2} \mathrm{GeO}_{4}$ NPs and restacking of g- $\mathrm{C}_{3} \mathrm{~N}_{4}$ (Fig. 16b). $\mathrm{Zn}_{2} \mathrm{GeO}_{4}$ also functioned as a spacer to enlarge the interlayer distance of $\mathrm{g}-\mathrm{C}_{3} \mathrm{~N}_{4}$ sheet enabling metal ion adsorption and improved conductivity [111]. Wang et al. reported the synthesis of a $\mathrm{GO} / \mathrm{g}-\mathrm{C}_{3} \mathrm{~N}_{4}$ microsphere by an ethanol-assisted spray drying approach [112]. Zhang et al. also reported the design of a sponge-like free-standing 3D S/graphene@ $\mathrm{g}-\mathrm{C}_{3} \mathrm{~N}_{4}$ hybrid using a microemulsion-assisted assembly method (Fig. 16c) [113]. 


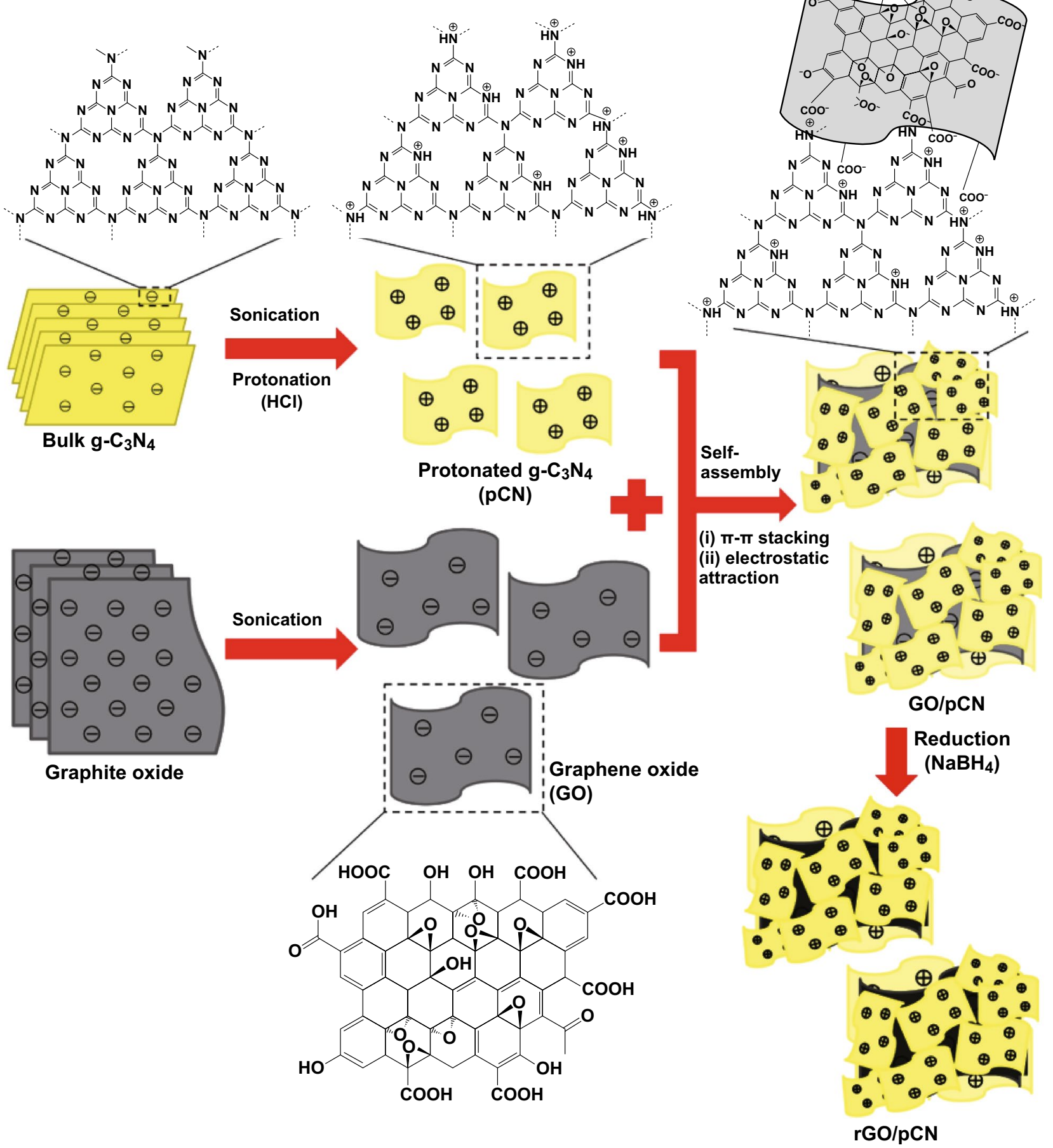

Fig. 15 Schematic diagram for the synthesis process of $\mathrm{rGO} / \mathrm{pCN}$ samples via a combined ultrasonic dispersion and electrostatic self-assembly strategy followed by a $\mathrm{NaBH}_{4}$-reduction process. Reproduced with permission from Ref. [109]. Copyright permission from Elsevier. (Color figure online) 


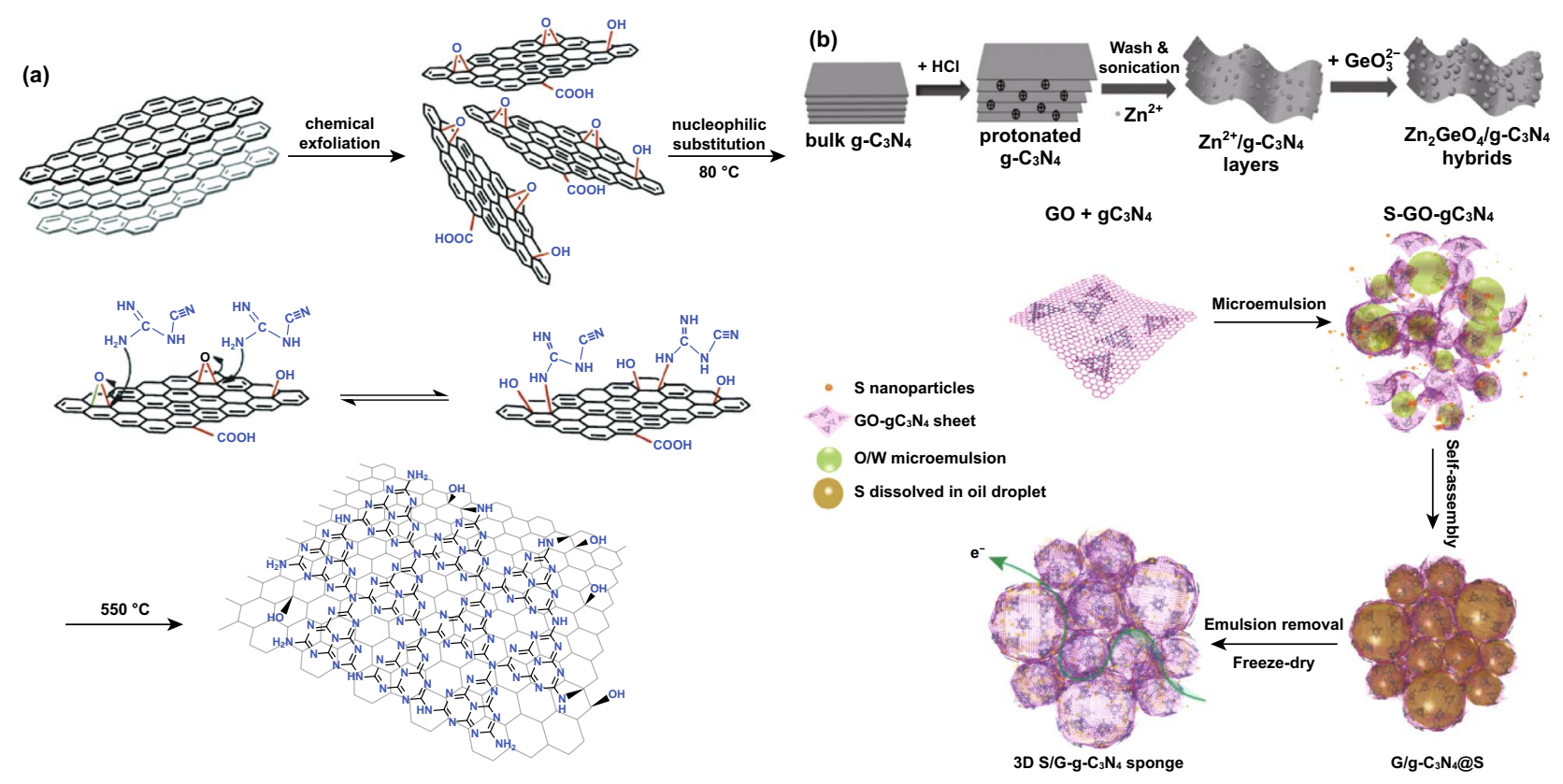

Fig. 16 a Illustration of the formation process of $\mathrm{g}-\mathrm{C}_{3} \mathrm{~N}_{4}-\mathrm{rGO}$. Reproduced with permission from Ref. [110]. b Schematic of the synthesis process of the $\mathrm{Zn}_{2} \mathrm{GeO}_{4} / \mathrm{g}-\mathrm{C}_{3} \mathrm{~N}_{4}$ hybrids. Reproduced with permission from Ref. [111]. c Schematic illustration of the procedure for preparing S/ GCN hybrid sponge. Reproduced with permission from Ref. [113]. Copyright permissions from Royal Society of Chemistry and Wiley-VCH. (Color figure online)

In summary, the advancement in experimental synthesis strategies of pure/doped carbon nitrides and CNBCs has been propelled by the conclusions of DFT studies on CNBMs. Precisely, DFT studies proposed that adjusting the $\mathrm{C} / \mathrm{N}$ ratio, increasing the concentration of pyridinic-N, heteroatom doping and CNBCs design are effective ways to inhibit the problem of irreversible intercalation/deintercalation, poor conductivity, and instability experienced by pure layered CNBMs in rechargeable batteries. These conclusions from DFT studies have guided the experimental synthesis of CNBMs to fabricate functional CNBMs which exhibit the desired requirements and deliver superior battery performance.

\section{Electrochemical Studies of CNBMs for Energy Storage Devices}

The structural/electronic properties and surface functionalities of CNBMs qualify them as promising electrode materials for energy storage devices. In this section, we give an overview of experimental works on carbon nitrides for energy storage devices including LIBs, SIBs and PIBs, Li-S, LABs, LMBs, ZABs, and SSBs.

\subsection{Lithium-Ion Batteries (LIBs)}

LIBs offer benefits such as lightweight, superior energy density, and long cycle life [3, 114, 115]; CNBMs (pure/ doped carbon nitrides and CNBCs) have been reported as electrodes.

\subsubsection{Pure Carbon Nitrides for LIBs}

Due to the structural and electronic properties of carbon nitrides, different atomic composition of carbon nitrides has been studied for LIBs. Yin and co-workers reported $\mathrm{C}_{3} \mathrm{~N}_{3}$ for LIBs but only a low reversible capacity of $197.8 \mathrm{mAh} \mathrm{g}^{-1}$ was obtained at $100 \mathrm{~mA} \mathrm{~g}^{-1}$ after 300 cycles and a ICE of $34.3 \%$ [81]. Xu et al. tested $\mathrm{C}_{2} \mathrm{~N}$ $\left(\mathrm{C}_{2} \mathrm{~N}-450\right)$ and $\mathrm{C}_{3} \mathrm{~N}$ for LIBs and at $1 \mathrm{C}, \mathrm{C}_{3} \mathrm{~N}$ only retained $285.1 \mathrm{mAh} \mathrm{g}^{-1}$ after 500 cycles, while $\mathrm{C}_{2} \mathrm{~N}-450$ maintained a reversible capacity of $516.1 \mathrm{mAh} \mathrm{g}^{-1}$ although it displayed large activation (Fig. 17a) [50]. Other carbon nitride compositions such as $\mathrm{C}_{4} \mathrm{~N}$ and $\mathrm{C}_{5} \mathrm{~N}$ have not been experimentally tested for any metal ion batteries. 

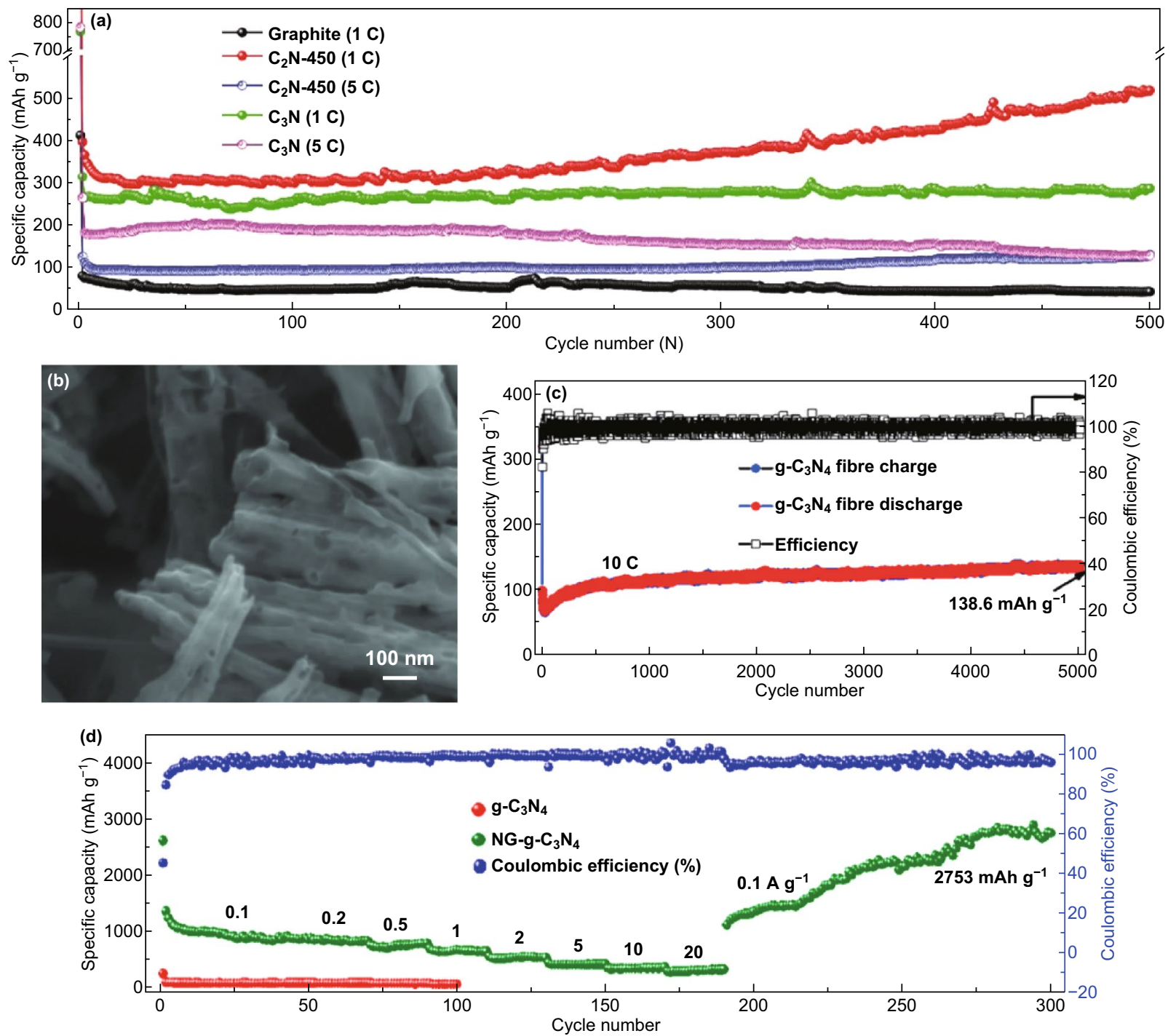

Fig. 17 a Long cycle life of $\mathrm{C}_{2} \mathrm{~N}-450, \mathrm{C}_{3} \mathrm{~N}$. Reproduced with permission from Ref. [50]. b SEM image of the $1 \mathrm{D}-\mathrm{g}-\mathrm{C}_{3} \mathrm{~N}_{4}$ fiber. c Cycling performance of $1 \mathrm{D}-\mathrm{g}-\mathrm{C}_{3} \mathrm{~N}_{4}$ fiber structure at a high current density of $10 \mathrm{C}$. Reproduced with permission from Ref. [46]. d Rate performance for ND-g- $\mathrm{C}_{3} \mathrm{~N}_{4}$ electrode at current density of $0.1,0.2,0.5,1,2,5,10$, and $20 \mathrm{~A} \mathrm{~g}^{-1}$ and galvanostatic discharge property for $\mathrm{g}_{-} \mathrm{C}_{3} \mathrm{~N}_{4}$ electrode. Reproduced with permission from Ref. [8]. Copyright permissions from Wiley-VCH, and American Chemical Society. (Color figure online)

We reported the synthesis of a porous $1 \mathrm{D}-\mathrm{C}_{3} \mathrm{~N}_{4}$ fiber with large surface area and multiple active sites (see SEM image-Fig. 17b) for LIBs; a reversible capacity of $181.7 \mathrm{mAh} \mathrm{g}^{-1}$ was achieved at $0.5 \mathrm{C}$ and $138.6 \mathrm{mAh} \mathrm{g}^{-1}$ at $10 \mathrm{C}$ (Fig. 17c) [46]. Chen et al. also reported the application of $\mathrm{C}_{3} \mathrm{~N}_{4}\left(\mathrm{ND}-\mathrm{g}-\mathrm{C}_{3} \mathrm{~N}_{4}\right)$ for LIBs and obtained a capacity of $2753 \mathrm{mAh} \mathrm{g}^{-1}$ after 300 cycles) although significant activation occurred (Fig. 17d). To provide a brief summary, pure carbon nitrides of different crystalline structures have been reported for LIBs, and commendable performances have been recorded (Table 2). However, the issues of ineffective intercalation/deintercalation due to extremely high $\mathrm{Li}$ adsorption energy, high Li diffusion barrier, structural deformation, and loss of crystallinity has severely limited the exploitation of their full potential. Therefore, DCNs and CNBCs are necessary to achieve improved performance. 
Table 2 Pure and doped carbon nitrides for LIBs and SIBs

\begin{tabular}{|c|c|c|c|c|c|c|c|}
\hline Battery type & Materials & Synthesis & Morphology & $\begin{array}{l}\text { Initial capacity (mAh } \\
\left.\mathrm{g}^{-1}\right)\end{array}$ & $\mathrm{ICE}^{a}$ & $\begin{array}{l}\text { Reversible capacity } \\
\left(\mathrm{mAh} \mathrm{g}^{-1}\right)\end{array}$ & References \\
\hline \multirow[t]{9}{*}{ LIBs } & $\mathrm{ND}-\mathrm{g}-\mathrm{C}_{3} \mathrm{~N}_{4}$ & $\begin{array}{l}\text { Magnesiothermic } \\
\text { denitriding method }\end{array}$ & Porous nanosheet & $2627 @ 100 \mathrm{~mA} / \mathrm{g}$ & $45.7 \%$ & $2753 @ 300$ cycles & {$[8]$} \\
\hline & $\mathrm{CN}-480-600$ & $\begin{array}{l}\text { Solid-state Wurtz } \\
\text { reaction }\end{array}$ & $\begin{array}{l}\text { Macroporous } \\
\text { graphite-like }\end{array}$ & $575.7 @ 100 \mathrm{~mA} / \mathrm{g}$ & $19.9 \%$ & $197.8 @ 300$ cycles & [144] \\
\hline & $\mathrm{C}_{2} \mathrm{~N}-450$ & $\begin{array}{l}\text { Bottom-up wet-chem- } \\
\text { ical reaction. }\end{array}$ & Stacked sheet & $1629.6 @ 0.1 \mathrm{C}$ & $57.2 \%$ & $516.1 @ 500$ cycles & [146] \\
\hline & $\mathrm{C}_{3} \mathrm{~N}$ & $\begin{array}{l}\text { Bottom-up wet-chem- } \\
\text { ical reaction. }\end{array}$ & Rod-like & $787.3 @ 0.1 \mathrm{C}$ & $48.7 \%$ & $\begin{array}{l}\text { 1C, } 285.1 @ 500 \\
\text { cycles }\end{array}$ & {$[126]$} \\
\hline & $\mathrm{Li}-\mathrm{C}_{3} \mathrm{~N}_{4}$ & $\begin{array}{l}\text { Electrochemical and } \\
\text { solid-state reactions }\end{array}$ & Sheet-like & 188 & - & $38 @ 6$ cycles & [121] \\
\hline & $\mathrm{C}_{6} \mathrm{~N}_{8}\left(\mathrm{C}_{3} \mathrm{~N}_{4}\right)$ & Thermal oxidation & - & $250 @ 30 \mathrm{~mA} / \mathrm{g}$ & - & $50 @ 50$ cycles & [122] \\
\hline & $1 \mathrm{D}-\mathrm{C}_{3} \mathrm{~N}_{4}$ fiber & $\begin{array}{l}\text { Polyaddition/polycon- } \\
\text { densation reaction }\end{array}$ & Porous layered fiber & $419.7 @ 0.5 \mathrm{C}$ & $84.1 \%$ & $181.7 @ 200$ cycles & [46] \\
\hline & NGC & Carbonization & Graphene-like & $2749 @ 50 \mathrm{~mA} / \mathrm{g}$ & $50.3 \%$ & $1143 @ 200$ cycles & [145] \\
\hline & P-MCN-1 & Template synthesis & Spherical particles & $2850 @ 1 \mathrm{~A} / \mathrm{g}$ & $44.2 \%$ & $963 @ 1000$ cycles & [105] \\
\hline SIBs & $\mathrm{C}_{6} \mathrm{~N}_{8}\left(\mathrm{C}_{3} \mathrm{~N}_{4}\right)$ & Thermal oxidation & - & $250 @ 30 \mathrm{~mA} / \mathrm{g}$ & - & $10 @ 50$ cycles & [122] \\
\hline SIBs & S-MCN & $\begin{array}{l}\text { Hard template } \\
\text { approach }\end{array}$ & Rod-like morphology & 850@100 mA/g & $47 \%$ & $304.2 @ 100$ cycles & {$[31]$} \\
\hline
\end{tabular}

${ }^{\mathrm{a}}$ ICE Initial coulombic efficiency

\subsubsection{CNBCs for LIBs}

CNBCs can deliver superior structural/electronic properties, enhanced structural stability and extremely large surface area which will boost the overall LIBs performance. In this section, we highlight some significant CNBCs including binary CNBCs and ternary CNBCs.

6.1.2.1 Binary CNBCs for LIBs Binary CNBCs involving carbonaceous materials such as graphene oxide are commonly reported because of the inherent $\pi-\pi$ stacking, extremely large surface area, surface functional groups, and electronic conductivity. For instance, Fu et al. [110] reported the application of a $2 \mathrm{D}-2 \mathrm{D}$ stacked $\mathrm{g}-\mathrm{C}_{3} \mathrm{~N}_{4}$-rGO hybrid for LIBs. The 2D-2D stacked $\mathrm{g}-\mathrm{C}_{3} \mathrm{~N}_{4}-\mathrm{rGO}$ hybrid achieved a reversible capacity of $1525 \mathrm{mAh} \mathrm{g}^{-1}$ at $100 \mathrm{~mA} \mathrm{~g}^{-1}$ and up to $943 \mathrm{mAh} \mathrm{g}^{-1}$ at $1000 \mathrm{~mA} \mathrm{~g}^{-1}$ [110]. Mohamed et al. designed a $\mathrm{CuO} / \mathrm{O}$-doped $\mathrm{g}-\mathrm{C}_{3} \mathrm{~N}_{4}$ composite which delivered a reversible capacity of $738 \mathrm{mAh} \mathrm{g}^{-1}$ after 100 cycles and $503 \mathrm{mAh} \mathrm{g}^{-1}$ after 500 cycles when tested at 100 and $1000 \mathrm{~mA} \mathrm{~g}^{-1}$, respectively. A depiction of the $\mathrm{Li}^{+}$storage mechanism is shown in Fig. 18a [116]. Li et al. also reported the application of metal oxide-based composite- $\mathrm{Zn}_{2} \mathrm{GeO}_{4} /$ g- $\mathrm{C}_{3} \mathrm{~N}_{4}$ composite for LIBs. The lithium storage mechanism for $\mathrm{g}-\mathrm{C}_{3} \mathrm{~N}_{4}$ and the composite is depicted by the scheme provided in Fig. 18b-e. The composite exhibited a supe- rior reversible capacity of $1370 \mathrm{mAh} \mathrm{g}^{-1}$ at $200 \mathrm{~mA} \mathrm{~g}^{-1}$ after 140 cycles [111]. Yin et al. designed a composite comprising of $\mathrm{SnS}_{2}$ anchored on $\mathrm{g}^{-} \mathrm{C}_{3} \mathrm{~N}_{4}$ nanosheet, and the $\mathrm{SnS}_{2} / \mathrm{CN}$ composite followed the conversion $\mathrm{SnS}_{2}+\mathrm{xLi}^{+}+\mathrm{xe}^{-} \rightarrow \mathrm{Li}_{\mathrm{x}} \mathrm{SnS}_{2}$ and alloying/dealloying lithium storage mechanism $\left(\mathrm{Sn}+4.4 \mathrm{Li}^{+}+4.4 \mathrm{e}^{-} \rightarrow \mathrm{Li}_{4.4} \mathrm{Sn}\right)$. Schematic of this storage mechanism is provided in Fig. $18 \mathrm{f}$. A high reversible capacity of $444.7 \mathrm{mAh} \mathrm{g}^{-1}$ was delivered at $100 \mathrm{~mA} \mathrm{~g}^{-1}$ after 100 cycles with structural stability and no pulverization [117].

6.1.2.2 Ternary CNBCs for LIBs Ternary composites which can provide additional benefits than binary composites have also been reported. Wang et al. reported the application of a Si@rGO/g- $\mathrm{C}_{3} \mathrm{~N}_{4}$ composite for LIBs. By taking advantage of the interfacial chemical bonding on functionalized $\mathrm{rGO} / \mathrm{g}-\mathrm{C}_{3} \mathrm{~N}_{4}$, Si nanoparticles (NPS) were effectively anchored on 2D-composite of $\mathrm{rGO} / \mathrm{g}-\mathrm{C}_{3} \mathrm{~N}_{4}$ (Fig. 19a), and such composite design resulted in a reversible capacity of 1354.8 and $799.6 \mathrm{mAh} \mathrm{g}^{-1}$ when cycled at 0.1 and $0.5 \mathrm{C}$, respectively [118]. Kong et al. also reported a red phosphorus/rGO- $\mathrm{C}_{3} \mathrm{~N}_{4}$ composite which delivered a capacity of $1032.6 \mathrm{~mA} \mathrm{~g}^{-1}$ after 600 cycles when tested at $200 \mathrm{~mA} \mathrm{~g}^{-1}$ [119]. Shi et al. reported the synthesis of a $\mathrm{Fe}_{2} \mathrm{O}_{3} / \mathrm{C}_{3} \mathrm{~N}_{4^{-}}$ graphene composite for LIBs. The Li storage mechanism of the $\mathrm{Fe}_{2} \mathrm{O}_{3} / \mathrm{CN}-\mathrm{G}$ composite is depicted in Fig. 19b, a high reversible capacity of $980 \mathrm{mAh} \mathrm{g}^{-1}$ at $50 \mathrm{~mA} \mathrm{~g}^{-1}$ after 50 

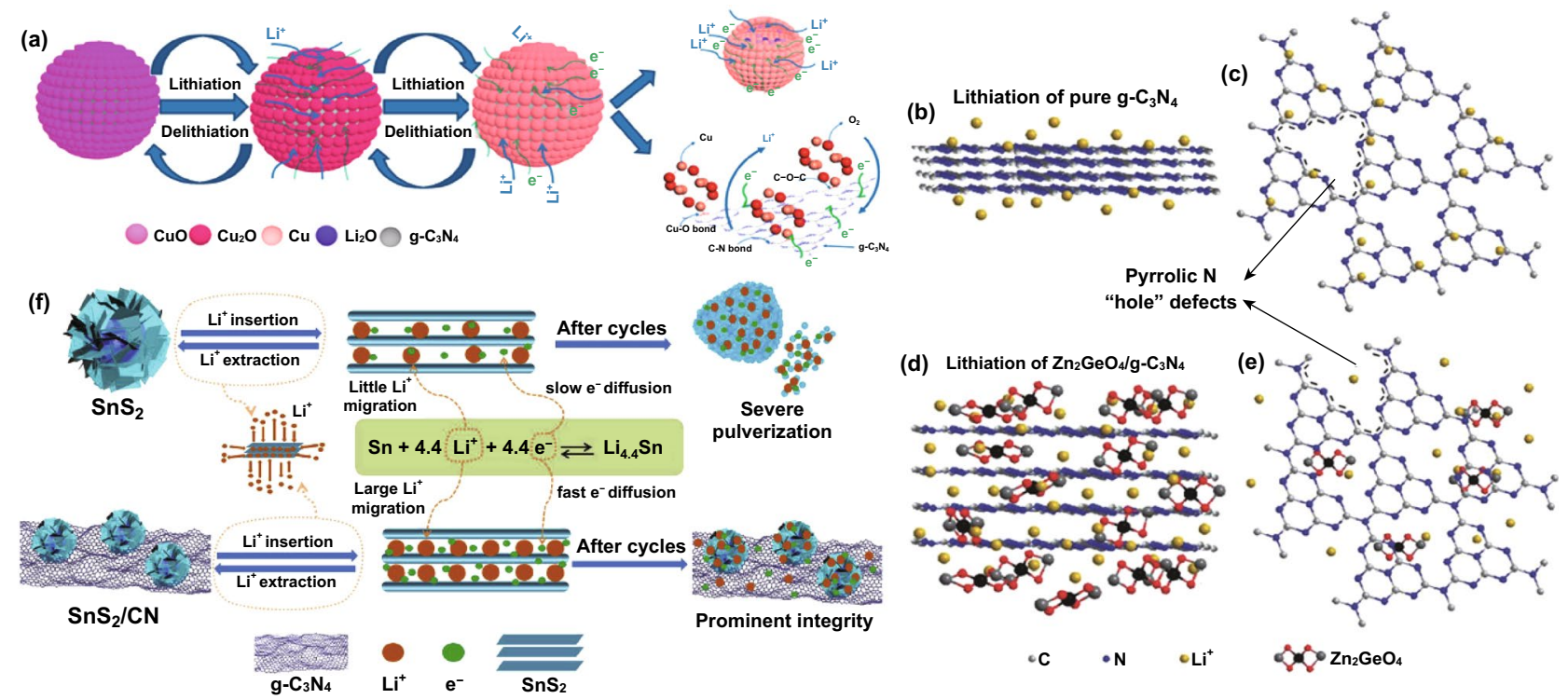

Fig. 18 a Schematic description explaining the reaction mechanism of the CuO/O-doped $g-\mathrm{C}_{3} \mathrm{~N}_{4}$ anode during the charge/discharge process. Reproduced with permission from Ref. [116]. Illustrations of pure (b, c) $g-\mathrm{C}_{3} \mathrm{~N}_{4}$ and (d, e) $\mathrm{Zn}_{2} \mathrm{GeO}_{4} / \mathrm{g}-\mathrm{C}_{3} \mathrm{~N}_{4}$ hybrids for Li-insertion viewed from the (b, c) edge and (d, e) basal plan directions. Reproduced with permission from Ref. [111]. f Schematic illustration of the Li-ions diffusion and electronic transport in the $\mathrm{SnS}_{2}$ and $\mathrm{SnS}_{2} / \mathrm{CN}$ composite electrode during the charge/discharge processes. Reproduced with permission from Ref. [117]. Copyright permissions from Elsevier, Royal Society of Chemistry, American Chemical Society and Wiley-VCH. (Color figure online)

cycles along with a stable rate performance exceeding that of $\mathrm{Fe}_{2} \mathrm{O}_{3} / \mathrm{G}$ [120] (Table 3).

Ternary CNBCs involving metal chalcogenides such as $\mathrm{MoS}_{2}$ and $\mathrm{SnS}_{2}$ have also been studied. Hou et al. reported $\mathrm{a} \mathrm{C}_{3} \mathrm{~N}_{4} / \mathrm{NRGO} / \mathrm{MoS}_{2}$ composite which exhibited a reversible capacity of $855 \mathrm{mAh} \mathrm{g}^{-1}$ after 100 cycles when tested at $100 \mathrm{~mA} \mathrm{~g}^{-1}$ (Fig. 19c) [121]. Shah et al. reported the design of a $\mathrm{SnS}_{2}, \mathrm{rGO}$ and $\mathrm{g}-\mathrm{C}_{3} \mathrm{~N}_{4}$ composite with intimate $2 \mathrm{D}-2 \mathrm{D}$ contact for LIBs. A stepwise detail of the synthesis method and the reaction processes involved is depicted in Fig. 19d. A reversible capacity of $1248.4 \mathrm{mAh} \mathrm{g}^{-1}$ was retained after 276 cycles at $100 \mathrm{mAg}^{-1}$ [122]. Shi et al. also prepared a $\mathrm{rGO} / \mathrm{g}-\mathrm{C}_{3} \mathrm{~N}_{4} @ \mathrm{SnS}_{2}$ composite with effective surface contact of all constituents which can be seen from the TEM image (Fig. 19e). After 1000 cycles at $800 \mathrm{~mA} \mathrm{~g}^{-1}$, a reversible capacity of $864.9 \mathrm{mAh} \mathrm{g}^{-1}$ was retained [123].

\subsection{Sodium and Potassium-Ion Batteries (SIBs and PIBs)}

Due to their large-sized ions, one of the major focus for sodium and potassium ion battery electrode materials is the enlargement of their interlayer distance. The low interlayer $/ d$-spacing of graphite $(0.334 \mathrm{~nm})$ and its low theoretical capacity $\left(279 \mathrm{mAh} \mathrm{g}^{-1}\right)$ has limited its application in either of these two battery systems [125-127]. $g-\mathrm{C}_{3} \mathrm{~N}_{4}$ can be a source of $\mathrm{N}$-doped carbon with large interlayer distance; this approach was reported by Qiao et al. who successfully fabricated a series of $\mathrm{N}$-doped graphene 2D-sheet with different interlayer distances (Fig. 20c). The optimized $\mathrm{N}$-doped graphene sheet (N-FLG-800) delivered a superior rate capability of $56.6 \mathrm{mAh} \mathrm{g}^{-1}$ at a current density of $40 \mathrm{~A} \mathrm{~g}^{-1}$ (Fig. 20e) and outstanding long-cycle stability of $211.3 \mathrm{mAh} \mathrm{g}^{-1}$ after 2000 cycles at $0.5 \mathrm{~A} \mathrm{~g}^{-1}$ [128]. Weng et al. reported the synthesis of a $\mathrm{C} / \mathrm{g}-\mathrm{C}_{3} \mathrm{~N}_{4}$ composite via a simple one-pot synthesis approach, and the composite delivered a capacity of $254 \mathrm{mAh} \mathrm{g}^{-1}$ at $0.1 \mathrm{~A} \mathrm{~g}^{-1}$ and $160 \mathrm{mAh} \mathrm{g}^{-1}$ at $0.4 \mathrm{~A} \mathrm{~g}^{-1}$ (see Fig. 20g) [53]. Recently, Chen et al. showed that coating the surface of copper metal current collector with a thin film of $2 \mathrm{D}-\mathrm{C}_{3} \mathrm{~N}_{4}$ can improve $\mathrm{Na}$ storage by inhibiting unwanted surface interaction with the liquid electrolyte. The $\mathrm{Na}^{+}$storage mechanism is illustrated by the scheme in Fig. 20h. At an areal current density of $0.013 \mathrm{~mA} \mathrm{~cm}^{-2}$, a high areal capacity of $0.036 \mathrm{mAh} \mathrm{cm}^{-2}$ was achieved [129]. 


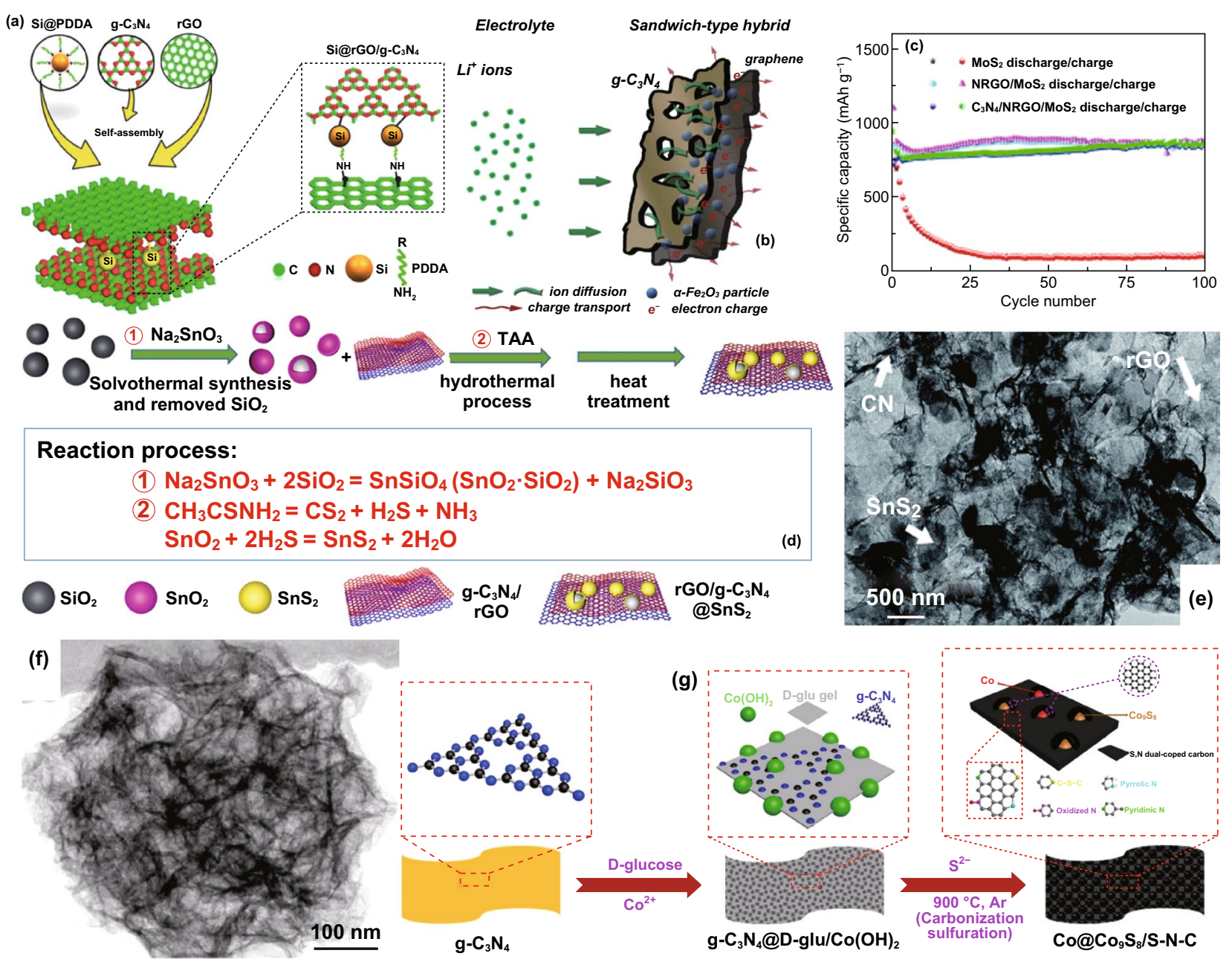

Fig. 19 a Schematic reaction scheme of the $\mathrm{Si} @ \mathrm{rGO} / \mathrm{g}-\mathrm{C}_{3} \mathrm{~N}_{4}$ hybrid and illustration of $\mathrm{Si} \mathrm{NPs}$ anchored on $\mathrm{rGO} / \mathrm{g}-\mathrm{C}_{3} \mathrm{~N}_{4}$ via strong covalent and hydrogen bonding formed during the pyrolysis process. Reproduced with permission from Ref. [118]. b Schematic diagram of ionic diffusion and charge transport in the porous $\mathrm{Fe}_{2} \mathrm{O}_{3} / \mathrm{CN}-\mathrm{G}$ anode with a 2D sandwich-like nanosheet architecture. Reproduced with permission from Ref. [124].

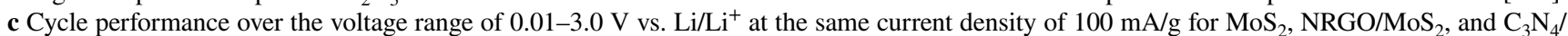
NRGO/MoS ${ }_{2}$. Reproduced with permission from Ref. [121]. d Schematic synthesis process of rGO/g- $\mathrm{C}_{3} \mathrm{~N}_{4} @ \mathrm{SnS}_{2}$. Reproduced with permission from Ref. [123]. e TEM micrograph of porous ternary composite architectures of reduced graphene oxide, $\mathrm{SnS}_{2}$, and CN (GSC6). Reproduced with permission from Ref. [122]. Copyright permissions from Royal Society of Chemistry, Elsevier, and Springer Nature. (Color figure online)

In the case of potassium-ion batteries (PIBs), we showed that the high $\mathrm{K}^{+}$affinity of $1 \mathrm{D}-\mathrm{C}_{3} \mathrm{~N}_{4}$ fiber facilitates high initial PIBs capacity, but it suffers from poor cycle life and DFT study showed that this was due to the high potassium diffusion barrier and poor conductivity. Guided by this theoretical discovery, we combined $1 \mathrm{D}-\mathrm{C}_{3} \mathrm{~N}_{4}$ fiber with $\mathrm{rGO}$ and fabricated a $1 \mathrm{D} / 2 \mathrm{D} \mathrm{C}_{3} \mathrm{~N}_{4} /$ rGO composite (Fig. 21a-SEM) which exhibited a larger surface area, superior $\mathrm{K}^{+}$diffusivity, and improved conductivity. The composite delivered a superior reversible capacity $557.4 \mathrm{mAh} \mathrm{g}^{-1}$ after 50 cycles with impressive cycle stability (Fig. 21b). The K-ion storage mechanism is depicted in Fig. 21c and shows the bi-directional transport of ions through the interlayer of the composite [54]. In our recent work, we resolved the inadequate interlayer spacing of $\mathrm{Co}_{3} \mathrm{O}_{4}$ by coating it with $\mathrm{N}$-doped carbon sourced from 1D- $\mathrm{C}_{3} \mathrm{~N}_{4}$ fiber. The $\mathrm{Co}_{3} \mathrm{O}_{4} @ \mathrm{~N}-\mathrm{C}$ possessed a core-shell morphology (Fig. 21d) in which $\mathrm{N}-\mathrm{C}$ at the surface of $\mathrm{Co}_{3} \mathrm{O}_{4}$ ensured effective transfer of attracted $\mathrm{K}^{+}$to the $\mathrm{Co}_{3} \mathrm{O}_{4}$ core. The composite delivered a superior reversible capacity of $448.7 \mathrm{mAh} \mathrm{g}^{-1}$ unlike pure $\mathrm{Co}_{3} \mathrm{O}_{4}$ spheres which only recorded $\sim 10 \mathrm{mAh} \mathrm{g}^{-1}$ after 40 cycles (Fig. 21e). The potassium storage mechanism of the composite is depicted in Fig. 21f. 
Table 3 CNBCs for metal-ion batteries LIBs, SIBs and PIBs

\begin{tabular}{|c|c|c|c|c|c|c|c|}
\hline Battery type & Materials & Synthesis & Morphology & $\begin{array}{l}\text { Initial capacity } \\
\left(\mathrm{mAh} \mathrm{g}^{-1}\right)\end{array}$ & $\mathrm{ICE}^{a}$ & $\begin{array}{l}\text { Reversible capacity } \\
\left(\mathrm{mAh}^{-1}\right)\end{array}$ & References \\
\hline \multirow[t]{8}{*}{ LIBs } & $\mathrm{huCP} / \mathrm{g}-\mathrm{C}_{3} \mathrm{~N}_{4}$ & $\begin{array}{l}\text { Hydrothermal treat- } \\
\text { ment }\end{array}$ & $\begin{array}{l}\text { Carbon fibers with } \\
\text { large pores and } \\
\text { hollow structure }\end{array}$ & $1199 @ 1$ A/g & $\sim 93 \%$ & $1030 @ 1000$ cycles & {$[147]$} \\
\hline & $\mathrm{g}-\mathrm{C}_{3} \mathrm{~N}_{4}-\mathrm{rGO}$ & $\begin{array}{l}\text { In-situ chemical } \\
\text { synthetic approach }\end{array}$ & 2D sheets & $3002 @ 100$ mA/g & $57 \%$ & $1525 @ 50$ cycles & [108] \\
\hline & $\mathrm{CN}-\mathrm{rGO}$ & $\begin{array}{l}\text { Hydrothermal } \\
\text { synthesis }\end{array}$ & $\begin{array}{l}\text { 3D Sandwich archi- } \\
\text { tecture }\end{array}$ & $1632 @ 50 \mathrm{~mA} / \mathrm{g}$ & $41.3 \%$ & $970 @ 300$ cycles & {$[130]$} \\
\hline & $\mathrm{g}-\mathrm{C}_{3} \mathrm{~N}_{4} @ \mathrm{rGO}$ & $\begin{array}{l}\text { Hydrothermal reac- } \\
\text { tion }\end{array}$ & $\begin{array}{l}\text { Spongy, porous, and } \\
\text { tangled ultrathin } \\
\text { sheets }\end{array}$ & $2731 @ 0.1 \mathrm{C}$ & $\sim 89 \%$ & $901 @ 50$ cycles & {$[131]$} \\
\hline & $\mathrm{SN} / \mathrm{CN}$ & Hydrothermal & $\begin{array}{c}\text { Cauliflower-like } \\
\text { morphology }\end{array}$ & $733 @ 0.1 \mathrm{C}$ & $55.4 \%$ & 420@60 cycles & [132] \\
\hline & $\mathrm{SnO}_{2} @ \mathrm{C}_{3} \mathrm{~N}_{4}$ & $\begin{array}{l}\text { Scalable solid-state } \\
\text { reaction }\end{array}$ & $\begin{array}{l}\text { Porous and wrin- } \\
\text { kled material }\end{array}$ & $1200 @ 0.1 \mathrm{C}$ & $\sim 50 \%$ & $550 @ 100$ cycles & [149] \\
\hline & TiO ${ }_{2} @ \mathrm{CNS}$ (TCNS) & $\begin{array}{l}\text { Self-assembly } \\
\text { approach/hydro- } \\
\text { thermal }\end{array}$ & $\begin{array}{l}\text { Spherical Core- } \\
\text { shell particles }\end{array}$ & $359 @ 0.1 \mathrm{C}$ & $\sim 90 \%$ & $303 @ 125$ cycles & [100] \\
\hline & $\mathrm{Zn}_{2} \mathrm{GeO}_{4} / \mathrm{g}-\mathrm{C}_{3} \mathrm{~N}_{4}$ & $\begin{array}{l}\text { Facile solution } \\
\text { approach }\end{array}$ & ultrathin nanosheet. & $1068 @ 200$ mA/g & $58.6 \%$ & $1370 @ 140$ cycles & [109] \\
\hline \multirow[t]{11}{*}{ LIBs } & $\mathrm{NiCo}_{2} \mathrm{O}_{4} / \mathrm{g}-\mathrm{C}_{3} \mathrm{~N}_{4}$ & $\begin{array}{l}\text { Facile ultrasonic } \\
\text { treatment }\end{array}$ & Nanosheet structure & $1367 @ 100$ mA/g & $84.5 \%$ & $1252 @ 100$ cycles & {$[150]$} \\
\hline & $\mathrm{Li}_{4} \mathrm{Ti}_{5} \mathrm{O}_{12} / \mathrm{g}-\mathrm{C}_{3} \mathrm{~N}_{4}$ & $\begin{array}{l}\text { Solvothermal } \\
\text { method }\end{array}$ & Nanoparticles & $173.7 @ 0.5 \mathrm{C}$ & - & $150.8 @ 502$ cycles & [133] \\
\hline & $\begin{array}{l}\text { Nitrogen-doped } \\
\text { LTO/C (NCLTO) }\end{array}$ & $\begin{array}{l}\text { Thermal decompo- } \\
\text { sition }\end{array}$ & $\begin{array}{c}\text { Irregular sized } \\
\text { nanoparticles }\end{array}$ & $189 @ 1 \mathrm{C}$ & $\sim 92 \%$ & $122 @ 500$ cycles & [109] \\
\hline & 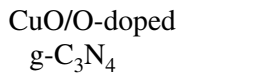 & Hydrothermal & Nanospheres & $980 @ 100 \mathrm{~mA} / \mathrm{g}$ & $94.7 \%$ & $738 @ 100$ cycles & {$[101]$} \\
\hline & $\begin{array}{l}\text { 3D N-rich } \mathrm{C}_{3} \mathrm{~N}_{4} @ \\
\mathrm{MoS}_{2}\end{array}$ & Hydrothermal & Nanosphere & $2390 @ 0.1 \mathrm{C}$ & $\sim 74 \%$ & $857 @ 50$ cycles & {$[154]$} \\
\hline & $\begin{array}{l}\mathrm{MoS}_{3} / \mathrm{g}_{-} \mathrm{C}_{3} \mathrm{~N}_{4}-\mathrm{H}^{+} / \\
\quad \mathrm{GO}\end{array}$ & $\begin{array}{l}\text { Sonication/thermal } \\
\text { treatment }\end{array}$ & $\begin{array}{l}\text { 2D sheet-like } \\
\text { structure }\end{array}$ & $1728 @ 0.1 \mathrm{~mA} / \mathrm{g}$ & - & $1450 @ 200$ cycles & [103] \\
\hline & $\mathrm{MoS}_{2} / \mathrm{g}-\mathrm{C}_{3} \mathrm{~N}_{4}$ & $\begin{array}{l}\text { Thermal treatment } \\
\text { (calcination) }\end{array}$ & Spherical particles & $2467 @ 0.05 \mathrm{C}$ & $\sim 41 \%$ & $1204 @ 200$ cycles & {$[175]$} \\
\hline & $\mathrm{WS}_{2} / \mathrm{g}-\mathrm{C}_{3} \mathrm{~N}_{4}$ & Solid-state reaction & $\begin{array}{l}\text { Nano-sized petal- } \\
\text { like sheets }\end{array}$ & $\begin{array}{l}1933.6 @ \\
100 \mathrm{~mA} / \mathrm{g}\end{array}$ & $63.6 \%$ & $622.7 @ 400$ cycles & {$[156]$} \\
\hline & $\mathrm{SnS}_{2} / \mathrm{CN}$ & $\begin{array}{l}\text { Microwave hydro- } \\
\text { thermal method }\end{array}$ & Nanoflower & $\begin{array}{l}1465.9 @ \\
100 \mathrm{~mA} / \mathrm{g}\end{array}$ & $47 \%$ & 383.8 & [153] \\
\hline & $\mathrm{Co}_{1-\mathrm{x}} \mathrm{S} @ \mathrm{~g}-\mathrm{C}_{3} \mathrm{~N}_{4}$ & $\begin{array}{l}\text { Solvothermal } \\
\text { method }\end{array}$ & Spherical-like & 1250@0.1 A/g & $\sim 55 \%$ & $\begin{array}{l}789.59 @ \\
210 \text { cycles }\end{array}$ & {$[155]$} \\
\hline & $\mathrm{C}_{3} \mathrm{~N}_{5} / \mathrm{MoS}_{2}$ & $\begin{array}{l}\text { Soft- and hard tem- } \\
\text { plating methods }\end{array}$ & $\begin{array}{l}\text { Highly ordered } \\
\text { mesoporous } \\
\text { nanosheet }\end{array}$ & $271 @ 100 \mathrm{~mA} / \mathrm{g}$ & $60 \%$ & $193 @ 100$ cycles & {$[112]$} \\
\hline SIBs & $\mathrm{huCP} / \mathrm{g}-\mathrm{C}_{3} \mathrm{~N}_{4}$ & $\begin{array}{l}\text { Hydrothermal treat- } \\
\text { ment }\end{array}$ & $\begin{array}{l}\text { Carbon fibers with } \\
\text { large pores and } \\
\text { hollow structure }\end{array}$ & $222 @ 0.1 \mathrm{~A} / \mathrm{g}$ & - & $345 @ 380$ cycles & [147] \\
\hline
\end{tabular}


Table 3 (continued)

\begin{tabular}{|c|c|c|c|c|c|c|c|}
\hline Battery type & Materials & Synthesis & Morphology & $\begin{array}{l}\text { Initial capacity } \\
\left(\mathrm{mAh} \mathrm{g}^{-1}\right)\end{array}$ & $\mathrm{ICE}^{a}$ & $\begin{array}{l}\text { Reversible capacity } \\
\left(\mathrm{mAh} \mathrm{g}^{-1}\right)\end{array}$ & References \\
\hline & N-doped MoC & Pyrolysis & $\begin{array}{l}\text { Hollow micro- } \\
\text { spheres }\end{array}$ & $1040 @ 0.16 \mathrm{~A} / \mathrm{g}$ & - & 410@200 cycles & {$[172]$} \\
\hline & $\begin{array}{l}\text { Amorphous carbon } \\
\text { nitride }(\mathrm{ACN})\end{array}$ & $\begin{array}{l}\text { Copolymerization/ } \\
\text { direct carboniza- } \\
\text { tion }\end{array}$ & $\begin{array}{l}\text { Uniform rhombic } \\
\text { dodecahedral } \\
\text { shape }\end{array}$ & $640 @ 83 \mathrm{~mA} / \mathrm{g}$ & $67.2 \%$ & $175 @ 2000$ cycles & {$[173]$} \\
\hline & N-FLG-800 & Pyrolysis & $\begin{array}{l}\text { 2D lamellar struc- } \\
\text { ture of with plenty } \\
\text { of wrinkles }\end{array}$ & $256.7 @ 0.5 \mathrm{~A} / \mathrm{g}$ & $83.5 \%$ & $\begin{array}{l}211.3 @ 2000 \\
\text { cycles }\end{array}$ & {$[175]$} \\
\hline & $\mathrm{C} / \mathrm{g}-\mathrm{C}_{3} \mathrm{~N}_{4}$ & One-pot calcination & $\begin{array}{l}\text { 2D-sheet-like } \\
\text { structure }\end{array}$ & $\sim 200 @ 0.4$ A/g & $99 \%$ & 160 @ 400 cycles & [128] \\
\hline & $\mathrm{g}-\mathrm{C}_{3} \mathrm{~N}_{4}$ film & $\begin{array}{l}\text { Chemical vapor } \\
\text { deposition (CVD) }\end{array}$ & 2D thin film & - & $98 \%$ & $\begin{array}{l}\sim 6 \mathrm{Ah} / \mathrm{g} @ 500 \\
\text { cycles }\end{array}$ & [174] \\
\hline & $\mathrm{CN} / \mathrm{MoS}_{2}-600$ & $\begin{array}{l}\text { Nanotemplating } \\
\text { approach }\end{array}$ & $\begin{array}{l}\text { Corrugated } \\
\text { cardboard-like } \\
\text { morphology }\end{array}$ & - & $70 \%$ & 605 & [98] \\
\hline & $\mathrm{C}_{3} \mathrm{~N}_{5} / \mathrm{MoS}_{2}$ & $\begin{array}{l}\text { Combined soft- and } \\
\text { hard templating } \\
\text { methods }\end{array}$ & $\begin{array}{l}\text { Ordered } \\
\text { mesoporous } \\
\text { nanosheet }\end{array}$ & $126 @ 100 \mathrm{~mA} / \mathrm{g}$ & $46 \%$ & $54 @ 100$ cycles & [112] \\
\hline PIBs & $1 \mathrm{D} / 2 \mathrm{D} \mathrm{C}_{3} \mathrm{~N}_{4} / \mathrm{rGO}$ & $\begin{array}{l}\text { Hydrothermal/ } \\
\text { freeze drying } \\
\text { method }\end{array}$ & $\begin{array}{l}1 \mathrm{D}-\mathrm{C}_{3} \mathrm{~N}_{4} \text { rod } \\
\text { infused in- } \\
\text { between the } \\
2 \mathrm{D} \text {-sheet }\end{array}$ & $682.7 @ 0.5 \mathrm{~A} / \mathrm{g}$ & $56.8 \%$ & $557.4 @ 50$ cycles & {$[54]$} \\
\hline PIBs & $\mathrm{Co}_{3} \mathrm{O}_{4} @ \mathrm{~N}-\mathrm{C}$ & $\begin{array}{l}\text { Ionic liquid-assisted } \\
\text { solvothermal } \\
\text { method }\end{array}$ & Spherical & $1229.2 @ 50 \mathrm{~mA} / \mathrm{g}$ & $48.2 \%$ & $448.7 @ 40$ cycles & {$[176]$} \\
\hline \multirow[t]{7}{*}{ LIBs } & $\mathrm{Si} @ \mathrm{rGO} / \mathrm{g}-\mathrm{C}_{3} \mathrm{~N}_{4}$ & $\begin{array}{l}\text { Template-free } \\
\text { self-assembly and } \\
\text { pyrolysis process }\end{array}$ & $\begin{array}{l}\text { Multilayered 3D } \\
\text { framework }\end{array}$ & $1354.8 @ 0.5 \mathrm{C}$ & $70.9 \%$ & $\begin{array}{l}799.6 @ 1000 \\
\text { cycles }\end{array}$ & [159] \\
\hline & $\mathrm{P} / \mathrm{rGO}-\mathrm{C}_{3} \mathrm{~N}_{4}$ & Ball milling & $\begin{array}{l}\text { Nubby structure } \\
(40-200 \mathrm{~nm})\end{array}$ & $\begin{array}{l}2423.4 @ \\
200 \mathrm{~mA} / \mathrm{g}\end{array}$ & $99 \%$ & $\begin{array}{l}1032.6 @ 600 \\
\text { cycles }\end{array}$ & [160] \\
\hline & $\begin{array}{l}\mathrm{rGO} / \mathrm{g}-\mathrm{C}_{3} \mathrm{~N}_{4} / \mathrm{SnS}_{2} \\
\quad(\mathrm{GSC} 6)\end{array}$ & Hydrothermal route & $3 \mathrm{D}$ porous structure & $\begin{array}{l}1073.1 @ \\
100 \mathrm{~mA} / \mathrm{g}\end{array}$ & $61.1 \%$ & $\begin{array}{l}\text { 1118.6@ } 100 \\
\text { cycles }\end{array}$ & [122] \\
\hline & $\mathrm{rGO} / \mathrm{g}-\mathrm{C}_{3} \mathrm{~N}_{4} @ \mathrm{SnS}_{2}$ & $\begin{array}{l}\text { Solvothermal syn- } \\
\text { thesis }\end{array}$ & $\begin{array}{r}\text { Nano-spheres } \\
\text { anchored on } \\
\text { hybrid sheet }\end{array}$ & $\sim 600 @ 800 \mathrm{~mA} / \mathrm{g}$ & - & $\begin{array}{l}864.9 @ 1000 \\
\text { cycles }\end{array}$ & {$[164]$} \\
\hline & $\mathrm{MnO} / \mathrm{C}_{3} \mathrm{~N}_{4} / \mathrm{C}$ & $\begin{array}{l}\text { Sonication/calcina- } \\
\text { tion }\end{array}$ & 3D Porous sphere & $918.9 @ 0.5 \mathrm{C}$ & $66 \%$ & $781.9 @ 86$ cycles & {$[165]$} \\
\hline & $\mathrm{SnO}_{2}-\mathrm{TiO}_{2}-\mathrm{C}_{3} \mathrm{~N}_{4}$ & $\begin{array}{l}\text { Self-assembly } \\
\text { deposition }\end{array}$ & $\begin{array}{l}\text { Microspherical } \\
\text { shaped NPs }\end{array}$ & $853 @ 0.1 \mathrm{C}$ & 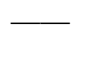 & 114.1@20 cycles & [188] \\
\hline & $\mathrm{Co} @ \mathrm{Co}_{9} \mathrm{~S}_{8} / \mathrm{S}-\mathrm{N}-\mathrm{C}$ & $\begin{array}{l}\text { Hydrothermal reac- } \\
\text { tion and pyrolysis } \\
\text { method }\end{array}$ & $\begin{array}{l}\text { Porous structure } \\
\text { with smooth-faced } \\
\text { surfaces }\end{array}$ & $1033.25 @ 0.2 \mathrm{~A} / \mathrm{g}$ & $60 \%$ & $652.1 @ 610$ cycles & [166] \\
\hline
\end{tabular}

${ }^{\mathrm{a}}$ ICE Initial coulombic efficiency

\subsection{Lithium-Sulfur Batteries}

Carbon nitrides have proven to be effective at anchoring LiPSs in Li-S batteries, thereby inhibiting their dissolution in the electrolyte and boosting overall battery performance
[134, 135]. Experimental battery studies on CNBMs as sulfur hosts for Li-S battery have confirmed the DFT predictions discussed earlier. For example, Liu et al. reported the application of a $2 \mathrm{D}$ graphene-like oxygenated $\mathrm{C}_{3} \mathrm{~N}_{4}$ via a scalable one-step self-supporting solid-state pyrolysis 


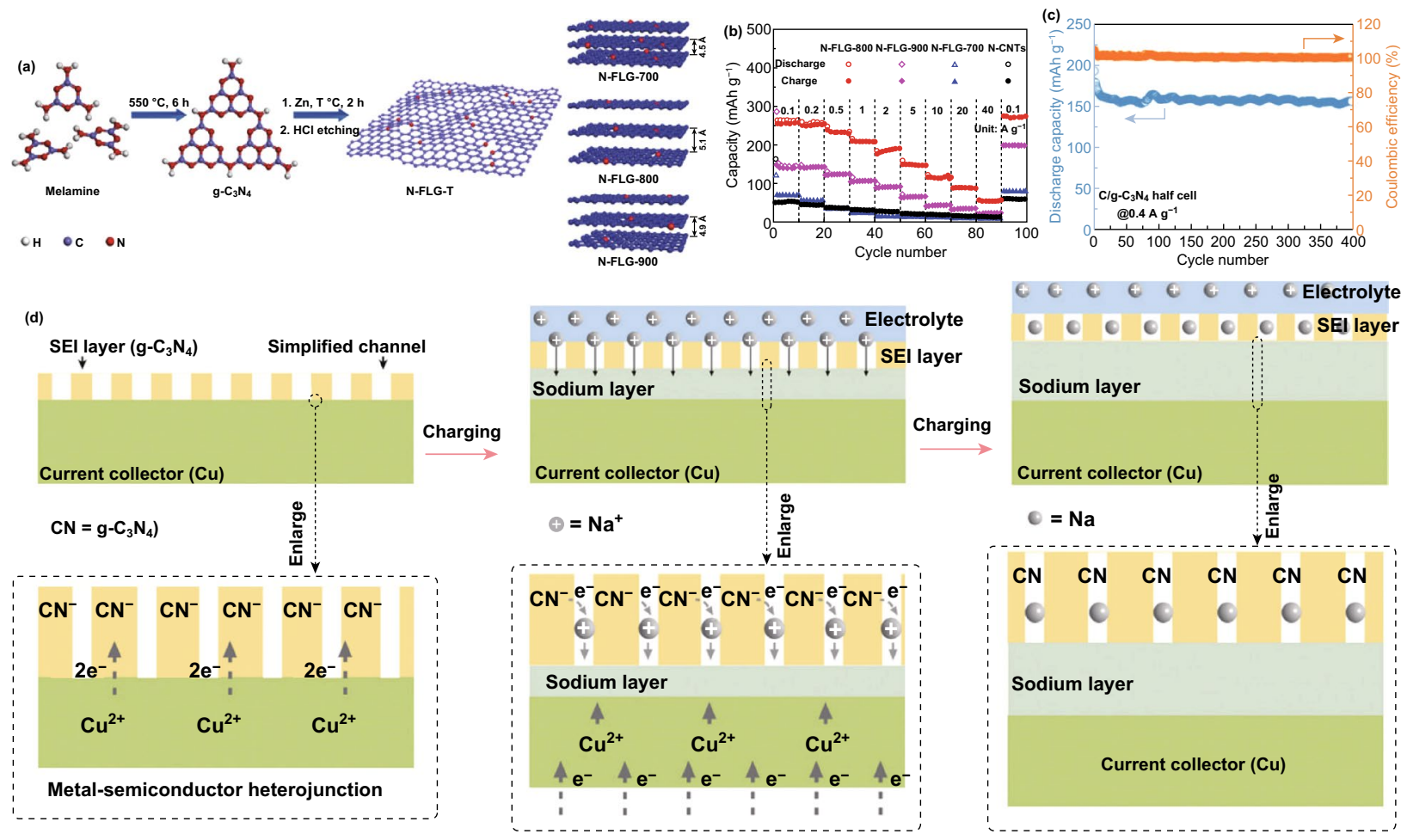

Fig. 20 a Schematic illustration of the synthetic routes for the fabrication of N-FLG-T. b Rate capability of N-CNTs and N-FLG-T at various current densities. Reproduced with permission from Ref. [128]. $\mathbf{c}$ Cycling performance of $\mathrm{C} / \mathrm{g}-\mathrm{C}_{3} \mathrm{~N}_{4} \mathrm{Na}$ half cells at $0.4 \mathrm{~A} \mathrm{~g} \mathrm{~g}^{-1}$. Reproduced with permission from Ref. [53]. d Illustration of the mechanism of the sodium storage in $\mathrm{g}-\mathrm{C}_{3} \mathrm{~N}_{4}$ film activated $\mathrm{Cu}$ foil. Reproduced with permission from Ref. [129]. Copyright permission from Wiley-VCH. (Color figure online)

(b)
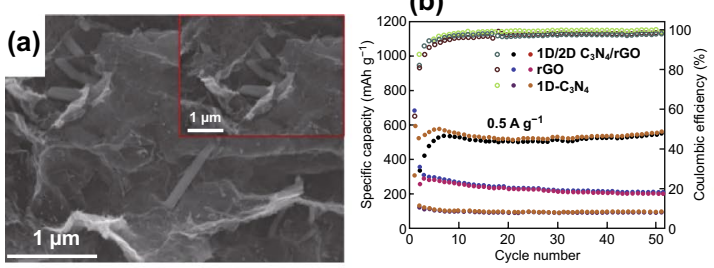

(c)

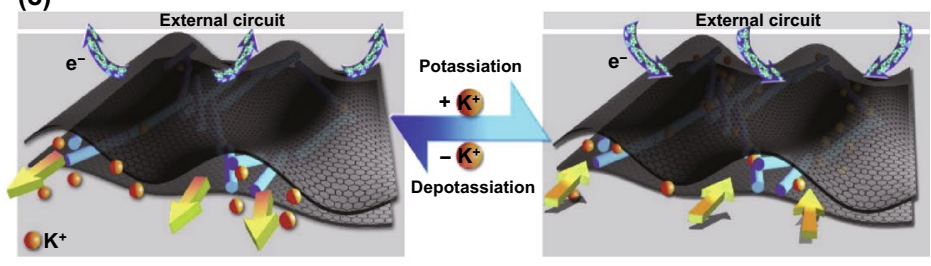

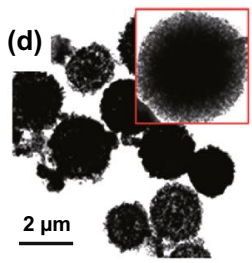
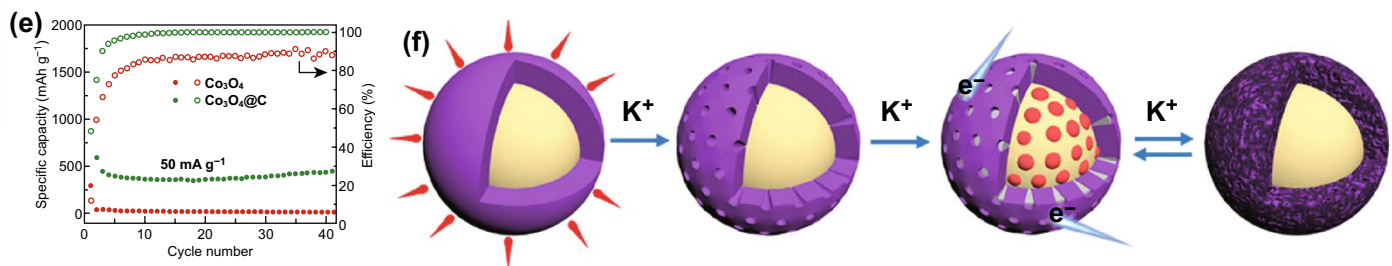

Fig. 21 a SEM image of $1 \mathrm{D} / 2 \mathrm{D} \mathrm{C} \mathrm{C}_{3} \mathrm{~N}_{4} / \mathrm{rGO}$. b Cycling performances and coulombic efficiency of $1 \mathrm{D}-\mathrm{C}_{3} \mathrm{~N}_{4}, \mathrm{rGO}$ and $1 \mathrm{D} / 2 \mathrm{D} \mathrm{C}_{3} \mathrm{~N}_{4} / \mathrm{rGO}$ at of 0.5 $\mathrm{A} \mathrm{g}^{-1}$. $\mathbf{c}$ Possible mechanism of potassium storage in the $1 \mathrm{D} / 2 \mathrm{D} \mathrm{C}_{3} \mathrm{~N}_{4} / \mathrm{rGO}$ composite. Reproduced with permission from Ref. [54]. $\mathbf{d}$ TEM and e comparison of the cycle life of $\mathrm{Co}_{3} \mathrm{O}_{4}$ and $\mathrm{Co}_{3} \mathrm{O}_{4} @ \mathrm{~N}-\mathrm{C}$ at $50 \mathrm{~mA} \mathrm{~g} \mathrm{~g}^{-1}$. f Scheme illustrating suggested potassiation and depotassiation mechanism of the $\mathrm{Co}_{3} \mathrm{O}_{4} @ \mathrm{~N}-\mathrm{C}$ electrode. Reproduced with permission from Ref. [108]. Copyright permissions from Elsevier and American Chemical Society. (Color figure online)

process (Fig. 22a). The oxygen-rich functional groups possess strong chemical adsorption toward sulfur atoms; hence, they can inhibit the dissolution of polysulfides in $\mathrm{Li}-\mathrm{S}$ electrolyte. As a cathode material, the resultant electrode delivered an initial columbic efficiency of $98 \%$ (S utilization of $84 \%$ ) with a reversible capacity of $1407.6 \mathrm{mAh} \mathrm{g}^{-1}$ 

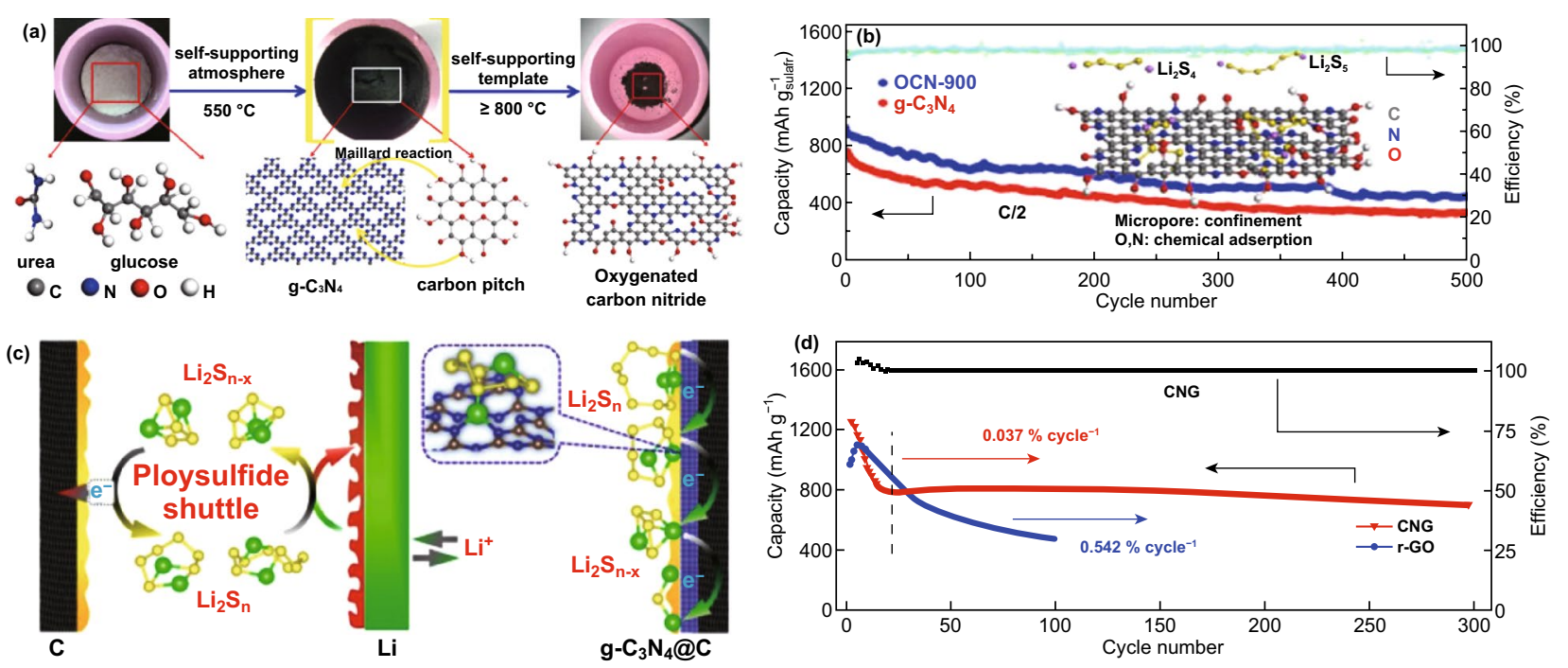

Fig. 22 a Schematic illustration of graphene-like oxygenated carbon nitride (OCN) prepared by one-step self-supporting solid-state pyrolysis. b Cycling performances of the OCN sample prepared at different conditions and $\mathrm{g}-\mathrm{C}_{3} \mathrm{~N}_{4}$ at $\mathrm{C} / 2$ after initial activation process to allow complete access of the electrolyte to the active material. Inset: OCN with adsorbed LiPSs molecules. Reproduced with permission from Ref. [136]. c Schematic of the mechanism for polysulfide adsorption by the $\mathrm{g}-\mathrm{C}_{3} \mathrm{~N}_{4} @ \mathrm{CFM}$ cathode. Reproduced with permission from Ref. [67]. d Cycling performance of LiPSs on CNG and r-GO. Reproduced with permission from Ref. [57]. Copyright permissions from American Chemical Society and Wiley-VCH. (Color figure online)

at $\mathrm{C} / 20$ (Fig. 22b) thanks to the surface functional groups [136].

Carbon coating for anchoring soluble polysulfides is an effective strategy to improve the conductivity of electrode materials in Li-S batteries [135]. Based on the conclusion of DFT calculations, Liao and co-workers showed that coating $\mathrm{g}-\mathrm{C}_{3} \mathrm{~N}_{4}$ on carbon-fiber mesh can serve as an effective anchoring strategy for LiPSs, and the g- $\mathrm{C}_{3} \mathrm{~N}_{4} @ \mathrm{CFM}$ electrode delivered $905 \mathrm{mAh} \mathrm{g}^{-1}$ at $0.1 \mathrm{C}$. Figure $22 \mathrm{c}$ shows the polysulfide adsorption mechanism of the composite electrode [67]. Liang et al. deployed polymeric $\mathrm{C}_{3} \mathrm{~N}_{4}\left(\mathrm{p}-\mathrm{C}_{3} \mathrm{~N}_{4}\right)$ as a suitable cathode material to effectively attract LiPSs in common electrolyte solvents (1,3-dioxolane (DOL) and 1,2-dimethoxyethane (DME)). DFT calculations proved that interaction between $\mathrm{p}-\mathrm{C}_{3} \mathrm{~N}_{4}$ and LiPSs can alter the bonding and spatial configuration of the lithium polysulfides, which in turn tunes their redox kinetics. The results of Li-S battery testing in Fig. 22d showed that the electrode consisting of $\mathrm{p}-\mathrm{C}_{3} \mathrm{~N}_{4}$ and $\mathrm{rGO}(\mathrm{CNG})$ performed better than its individual constituents, improved stabilization, and kinetics of LiPSs and restrained shuttling effect [57].

Coating of the commercial polypropylene separator with g- $\mathrm{C}_{3} \mathrm{~N}_{4}$ is another strategy to facilitate LiPSs adsorption and effectively suppress polysulfide dissolution [134, 135].
Fan et al. reported the blending of commercial separator with carbon black ( $\mathrm{g}-\mathrm{C}$-coated) and coating it on commercial glass fiber separator for LIPSs adsorption. The $\mathrm{g}-\mathrm{C}_{3} \mathrm{~N}_{4}$-coated separator showed better capacity retention in that after 400 cycles at $0.2 \mathrm{C}$, it could still deliver $773.2 \mathrm{mAh} \mathrm{g}^{-1}$, while the carbon-coated separator only had $611 \mathrm{mAh} \mathrm{g}^{-1}$ [68]. Chen et al. showed that coating of a transition metal ( $\mathrm{Fe}, \mathrm{Ni}, \mathrm{Cu}$, and $\mathrm{Co}$ ) coordinated $\mathrm{g}-\mathrm{C}_{3} \mathrm{~N}_{4} / \mathrm{C}$ commercial separator improved LiPSs adsorption and performance. Experimental $\mathrm{Li}-\mathrm{S}$ battery testing and DFT calculations concluded that Ni-modified $\mathrm{C}_{3} \mathrm{~N}_{4}$ facilitated the LiPSs adsorption the best; hence, it outperformed the other metal modified $\mathrm{C}_{3} \mathrm{~N}_{4} / \mathrm{C}$-coated separators in terms of battery performance (Fig. 23a). A schematic of the polysulfide adsorption mechanism of the metal modified electrode is depicted in Fig. 23b. In terms of CNBCs, Qu et al. reported the use of graphene as a conductive material combined with $\mathrm{C}_{3} \mathrm{~N}_{4}$ to form a g- $\mathrm{C}_{3} \mathrm{~N}_{4} / \mathrm{GS}$ interlayer for a sulfur filled kejten black cathode for Li-S battery. Due to the electrostatic forces present as a result of $\pi-\pi$ bonding between both materials, graphene and $\mathrm{g}-\mathrm{C}_{3} \mathrm{~N}_{4}$ heterogeneously intercalated with each in a closely packed fashion to form a laminated channel which inhibited diffusion of LiPSs toward the anode (Fig. 23c). The cathode material delivered a high reversible 


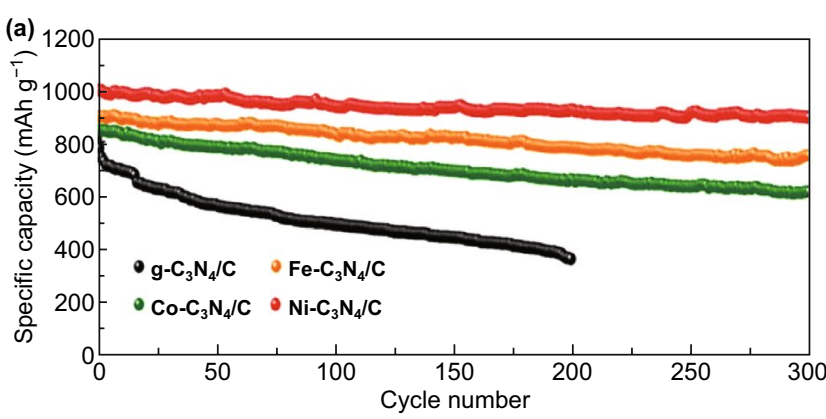

(b)
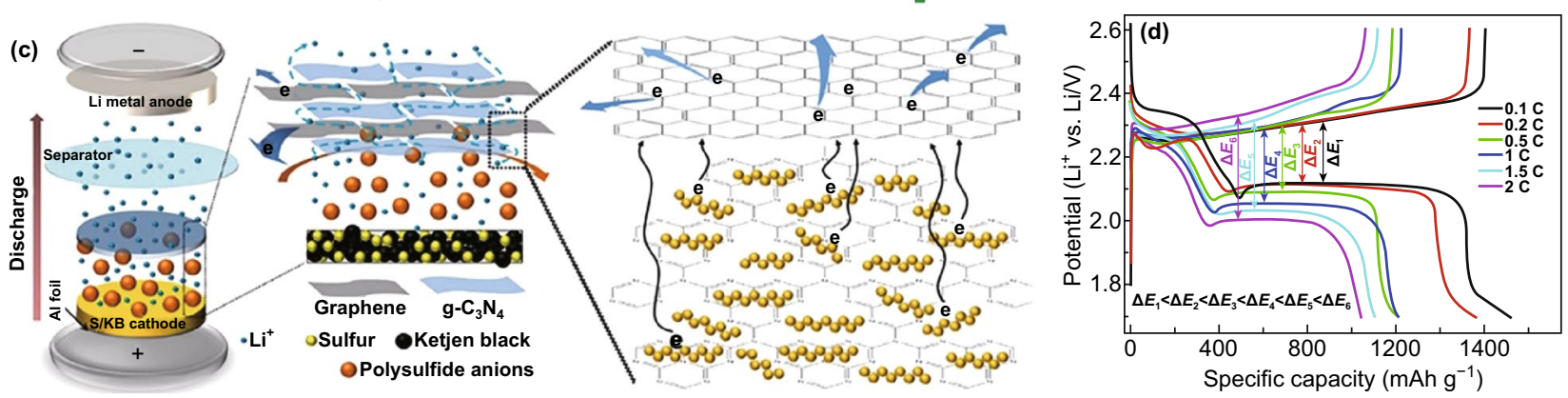

Fig. 23 a Cycling performance of the heteroatom-doped- $\mathrm{C}_{3} \mathrm{~N}_{4} / \mathrm{C}$-modified separators at $0.5 \mathrm{~A} \mathrm{~g}^{-1}$. b Schematic illustration of the M- $\mathrm{C}_{3} \mathrm{~N}_{4} / \mathrm{C}$ modified separator to suppress the shuttle of polysulfides and expedite conversion reaction kinetics of polysulfides. Reproduced with permission from Ref. [69]. c Schematic of cell configuration with a laminated structure $g_{-} \mathrm{C}_{3} \mathrm{~N}_{4} / \mathrm{GS}$ cathode interlayer. d Charge/discharge profiles for the $\mathrm{S} / \mathrm{KB} @ \mathrm{C}_{3} \mathrm{~N}_{4} / \mathrm{GS}$ cathode at various scan rates. Reproduced with permission from Ref. [137]. Copyright permissions from Elsevier and Wiley$\mathrm{VCH}$. (Color figure online)

capacity $\left(>1200 \mathrm{mAh} \mathrm{g}^{-1}\right)$ when cycled at $1 \mathrm{C}$ and retained up to $50 \%$ of its capacity after 100 cycles. Moreover, from Fig. 23d a stable and consistent charge/discharge profile was maintained even when the electrode was cycled at various current densities [137]. To summarize the discussion on $\mathrm{Li}-\mathrm{S}, \mathrm{CNBMs}$ have been used for several functions in $\mathrm{Li}-\mathrm{S}$ batteries and they have shown great promise as advanced electrode materials (Table 4). However, the percentage of $S$ loading needs to be increased from an average of $50 \%$ to an average of $\sim 80 \%$ for all CNBCs reports. Also, the binding mechanism and chemical interactions between the CNBMs and the binder need to be further investigated.

\subsection{Lithium-Oxygen Batteries}

As discussed earlier, DFT predictions show that carbon nitrides are promising for $\mathrm{Li}-\mathrm{O}_{2}$ battery because they possess a superior overpotential than most commercial electrodes because molecular level interaction with $\mathrm{LiO}_{2}$ indicates that they form a Li-N bonding which is dependent on the ratio of $\mathrm{N}$ in the material and greatly influences their overpotential [60].
Experimental study of pure and $\mathrm{CNBC}$ in $\mathrm{Li}-\mathrm{O}_{2}$ batteries has been reported in the literature. For instance, Liu et al. showed that $\mathrm{g}-\mathrm{C}_{3} \mathrm{~N}_{4}$ due to the lower conduction band (CB) potential of $\mathrm{g}-\mathrm{C}_{3} \mathrm{~N}_{4}$ and its low bandgap of $\sim 2.7 \mathrm{eV}$ the use of $\mathrm{g}-\mathrm{C}_{3} \mathrm{~N}_{4}$ together with an $\mathrm{I}^{-}$ion redox mediator and nonaqueous electrolyte resulted in a drastic decrease in charging voltage [139].

Heteroatom doping (especially single atom doping) is a well-known method of modulating the electronic properties $[140,141]$. Zhao et al. reported the application of a Pt-doped g- $\mathrm{C}_{3} \mathrm{~N}_{4}$ (CNHS) for Li- $\mathrm{O}_{2}$ battery, and the performance and cycle stability of Pt-g- $\mathrm{C}_{3} \mathrm{~N}_{4}$ (Pt-CNHS) exceeded those of pure holey $\mathrm{g}_{-} \mathrm{C}_{3} \mathrm{~N}_{4}$. A schematic illustration of the $\mathrm{Li}-\mathrm{O}_{2}$ reaction process is presented in Fig. 24a. Also, $\mathrm{Li}-\mathrm{O}_{2}$ battery analysis (charge/discharge voltage plateau) shows that Pt-CNHS possess a lower overpotential when compared to CNHS with a round trip efficiency of $69 \%$ compared to $65 \%$ for CNHS [63]. Gao et al. also reported the design of a tungsten carbide-modified $\mathrm{N}$-doped defective carbon $\left(\mathrm{W}_{2} \mathrm{C} @ \mathrm{NC}\right)$, and the composite exhibited a significant synergistic interaction (Fig. 24b) and delivered an initial reversible capacity of $10,976 \mathrm{mAh} \mathrm{g}^{-1}$ at a current density 


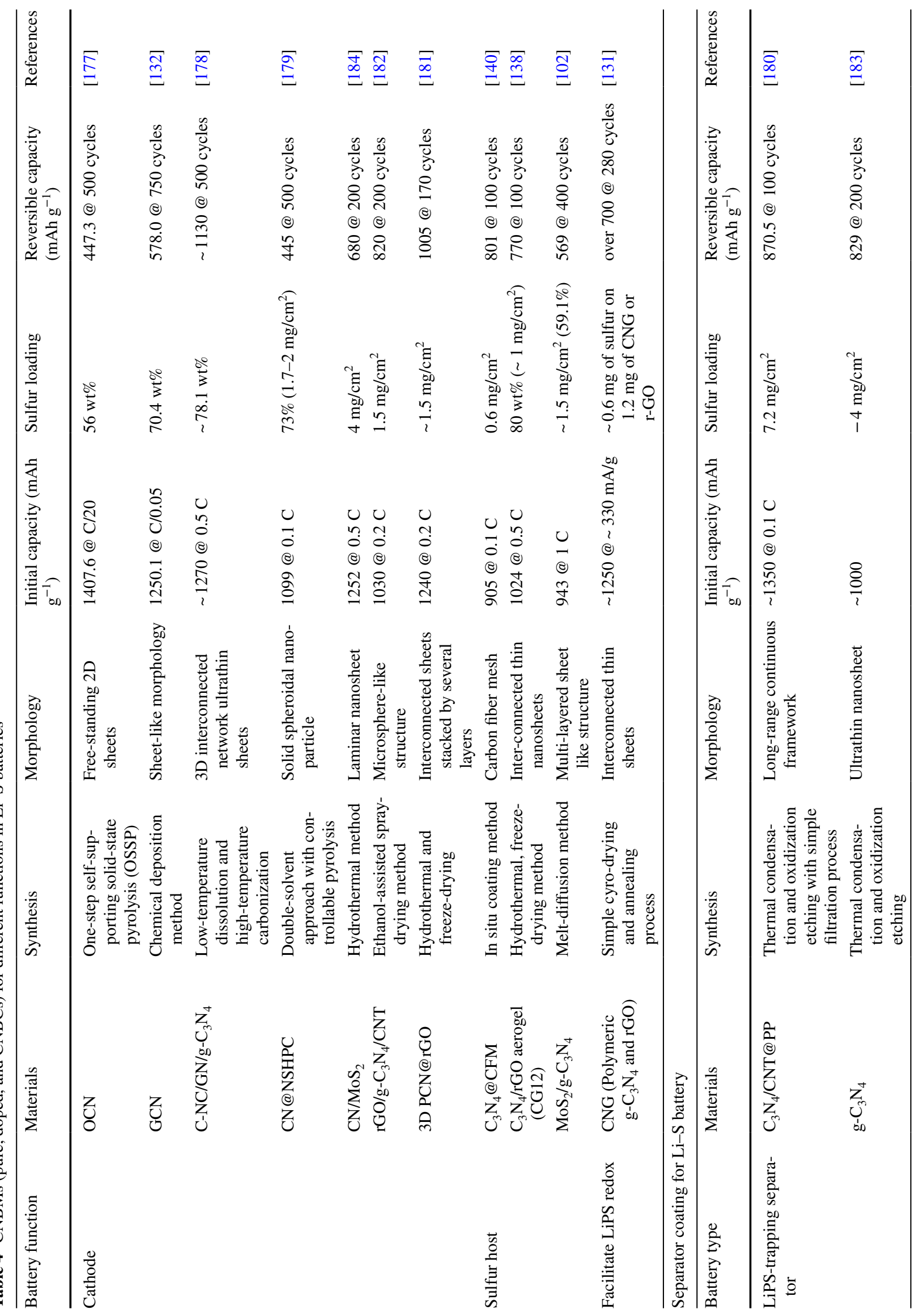




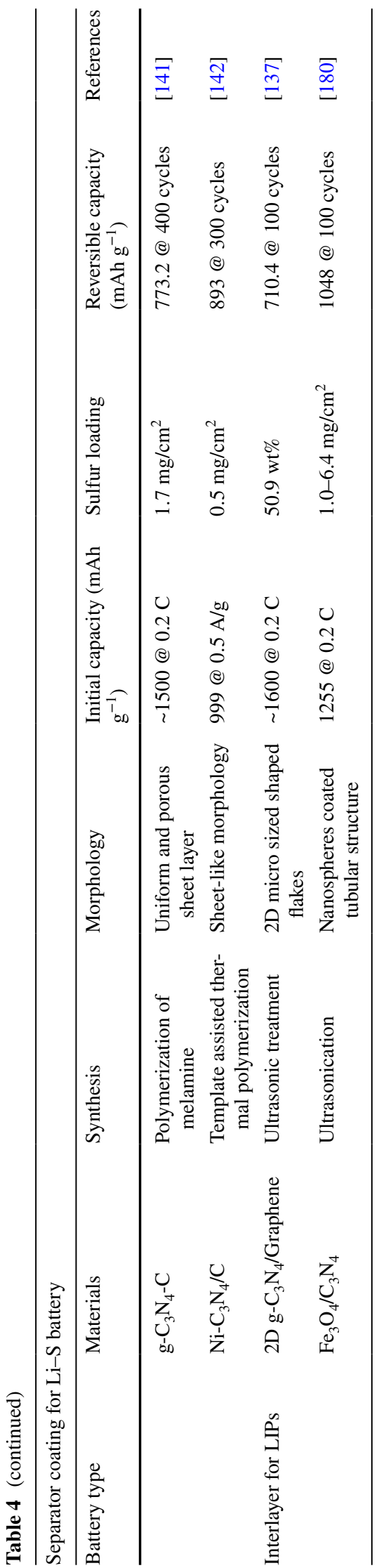

of $100 \mathrm{mAh} \mathrm{g}^{-1}$ with a low overpotential and long cycle life [142].

Luo et al. reported the fabrication of a 3D free-standing graphene@g- $\mathrm{C}_{3} \mathrm{~N}_{4}(\mathrm{G} @ \mathrm{CN})$ composite which delivered superior performance $\left(\sim 17,300 \mathrm{mAh} \mathrm{g}^{-1}\right.$ at a discharge voltage plateau of $2.6 \mathrm{~V})$, energy efficiency $(71 \%)$, and stable cycle life compared to the graphene electrode when applied in Li-O $\mathrm{O}_{2}$ battery (Fig. 24c) [143]. Lou et al. also reported the application of mesoporous boron-doped carbon nitride $(m-\mathrm{BCN})$ as a support for even distribution of ruthenium oxide $\left(\mathrm{RuO}_{2}\right.$ nanoparticles). As a $\mathrm{Li}-\mathrm{O}_{2}$ cathode, the $\mathrm{RuO}_{2} @ m$-BCN composite displayed a superior discharge capacity $\left(2.57 \mathrm{mAh} \mathrm{cm}^{-2}=512 \mathrm{mAh} \mathrm{g}^{-1}\right.$ based on the mass of the composite), smaller overpotential (0.18-discharge and 0.54 -recharge), and excellent cycle stability even after 126 cycles. The charge/discharge curve for the composite when cycled at $0.3 \mathrm{~mA} \mathrm{~cm}^{-2}$ is presented in Fig. 24d [144]. Guo and co-workers reported the synthesis of a ternary composite of $\mathrm{Co}_{3} \mathrm{O}_{4}$-modified $\mathrm{Ag} / \mathrm{g}-\mathrm{C}_{3} \mathrm{~N}_{4}$ for $\mathrm{Li}-\mathrm{O}_{2}$. The synergistic interaction between these three constituents produced a composite with superior battery performance and catalytic activity with stable cycle life, high reversible capacity, and round-trip efficiency (Fig. 24e, f) [145].

\subsection{Lithium-Metal Batteries}

Despite the benefits of lithium metal as a preferred anode for high energy batteries, its large-scale application is hampered by two major issues: performance and safety [1, 146, 147]. These two problems are related in that they are both caused by $\mathrm{Li}$ dendrite growth. Moreover, other issues such as formation of SEI film [148-150] and non-uniform $\mathrm{Li}^{+}$deposition are still of concern. These issues have been tackled in different ways, and because of the surface charges and functional groups of $\mathrm{g}-\mathrm{C}_{3} \mathrm{~N}_{4}$, it has been considered a very useful material for these various solutions. For instance, Luan and co-workers applied $\mathrm{O}$ - and $\mathrm{N}$-rich graphene-like $\mathrm{g}_{-} \mathrm{C}_{3} \mathrm{~N}_{4}$ as an effective artificial protective layer for Li-metal anode in half and full LIB and Li-S cells. Pristine g- $\mathrm{C}_{3} \mathrm{~N}_{4}(\mathrm{P}-\mathrm{G})$ and acid-treated $\mathrm{g}_{-} \mathrm{C}_{3} \mathrm{~N}_{4}$ (A-G) were tested for Li-metal, and the A-G-Li exhibited the best wettability, structural stability, and least contact angle of almost zero indicating uniform $\mathrm{Li}^{+}$distribution (Fig. 25a). From Fig. 25b, c, A-G-Li delivered the highest reversible capacity and superior capacity 

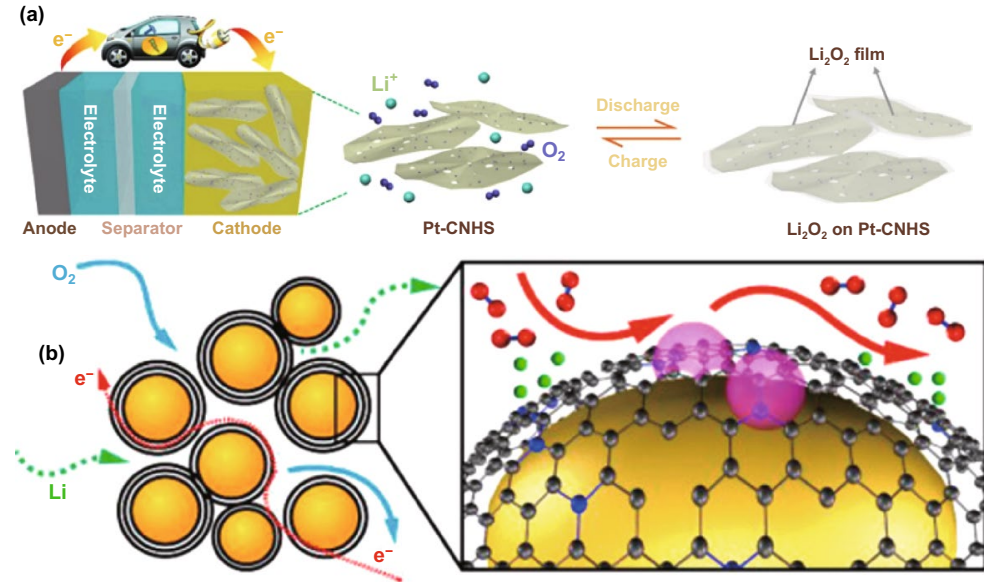

Synergistic effect for ORR and OER
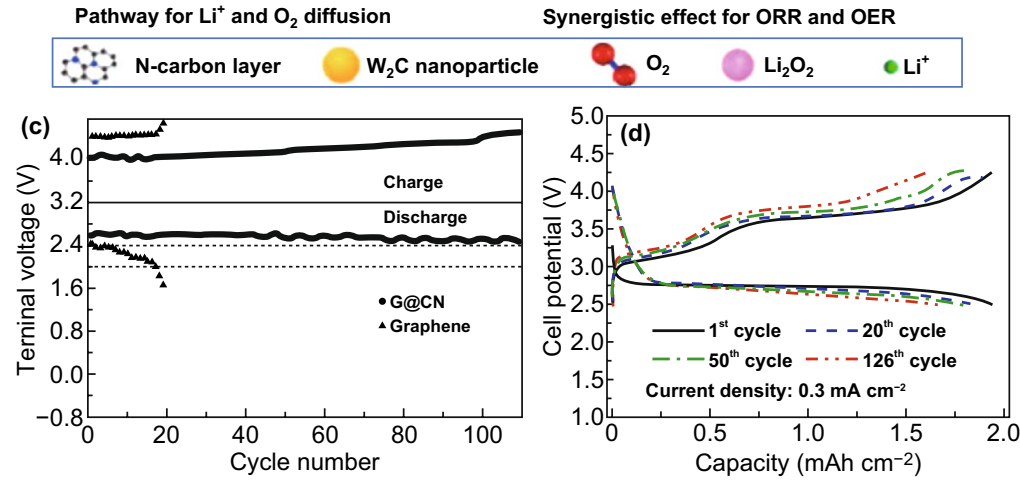
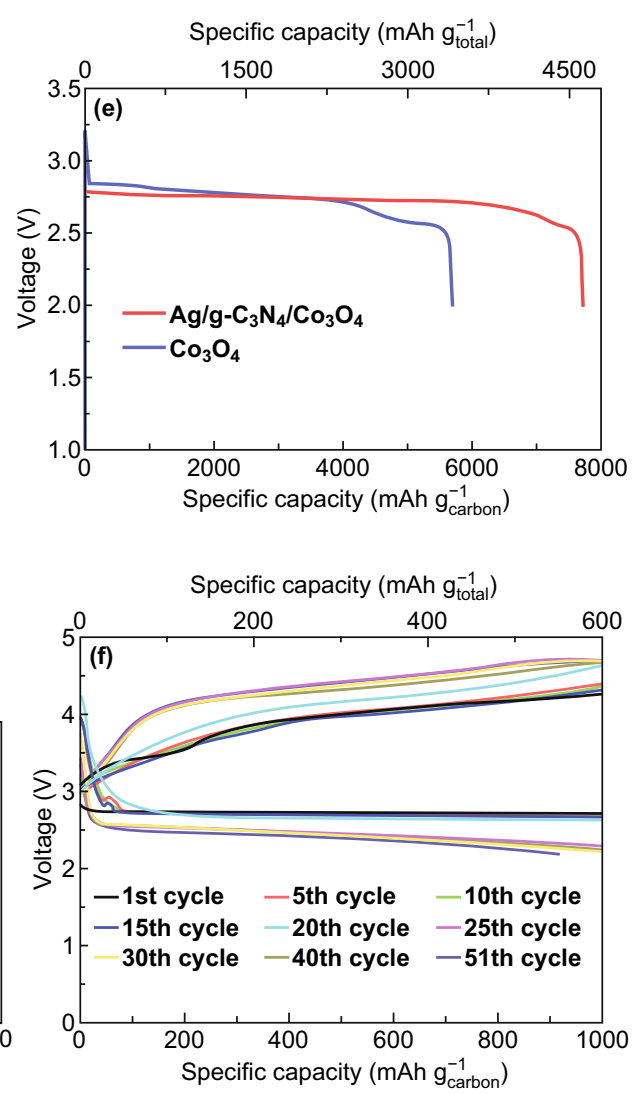

Fig. 24 a Schematic illustration for the reaction process during cycling. Reproduced with permission from Ref. [63]. b Schematic diagram of the synergistic effect of $\mathrm{N}$-doped carbon layer and $\mathrm{W}_{2} \mathrm{C}$ nanoparticles as Li- $\mathrm{O}_{2}$ battery catalyst. Reproduced with permission from Ref. [142]. $\mathrm{c}$ Comparison of the cycling performances of graphene and $\mathrm{G} @ \mathrm{CN}$ free-standing macroporous electrode. Reproduced with permission from Ref. [143]. d Cycle performance of $\mathrm{RuO}_{2} @ \mathrm{~m}-\mathrm{BCN}$ in Li- $\mathrm{O}_{2}$ batteries with a current density of $0.3 \mathrm{~mA} \mathrm{~cm}^{-2}$. Reproduced with permission from Ref. [144]. e First discharge curves of $\mathrm{Co}_{3} \mathrm{O}_{4}$ and $\mathrm{Ag} / \mathrm{g}-\mathrm{C}_{3} \mathrm{~N}_{4} / \mathrm{Co}_{3} \mathrm{O}_{4}$ as catalysts at a current density of $100 \mathrm{~mA} \mathrm{~g}^{-1} \mathrm{f}$ First charge/discharge curves of the $\mathrm{Ag} / \mathrm{g}-\mathrm{C}_{3} \mathrm{~N}_{4} / \mathrm{Co}_{3} \mathrm{O}_{4}$ as a catalyst at a current density of $500 \mathrm{~mA} \mathrm{~g}^{-1}$. Reproduced with permission from Ref. [145]. Copyright permissions from Springer Nature, Elsevier, Wiley-VCH, and Royal Society of Chemistry. (Color figure online)

retention (80\%) in both battery tests (LIB and $\mathrm{Li}-\mathrm{S}$, respectively) [151].

Considering the lithophilic nature of $\mathrm{g}-\mathrm{C}_{3} \mathrm{~N}_{4}$, its incredible mechanical strength, and unique morphology, $\mathrm{Hu}$ et al. reported the use of porous $\mathrm{g}-\mathrm{C}_{3} \mathrm{~N}_{4}$ microspheres as a polymeric electrolyte filler for lithium metal anode. $\mathrm{Li}$ dendrite was successfully suppressed in the $\mathrm{g}^{-} \mathrm{C}_{3} \mathrm{~N}_{4}$ filler (Fig. 25d). It delivered superior performance and stability to the commercial electrolyte (Fig. 25e, f) [152]. Luo et al. reported the uniform coating of $\mathrm{g}-\mathrm{C}_{3} \mathrm{~N}_{4}$ on a $3 \mathrm{D} \mathrm{Ni}$ foam (Fig. 25g) to design a g- $\mathrm{C}_{3} \mathrm{~N}_{4} @ \mathrm{Ni}$ foam which was applied as a current collector for Li-metal anode. The g- $\mathrm{C}_{3} \mathrm{~N}_{4} @ \mathrm{Ni}$ foam anode delivered superior capacity (Fig. 25h, i) to the pure Ni foam with excellent coulombic efficiency (98\%), cycle stability, and capacity retention $(72.9 \%$ at $1 \mathrm{C}$ after 200 cycles) [153].

\subsection{Zinc-Air Batteries}

The affordability, safety, and high specific energy density of ZABs are some of the reasons for the intensive research into this type of metal-air battery technology. However, the high cost and stability of metal-based catalysts for ZABs application [154, 155] have motivated researchers into designing metal-doped carbon materials [156, 157]. The high nitrogen content of $\mathrm{C}_{3} \mathrm{~N}_{4}$ makes it a viable material for composite design or as a reliable precursor for N-doped carbon synthesis. For instance, Shinde et al. developed a 3D carbon $\mathrm{NP}$ sandwiched in phosphorus and sulfur co-doped g- $\mathrm{C}_{3} \mathrm{~N}_{4}$ as a metal-free hybrid cathode material for ZAB. Electrochemical battery testing shows that the hybrid air-cathode operated at a voltage of approximately $1.51 \mathrm{~V}$ (Fig. 26a), 

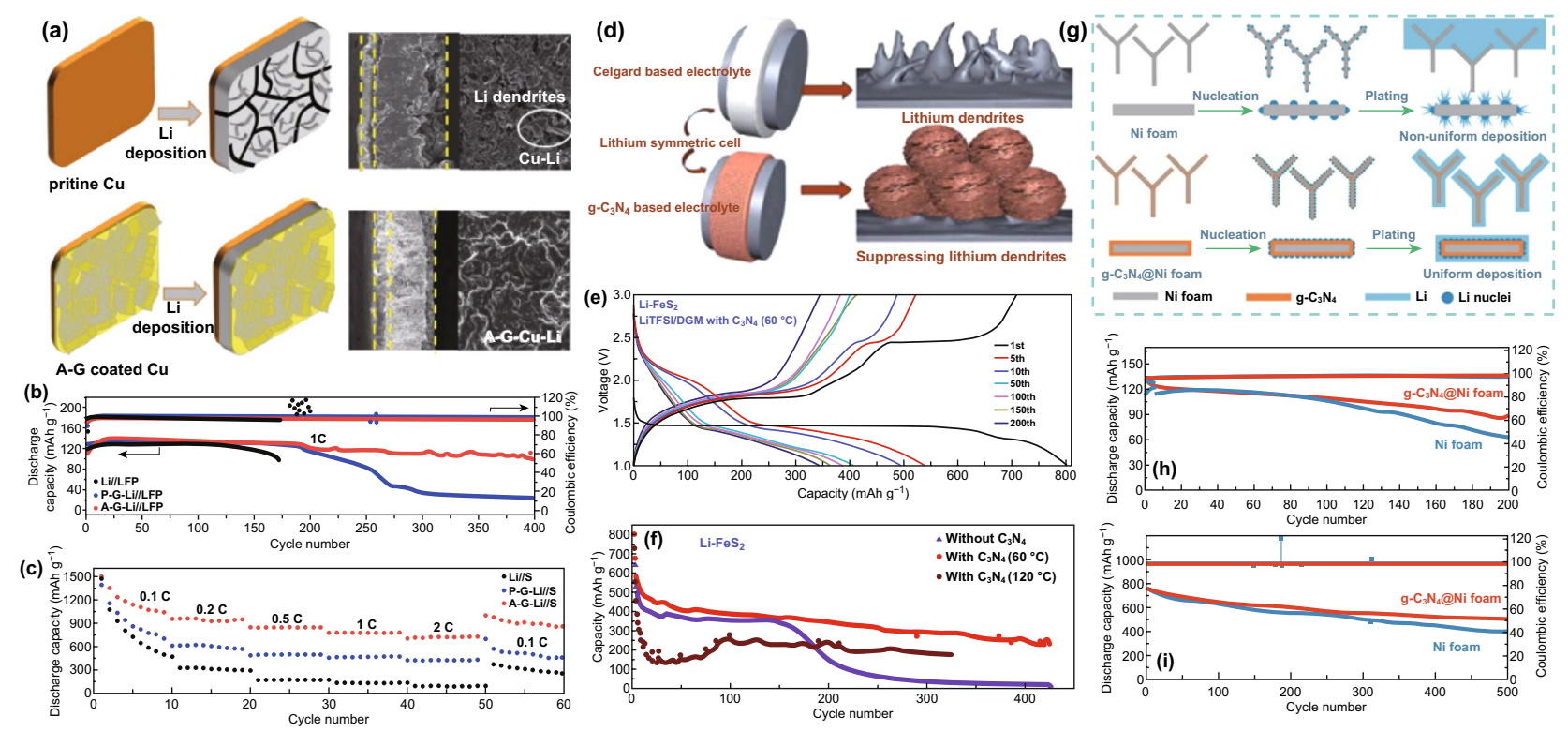

Fig. 25 a Schematic illustration and SEM images of the cross-sectional view of Li deposition on pristine $\mathrm{Cu}$ and A-G-Cu electrodes before

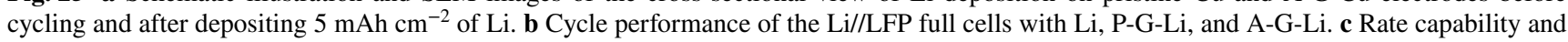
of the Li//S full cells with Li, P-G-Li, and A-G-Li. Reproduced with permission from Ref. [151]. d Scheme of Li dendrite growth and inhibition depending on $\mathrm{Li}$ symmetric cells with $\mathrm{g}_{-} \mathrm{C}_{3} \mathrm{~N}_{4}$ or without addition. e Galvanostatic charge/discharge curves of Li/FeS 2 cell based on LiTFSIDGM- $\mathrm{C}_{3} \mathrm{~N}_{4}$ electrolyte of at $0.1 \mathrm{C}$ in a voltage range of $1-3 \mathrm{~V}$. f Cycling performance of LiTFSI-DGM- $\mathrm{C}_{3} \mathrm{~N}_{4}$-based Li/FeS 2 cell (red circles) and its comparison with Li/LiTFSI-DGM/FeS ${ }_{2}$ cell. Reproduced with permission from Ref. [152]. g Schematic of the Li nucleation and plating process on $\mathrm{Ni}$ foam and $\mathrm{g}-\mathrm{C}_{3} \mathrm{~N}_{4} @ \mathrm{Ni}$ foam. h Discharge capacity and $\mathrm{CE}$ of Li@g- $\mathrm{C}_{3} \mathrm{~N}_{4} @ \mathrm{Ni}$ foamlLiCoO${ }_{2}$ and $\mathrm{Li} @ \mathrm{Ni}$ foamlLiCoO 2 cells at 1.0 C. i Discharge capacity and CE of Li@g- $\mathrm{C}_{3} \mathrm{~N}_{4} @ \mathrm{Ni}$ foamlS and Li@ Ni foamlS cells at 1.0 C. Reproduced with permission from Ref. [153]. Copyright permissions from American Chemical Society and Wiley-VCH. (Color figure online)

delivered a high reversible capacity of $830 \mathrm{mAh} \mathrm{g}^{-1}$ along with a high energy density of $970 \mathrm{Wh} \mathrm{kg}^{-1}, 198 \mathrm{~mW} \mathrm{~cm}^{-2}$ power density with excellent stability even after been recharged more than $210 \mathrm{~h}$ [158]. The composite was also tested in a tri-electrode ZABs system, and a schematic of the tri-electrode ZABs is shown in Fig. 26b.

Shinde et al. also synthesized 3D phosphorus, sulfur codoped carbon nitride nanofibers. As a cathode material in a primary zinc-air battery, the hybrid nanofiber architecture operated at a 1.49 circuit voltage (consider Fig. 26c) and delivered a reversible capacity of $698 \mathrm{mAh} \mathrm{g}^{-1}$, power and energy density of $231 \mathrm{~mW} / \mathrm{cm}^{2}$ and $785 \mathrm{Wh} / \mathrm{kg}$, respectively, with great stability even after $240 \mathrm{~h}$ of operation $[159,160]$. Ma et al. designed a flexible ZAB with bimetallic iron and cobalt $(\mathrm{FeCo})$ sandwiched in $\mathrm{N}$-doped carbon nanotubes (N-CNT). As an air-cathode in ZAB (Fig. 26d), the $\mathrm{FeCo} / \mathrm{N}-\mathrm{CNT}$ composite operated at an open-circuit voltage of $1.25 \mathrm{~V}$, delivered a power density of $97.8 \mathrm{~mW}$ $\mathrm{cm}^{-2}$, and showed excellent stability at $100 \mathrm{~mA} \mathrm{~cm}^{-2}$ even after 144 cycles [160]. Zhang et al. reported the synthesis of a zinc air electrode using $\mathrm{g}-\mathrm{C}_{3} \mathrm{~N}_{4}$ as a template for $\mathrm{N}$-doped carbon. The Fe-N-C air cathode operated at an open-circuit potential of $1.51 \mathrm{~V}$, delivered a power density of $100 \mathrm{~mW}$ $\mathrm{cm}^{-2}$ and was able to power a $3 \mathrm{~V}$ blue LED lamp. As seen in Fig. 26e, the air-cathode operated with excellent stability at a current density of $10 \mathrm{~mA} \mathrm{~cm}{ }^{-2}$ even after $6 \mathrm{~h}$ outshining the $\mathrm{N}-\mathrm{C}$ electrode. The cathode materials were able to light up LED lamps; photographs of the LED lights powered by the cathode materials are presented in Fig. 26f [161].

\subsection{Solid-State Batteries}

Unlike liquid organic electrolyte systems, the possibility of maximizing electron transfer in a solid-state electrolyte and lithium metal battery system is rather arduous because of the reducing property of Li metal when it interacts with most solid-state electrolytes [162]. This reductive process occurs because of the high reduction potential of solid-state electrolytes against that of $\mathrm{Li}$, for example $\mathrm{Li}_{10} \mathrm{GeP}_{2} \mathrm{~S}_{12}(1.71 \mathrm{~V})$, $\mathrm{Li}_{1.3} \mathrm{Ti}_{1.7} \mathrm{Al}_{0.3}\left(\mathrm{PO}_{4}\right)_{3}(2.17 \mathrm{~V})$, and $\mathrm{Li}_{0.33} \mathrm{La}_{0.56} \mathrm{TiO}_{3}(1.75)$ [163, 164]. While the reductive potential of $\mathrm{Li}_{7} \mathrm{La}_{3} \mathrm{Zr}_{5} \mathrm{O}_{12}(0.05 \mathrm{~V})$ 

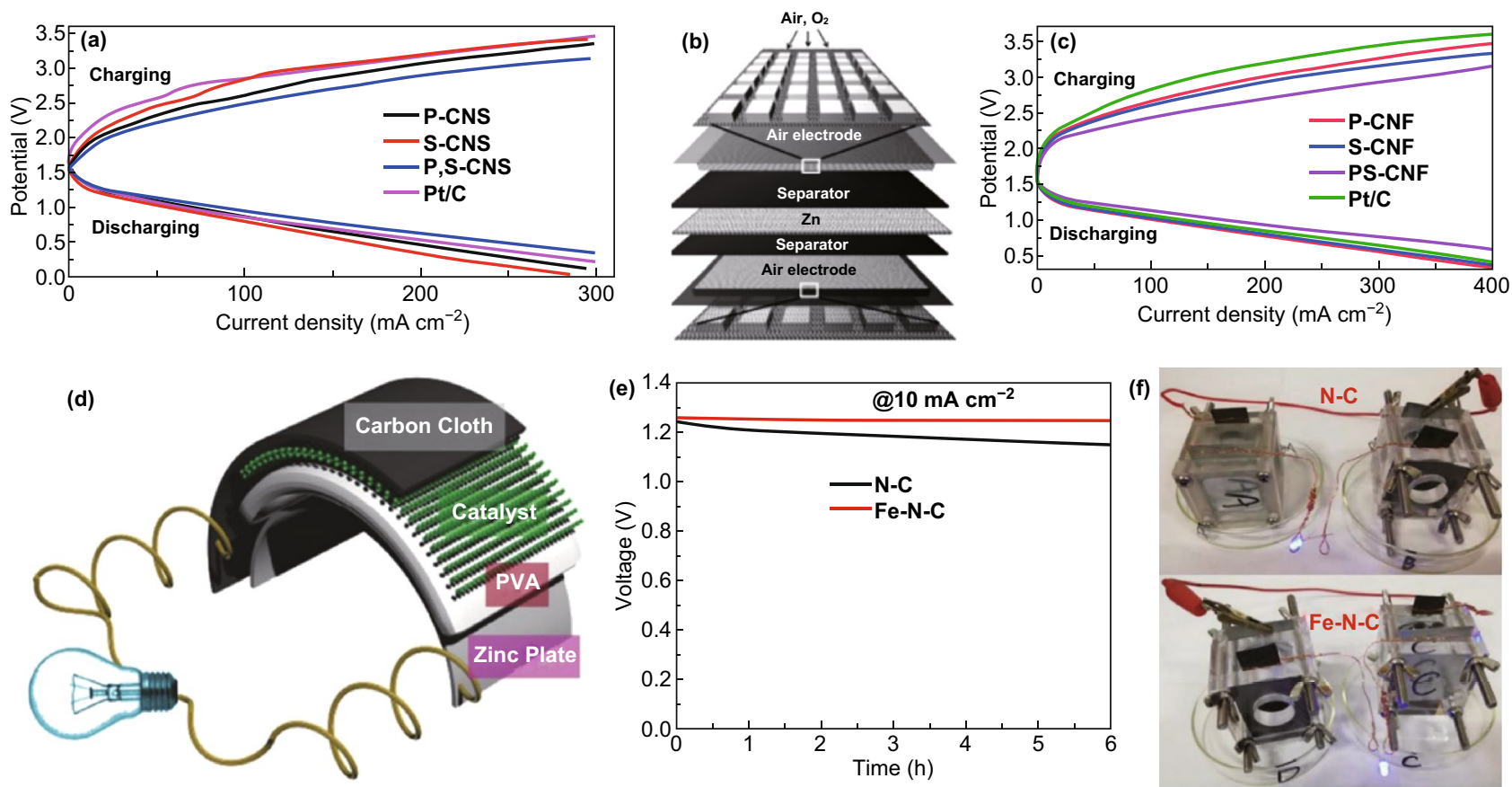

Fig. 26 a Three-electrode ZABs charge and discharge polarization plots of commercial Pt/C, P-CNS, S-CNS, and P, S-CNS catalyst as air electrodes. b Schematic representation for the tri-electrode ZABs. Reproduced with permission from Ref. [158]. c Charge and discharge polarization curves for three-electrode ZABs with P-CNF, S-CNF, PS-CNF, and Pt/C catalysts as both air electrodes. d Schematic representation of the all-solid-state rechargeable $\mathrm{Zn}$-air battery performance with N-GCNT/FeCo-3 acting as the air cathode. Reproduced with permission from Ref. [160]. e Galvanostatic discharge curves of the N-C or Fe-N-C cathode at the specific discharge current density of $10 \mathrm{~mA} \mathrm{~cm}{ }^{-2}$. f Photograph of blue-light LED powered by two primary Zn-air batteries connected in series with $\mathrm{N}-\mathrm{C}$ or $\mathrm{Fe}-\mathrm{N}-\mathrm{C}$ as the cathode catalyst. Reproduced with permission from Ref. [161]. Copyright permissions from Wiley-VCH, American Chemical Society, Elsevier, and Royal Society of Chemistry. (Color figure online)

is very far from that of $\mathrm{Li}$, it possesses a lithiophobic surface which means that it will experience poor contact and great surface resistance with lithium metal anode. However, this problem can be solved by meticulously coating its surface with a lithophilic material, thereby making changing its lithiophobicity and making $\mathrm{Li}_{7} \mathrm{La}_{3} \mathrm{Zr}_{5} \mathrm{O}_{12}$ lithophilic. Huang et al. used this approach when they reported the in situ formation of a $\mathrm{Li}_{3} \mathrm{~N}$ layer between $\mathrm{Li}$ and $\mathrm{Li}_{7} \mathrm{La}_{3} \mathrm{Zr}_{5} \mathrm{O}_{12}$ such that $\mathrm{Li}^{+}$can be effectively conducted and Li dendrite formation suppressed. This $\mathrm{Li}^{+}$conducting and electron-insulating $\mathrm{Li}_{3} \mathrm{~N}$ layer was created because of the reaction between molten $\mathrm{Li}$ and $\mathrm{g}-\mathrm{C}_{3} \mathrm{~N}_{4}$ to form a Li- $\mathrm{C}_{3} \mathrm{~N}_{4}$ composite such that the role of $\mathrm{C}_{3} \mathrm{~N}_{4}$ is for interface formation between $\mathrm{Li}$ and $\mathrm{Li}_{7} \mathrm{La}_{3} \mathrm{Zr}_{5} \mathrm{O}_{12}$ (Fig. 27a, b). The composite delivered a high capacity and stable cycle performance when tested in a solid-state battery (Fig. 27c) and maintained a strong/intimate contact with the Garnet (Fig. 27d) [165]. Lu et al. also reported the application of mesoporous carbon nitride $(\mathrm{MCN})$ and acetylene black $(\mathrm{AB})$ as a support for in situ growth of Pt nanoparticles for an all-solid-state lithium air battery system. A schematic of the assembled MCN-based electrode solidstate lithium-air battery is presented in Fig. 27e. As a cathode material in all-solid-state Li-air battery, the Pt@MCN electrode synthesized by $\mathrm{Lu}$ et al. recorded a significant high round trip efficiency (87\%) at a high discharge voltage of $\sim 2.87 \mathrm{~V}$ along with a low charge voltage of $\sim 3.3 \mathrm{~V}$ (Fig. 27f, g) [166]. Sun et al. reported the application of $\mathrm{g}-\mathrm{C}_{3} \mathrm{~N}_{4}$ as a polymeric filler to improve the coupling effect between the amorphous specie and coordination unit of a solid polymer electrolyte in solid-state 
(a)

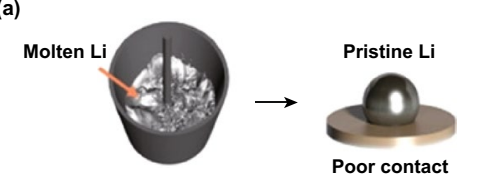

(b) $\mathrm{g}-\mathrm{C}_{3} \mathrm{~N}_{4}$

(b)

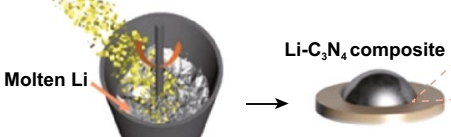

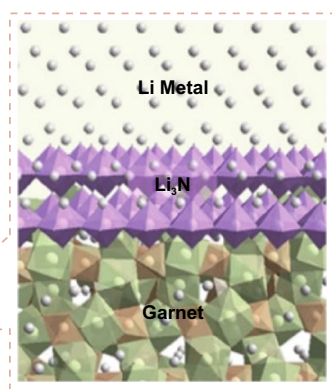
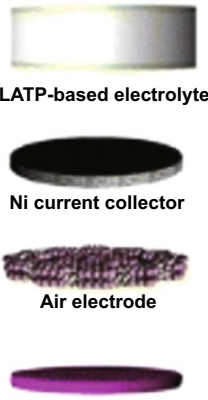

Li anode
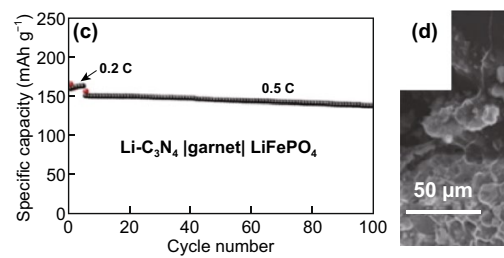

- $\mathrm{C}_{3} \mathrm{~N}_{4}$ composite

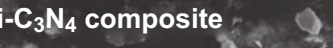

\section{Q9.8.}

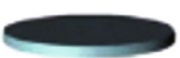

Stainless steel collector

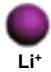

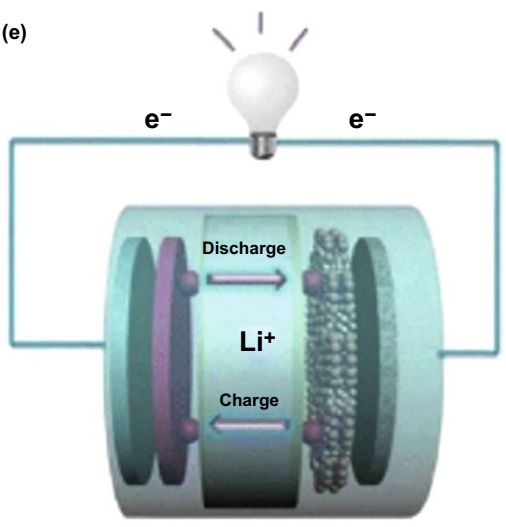
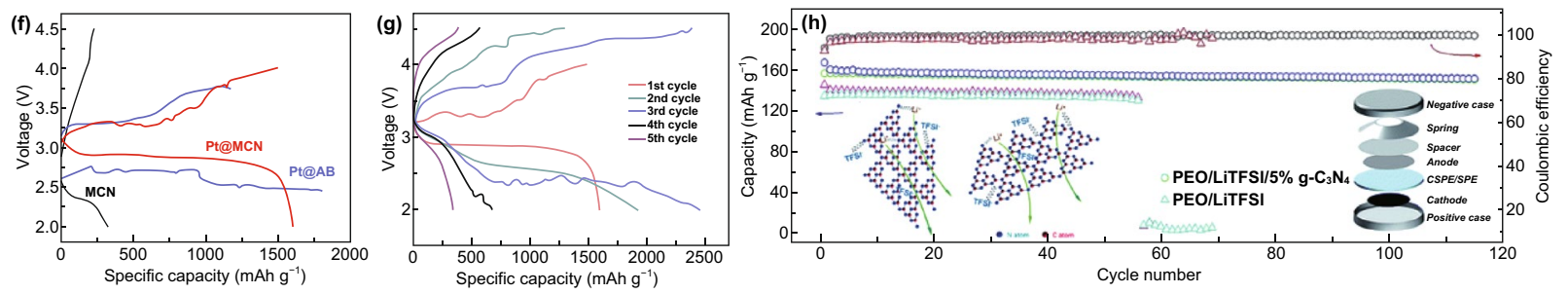

Fig. 27 a Schematic illustration of the synthesis process of $\mathrm{Li}_{-} \mathrm{C}_{3} \mathrm{~N}_{4}$ composite and the interfacial contact comparison of Li/garnet and Li- $\mathrm{C}_{3} \mathrm{~N}_{4} /$ garnet. a Garnet SSE presents a lithiophobic surface that forms pristine Li droplets. $\mathbf{b} \mathrm{Li}-\mathrm{C}_{3} \mathrm{~N}_{4}$ composite shows an intimate contact with garnet

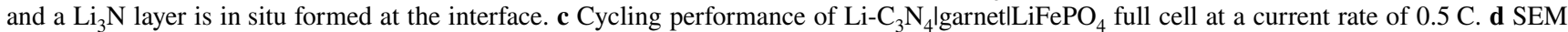
images of the cross sections of $\mathrm{Li}_{-} \mathrm{C}_{3} \mathrm{~N}_{4} /$ garnet interfaces. Reproduced with permission from Ref. [165]. e Scheme of the configuration of the MCN-based electrode solid-state lithium-air battery. $\mathbf{f}$ Charge and discharge curves of the first cycle of the prepared air electrodes at a current density of $0.02 \mathrm{~mA} \mathrm{~cm}{ }^{-2}$. $\mathbf{g}$ Cycling performance of Pt@MCN electrode at a current density of $0.02 \mathrm{~mA} \mathrm{~cm}^{-2}$. Reproduced with permission from Ref. [166]. h Capacity and coulombic efficiency versus cycle number for solid-state batteries using SPE and 5\% g- $\mathrm{C}_{3} \mathrm{~N}_{4} \mathrm{CSPE}$ at $0.2 \mathrm{C}$ rate. Inset: Schematics of enhanced lithium-ion migration in $\mathrm{g}-\mathrm{C}_{3} \mathrm{~N}_{4}$ CSPE. Reproduced with permission from Ref. [167]. Copyright permissions from Wiley-VCH, Springer Nature and Royal Society of Chemistry. (Color figure online)

batteries. When applied as an electrolyte with $\mathrm{LiFePO}_{4}$ in an all-solid-state battery, $60^{\circ} \mathrm{C}$ an initial reversible capacity of $161 \mathrm{mAh} \mathrm{g}^{-1}$ was delivered, and after 100 cycles, $155 \mathrm{mAh} \mathrm{g}^{-1}$ was still retained (Fig. 27h) [167].

\section{Conclusions and Future Perspectives}

A comprehensive overview of structure-guided synthesis/ fabrication and DFT-guided application of CNBMs for energy storage devices has been discussed in this review. CNBMs, including pure, doped, and CNBCs, exhibit high mechanical strength, excellent structural stability, abundant nitrogen-rich active sites, and surface functionalities, which are important for energy storage devices. Through the DFT-guided approach, CNBMs with superior structural and electronic properties are designed and their electrochemical properties can be modulated for improved performance. Moreover, the structure-guided approach facilitates the synthesis and fabrication of pure/doped $\mathrm{C}_{\mathrm{x}} \mathrm{N}_{\mathrm{y}}$ materials and CNBC's, respectively. The massive attention into CNBMs for electrochemical energy storage and conversion can be attributed to the combination of these two approaches, and they are paramount to the advancement in this field [140, 168-172].

Despite the significant progress made so far in the study of CNBMs for energy storage devices, there are still unresolved issues; therefore, we provide some perspectives to resolve them. Firstly, the important preconditions must be considered when carrying out a DFT-guided synthesis/ design of CNBMs. These prerequisites include the crystal phase and lattice parameter of the material, the interlayer 
distance (if it is a multi-layered material) and the exposed surface facet if it is a single-layered material, the ratio of $\mathrm{C} / \mathrm{N}$ or other elements and type of nitrogen (pyridinic or graphitic-N) dominant in the structure of the material. These preconditions are critical when designing a material via a DFT-guided approach. Secondly, a clear and concise investigation of the metal ion storage mechanism of CNBMs is essential. This will provide a fundamental/atomic-scale understanding of the electrochemical processes occurring at the surface and carbon matrix of the CNBMs. It will also show which surface functionalities of CNBMs impact their metal ion storage mechanism and how the interfacial interactions can be optimized. Thirdly, in situ characterization of CNBMs is required for a deeper understanding of structural changes, surface functional group transformation, and metal ion storage. For example, through in situ Fourier-transform infrared spectroscopy (FTIR), functional groups such as hydroxyl, amine, and carboxylic groups on the surface of CNBMs can be observed. Phase and oxidation state changes can also be identified through in situ X-ray photoelectron spectroscopy (XPS) analysis. These advanced characterization techniques can provide crucial information that will enlighten researchers on the relationship between the electronic properties and the CNBMs. Lastly, theoretical/computational studies of CNBMs have proven to be fundamental in understanding their electronic properties for energy storage devices; hence, it must remain a crucial part of its future research. However, DFT is limited in studying CNBMs for energy storage device because it involves the use of metal atoms instead of ions, and it cannot effectively account for the effect of electrolyte, SEI layer formation, pulverization of electrode, the surface charge of materials and interfacial interactions. Therefore, improvement of existing DFT tools/ functionals or the development of new ones that can account for these critical parameters is essential to achieve a closer alignment between DFT studies and experimental testing.

On a general note, the study of CNBMs is still at the early stage. Therefore, there is much room for improvement, and resolving these issues will surely propel the research to advance at a rapid pace.

Acknowledgements The authors gratefully acknowledge financial support from the Australia Research Council Discovery Projects (DP160102627 and DP1701048343) of Australia and Shenzhen Peacock Plan of China (KQTD2016112915051055), and the 111 Project (D20015) of China Three Gorges University.
Open Access This article is licensed under a Creative Commons Attribution 4.0 International License, which permits use, sharing, adaptation, distribution and reproduction in any medium or format, as long as you give appropriate credit to the original author(s) and the source, provide a link to the Creative Commons licence, and indicate if changes were made. The images or other third party material in this article are included in the article's Creative Commons licence, unless indicated otherwise in a credit line to the material. If material is not included in the article's Creative Commons licence and your intended use is not permitted by statutory regulation or exceeds the permitted use, you will need to obtain permission directly from the copyright holder. To view a copy of this licence, visit http://creativecommons.org/licenses/by/4.0/.

\section{References}

1. Z. Su, J. Liu, M. Li, Y. Zhu, S. Qian et al., Defect engineering in titanium-based oxides for electrochemical energy storage devices. Electrochem. Energ. Rev. 3, 286-343 (2020). https://doi.org/10.1007/s41918-020-00064-5

2. Y. Zhang, G. Shi, J. Qin, S.E. Lowe, S. Zhang, H. Zhao, Y.L. Zhong, Recent progress of direct ink writing of electronic components for advanced wearable devices. ACS Appl. Electron. Mater. 1(9), 1718-1734 (2019). https:// doi.org/10.1021/acsaelm.9b00428

3. Z. Wu, J. Xie, Z.J. Xu, S. Zhang, Q. Zhang, Recent progress in metal-organic polymers as promising electrodes for lithium/sodium rechargeable batteries. J. Mater. Chem. A 7(9), 4259-4290 (2019). https://doi.org/10.1039/C8TA1 1994E

4. C. Wu, X. Tong, Y. Ai, D.-S. Liu, P. Yu, J. Wu, Z.M. Wang, A review: enhanced anodes of $\mathrm{Li} / \mathrm{Na}$-ion batteries based on yolk-shell structured nanomaterials. Nano-Micro Lett. 10(3), 40 (2018). https://doi.org/10.1007/s40820-018-0194-4

5. C. Liu, X. Liu, J. Tan, Q. Wang, H. Wen, C. Zhang, Nitrogendoped graphene by all-solid-state ball-milling graphite with urea as a high-power lithium ion battery anode. J. Power Sources 342, 157-164 (2017). https://doi.org/10.1016/j.jpows our.2016.11.110

6. B. He, Y. Wang, Q. Zhai, P. Qiu, G. Dong, X. Liu, Y. Chen, Z. Li, From polymeric carbon nitride to carbon materials: extended application to electrochemical energy conversion and storage. Nanoscale 12(16), 8636-8646 (2020). https:// doi.org/10.1039/D0NR01612H

7. Q. Hao, G. Jia, W. Wei, A. Vinu, Y. Wang, H. Arandiyan, B.-J. Ni, Graphitic carbon nitride with different dimensionalities for energy and environmental applications. Nano Res. 13(1), 18-37 (2020). https://doi.org/10.1007/s 1227 4-019-2589-z

8. J. Chen, Z. Mao, L. Zhang, D. Wang, R. Xu, L. Bie, B.D. Fahlman, Nitrogen-deficient graphitic carbon nitride with enhanced performance for lithium ion battery anodes. ACS Nano 11(12), 12650-12657 (2017). https://doi.org/10.1021/ acsnano.7b07116 
9. H. Pang, Y. Luo, Y. Yan, S. Zheng, H. Xue, Graphitic carbon nitride based materials for electrochemical energy storage. J. Mater. Chem. A 7(3), 901-924 (2018). https://doi. org/10.1039/C8TA08464E

10. B. Zhu, B. Cheng, L. Zhang, J. Yu, Review on dft calculation of s-triazine-based carbon nitride. Carbon Energy 1(1), 32-56 (2019). https://doi.org/10.1002/cey2.1

11. A. Bafekry, S.F. Shayesteh, F.M. Peeters, Two-dimensional carbon nitride (2DCN) nanosheets: tuning of novel electronic and magnetic properties by hydrogenation, atom substitution and defect engineering. J. Appl. Phys. 126(21), 215104 (2019). https://doi.org/10.1063/1.5120525

12. R. Shibuya, T. Kondo, J. Nakamura, Active sites in nitrogen-doped carbon materials for oxygen reduction reaction. Carbon-Based Metal-Free Catalysts 1, 227-249 (2018). https ://doi.org/10.1002/9783527811458.vol1-ch8

13. K.S. Lakhi, D.-H. Park, K. Al-Bahily, W. Cha, B. Viswanathan, J.-H. Choy, A. Vinu, Mesoporous carbon nitrides: synthesis, functionalization, and applications. Chem. Soc. Rev. 46(1), 72-101 (2017). https://doi.org/10.1039/C6CS00532B

14. H. Xia, Q. Xu, J. Zhang, Recent progress on two-dimensional nanoflake ensembles for energy storage applications. NanoMicro Lett. 10(4), 66 (2018). https://doi.org/10.1007/s4082 $0-018-0219-\mathrm{z}$

15. H. Qiu, Z. Wang, X. Sheng, First-principles prediction of an intrinsic half-metallic graphitic hydrogenated carbon nitride. Phys. Lett. A 377(3-4), 347-350 (2013). https://doi. org/10.1016/j.physleta.2012.11.050

16. T. Hussain, D.J. Searles, M. Hankel, Insights into the trapping mechanism of light metals on $\mathrm{C}_{2} \mathrm{~N}-h 2 \mathrm{~d}$ : utilisation as an anode material for metal ion batteries. Carbon 160, 125-132 (2020). https://doi.org/10.1016/j.carbon.2019.12.063

17. Y. Zheng, H. Li, H. Yuan, H. Fan, W. Li, J. Zhang, Understanding the anchoring effect of graphene, $\mathrm{BN}, \mathrm{C}_{2} \mathrm{~N}$ and $\mathrm{C}_{3} \mathrm{~N}_{4}$ monolayers for lithium-polysulfides in $\mathrm{Li}-\mathrm{S}$ batteries. Appl. Surf. Sci. 434, 596-603 (2018). https://doi.org/10.1016/j. apsusc.2017.10.230

18. B. Zhu, L. Zhang, B. Cheng, J. Yu, First-principle calculation study of tri-s-triazine-based $\mathrm{g}_{-} \mathrm{C}_{3} \mathrm{~N}_{4}$ : a review. Appl. Cat. B Environ. 224, 983-999 (2018). https://doi.org/10.1016/j.apcat b.2017.11.025

19. Q. Weng, G. Li, X. Feng, K. Nielsch, D. Golberg, O.G. Schmidt, Electronic and optical properties of 2D materials constructed from light atoms. Adv. Mater. 30(46), 1801600 (2018). https://doi.org/10.1002/adma.201801600

20. H.-Z. Wu, L.-M. Liu, S.-J. Zhao, The effect of water on the structural, electronic and photocatalytic properties of graphitic carbon nitride. Phys. Chem. Chem. Phys. 16(7), 3299-3304 (2014). https://doi.org/10.1039/C3CP54333A

21. A. Wang, C. Wang, L. Fu, W. Wong-Ng, Y. Lan, Recent advances of graphitic carbon nitride-based structures and applications in catalyst, sensing, imaging, and leds. NanoMicro Lett. 9(4), 47 (2017). https://doi.org/10.1007/s4082 0-017-0148-2

22. J. Zhang, Y. Chen, X. Wang, Two-dimensional covalent carbon nitride nanosheets: synthesis, functionalization, and applications. Energy Environ. Sci. 8(11), 3092-3108 (2015). https://doi.org/10.1039/C5EE01895A

23. J. Mahmood, E.K. Lee, M. Jung, D. Shin, H.-J. Choi et al., Two-dimensional polyaniline $\left(\mathrm{C}_{3} \mathrm{~N}\right)$ from carbonized organic single crystals in solid state. Proc. Natl. Acad. Sci. 113(27), 7414-7419 (2016). https://doi.org/10.1073/pnas.1605318113

24. L. Li, X. Kong, O. Leenaerts, X. Chen, B. Sanyal, F.M. Peeters, Carbon-rich carbon nitride monolayers with dirac cones: dumbbell $\mathrm{C}_{4}$ N. Carbon 118, 285-290 (2017). https:// doi.org/10.1016/j.carbon.2017.03.045

25. B. Peng, B. Mortazavi, H. Zhang, H. Shao, K. Xu et al., Tuning thermal transport in $\mathrm{C}_{3} \mathrm{~N}$ monolayers by adding and removing carbon atoms. Phys. Rev. Appl. 10(3), 034046 (2018). https://doi.org/10.1103/PhysRevApplied.10.034046

26. C. Pu, D. Zhou, Y. Li, H. Liu, Z. Chen, Y. Wang, Y. Ma, Two-dimensional $\mathrm{C}_{4} \mathrm{~N}$ global minima: unique structural topologies and nanoelectronic properties. J. Phys. Chem. C 121(5), 2669-2674 (2017). https://doi.org/10.1021/acs. jpcc.6b09960

27. D. Wang, H. Li, L. Zhang, Z. Sun, D. Han, L. Niu, J. Zhao, $2 \mathrm{D}$ nitrogen-containing carbon material $\mathrm{C}_{5} \mathrm{~N}$ as potential host material for lithium polysulfides: a first-principles study. Adv. Theory Simul. 2(2), 1800165 (2019). https://doi.org/10.1002/ adts.201800165

28. H. Lin, R. Jin, A. Wang, S. Zhu, H. Li, Transition metal embedded $\mathrm{C}_{2} \mathrm{~N}$ with efficient polysulfide immobilization and catalytic oxidation for advanced lithium-sulfur batteries: a first principles study. Ceram. Int. 45(14), 17996-18002 (2019). https://doi.org/10.1016/j.ceramint.2019.06.018

29. B. Tian, T. Huang, J. Guo, H. Shu, Y. Wang, J. Dai, Performance effects of doping engineering on graphene-like $\mathrm{C}_{3} \mathrm{~N}$ as an anode material for alkali metal ion batteries. Mater. Sci. Semicond. Proc. 109, 104946 (2020). https://doi. org/10.1016/j.mssp.2020.104946

30. M. Xu, H. Wang, S. Sun, H. Li, X. Li, Y. Chen, Y. Ni, Firstprinciples study of metal atoms adsorption on 2D dumbbell $\mathrm{C}_{4}$ N. Phys. Status Solidi B 257(1), 1900205 (2020). https:// doi.org/10.1002/pssb.201900205

31. W. Cha, I.Y. Kim, J.M. Lee, S. Kim, K. Ramadass, K. Gopalakrishnan, S. Premkumar, S. Umapathy, A. Vinu, Sulfur-doped mesoporous carbon nitride with an ordered porous structure for sodium-ion batteries. ACS Appl. Mater. Interfaces 11(30), 27192-27199 (2019). https://doi.org/10.1021/ acsami.9b07657

32. M. Molaei, S.M. Mousavi-Khoshdel, M. Ghiasi, Exploring the effect of phosphorus doping on the utility of $\mathrm{g}-\mathrm{C}_{3} \mathrm{~N}_{4}$ as an electrode material in Na-ion batteries using DFT method. J. Mol. Model. 25(8), 256 (2019). https://doi.org/10.1007/ s00894-019-4109-1

33. M.-S. Balogun, Z. Wu, Y. Luo, W. Qiu, X. Fan, B. Long, M. Huang, P. Liu, Y. Tong, High power density nitridated hematite $\left(\alpha-\mathrm{Fe}_{2} \mathrm{O}_{3}\right)$ nanorods as anode for high-performance flexible lithium ion batteries. J. Power Sources 308, 7-17 (2016). https://doi.org/10.1016/j.jpowsour.2016.01.043

34. S. Kim, M. Hankel, W. Cha, G. Singh, J.M. Lee, I.Y. Kim, A. Vinu, Theoretical and experimental investigations of 
mesoporous $\mathrm{C}_{3} \mathrm{~N}_{5} / \mathrm{MoS}_{2}$ hybrid for lithium and sodium ion batteries. Nano Energy 72, 104702 (2020). https://doi. org/10.1016/j.nanoen.2020.104702

35. X. Wu, F. Kang, W. Duan, J. Li, Density functional theory calculations: a powerful tool to simulate and design highperformance energy storage and conversion materials. Prog. Nat. Sci. 29(3), 247-255 (2019). https://doi.org/10.1016/j. pnsc.2019.04.003

36. M. Li, T. Gould, Z. Su, S. Li, F. Pan, S. Zhang, Electrochromic properties of $\mathrm{Li}_{4} \mathrm{Ti}_{5} \mathrm{O}_{12}$ : from visible to infrared spectrum. Appl. Phys. Lett. 115(7), 073902 (2019). https://doi. org/10.1063/1.5099330

37. Y. Wang, Z. Jiao, S. Ma, Y. Guo, Probing $\mathrm{C}_{3} \mathrm{~N} /$ graphene heterostructures as anode materials for $\mathrm{Li}$-ion batteries. J. Power Sources 413, 117-124 (2019). https://doi.org/10.1016/j.jpows our.2018.12.031

38. Y. Ding, B. Xiao, J. Li, Q. Deng, Y. Xu, H. Wang, D. Rao, Improved transport properties and novel Li diffusion dynamics in van der waals $\mathrm{C}_{2} \mathrm{~N} /$ graphene heterostructure as anode materials for lithium-ion batteries: a first-principles investigation. J. Phys. Chem. C 123(6), 3353-3367 (2019). https://doi.org/10.1021/acs.jpcc.8b11044

39. D. Adekoya, S. Zhang, M. Hankel, 1D/2D $\mathrm{C}_{3} \mathrm{~N}_{4}$ /graphene composite as a preferred anode material for lithium ion batteries: importance of heterostructure design via DFT computation. ACS Appl. Mater. Interfaces 12(23), 2587525883 (2020). https://doi.org/10.1021/acsami.0c04900

40. Q. Liu, B. Xiao, J. Cheng, Y.-C. Li, Q. Li et al., Carbon excess $\mathrm{C}_{3} \mathrm{~N}$ : a potential candidate as Li-ion battery material. ACS Appl. Mater. Interfaces 10(43), 37135-37141 (2018). https://doi.org/10.1021/acsami.8b14183

41. A. Jain, Y. Shin, K.A. Persson, Computational predictions of energy materials using density functional theory. Nat. Rev. Mater. 1(1), 15004 (2016). https://doi.org/10.1038/ natrevmats.2015.4

42. M. Wu, Q. Wang, Q. Sun, P. Jena, Functionalized graphitic carbon nitride for efficient energy storage. J. Phys. Chem. C 117(12), 6055-6059 (2013). https://doi.org/10.1021/jp311 $972 \mathrm{f}$

43. Y. Mao, H. Duan, B. Xu, L. Zhang, Y. Hu et al., Lithium storage in nitrogen-rich mesoporous carbon materials. Energy Environ. Sci. 5(7), 7950-7955 (2012). https://doi. org/10.1039/c2ee21817h

44. G.M. Veith, L. Baggetto, L.A. Adamczyk, B. Guo, S.S. Brown et al., Electrochemical and solid-state lithiation of graphitic $\mathrm{C}_{3} \mathrm{~N}_{4}$. Chem. Mater. 25(3), 503-508 (2013). https ://doi.org/10.1021/cm303870x

45. M. Hankel, D. Ye, L. Wang, D.J. Searles, Lithium and sodium storage on graphitic carbon nitride. J. Phys. Chem. C 119(38), 21921-21927 (2015). https://doi.org/10.1021/ acs.jpcc. 5 b07572

46. D. Adekoya, X. Gu, M. Rudge, W. Wen, C. Lai, M. Hankel, S. Zhang, Carbon nitride nanofibres with exceptional lithium storage capacity: from theoretical prediction to experimental implementation. Adv. Funct. Mater. 28(50), 1803972 (2018). https://doi.org/10.1002/adfm.201803972
47. H. Pan, Graphitic carbon nitride nanotubes as Li-ion battery materials: a first-principles study. J. Phys. Chem. C 118(18), 9318-9323 (2014). https://doi.org/10.1021/jp412 2722

48. M. Hankel, D.J. Searles, Lithium storage on carbon nitride, graphenylene and inorganic graphenylene. J. Phys. Chem. C 18(21), 14205-14215 (2016). https://doi.org/10.1039/C5CP0 $7356 \mathrm{~A}$

49. D. Wu, B. Yang, H. Chen, E. Ruckenstein, Nitrogenated holey graphene $\mathrm{C}_{2} \mathrm{~N}$ monolayer anodes for lithium- and sodium-ion batteries with high performance. Energy Storage Mater. 16, 574-580 (2019). https://doi.org/10.1016/j.ensm.2018.09.001

50. J. Xu, J. Mahmood, Y. Dou, S. Dou, F. Li, L. Dai, J.B. Baek, 2D frameworks of $\mathrm{C} 2 \mathrm{~N}$ and $\mathrm{C} 3 \mathrm{~N}$ as new anode materials for lithium-ion batteries. Adv. Mater. 29(34), 1702007 (2017). https://doi.org/10.1002/adma.201702007

51. G. Guo, R. Wang, S. Luo, B. Ming, C. Wang et al., Metallic two-dimensional $\mathrm{C}_{3} \mathrm{~N}$ allotropes with electron and ion channels for high-performance Li-ion battery anode materials. Appl. Surf. Sci. 518, 146254 (2020). https://doi. org/10.1016/j.apsusc.2020.146254

52. C. Yang, X. Zhang, J. Ma, B. Shi, H. Zhang et al., Ultrahigh capacity of monolayer dumbbell $\mathrm{C}_{4} \mathrm{~N}$ as a promising anode material for lithium-ion battery. J. Electrochem. Soc. 167(2), 020538 (2020). https://doi.org/10.1149/1945-7111/ ab6bbd

53. G.M. Weng, Y. Xie, H. Wang, C. Karpovich, J. Lipton et al., A promising carbon/g-C3N4 composite negative electrode for a long-life sodium-ion battery. Angew. Chem. Int. Ed. 131(39), 13865-13871 (2019). https://doi.org/10.1002/ ange. 201905803

54. D. Adekoya, M. Li, M. Hankel, C. Lai, M.-S. Balogun, Y. Tong, S. Zhang, Design of a $1 \mathrm{D} / 2 \mathrm{D} \mathrm{C}_{3} \mathrm{~N}_{4} / \mathrm{rGO}$ composite as an anode material for stable and effective potassium storage. Energy Storage Mater. 25, 495-501 (2019). https://doi. org/10.1016/j.ensm.2019.09.033

55. P. Bhauriyal, A. Mahata, B. Pathak, Graphene-like carbonnitride monolayer: a potential anode material for $\mathrm{Na}$-and K-ion batteries. J. Phys. Chem. C 122(5), 2481-2489 (2018). https://doi.org/10.1021/acs.jpcc.7b09433

56. T. Li, C. He, W. Zhang, A novel porous $\mathrm{C}_{4} \mathrm{~N}_{4}$ monolayer as a potential anchoring material for lithium-sulfur battery design. J. Mater. Chem. A 7(8), 4134-4144 (2019). https:// doi.org/10.1039/C8TA10933H

57. J. Liang, L. Yin, X. Tang, H. Yang, W. Yan et al., Kinetically enhanced electrochemical redox of polysulfides on polymeric carbon nitrides for improved lithium-sulfur batteries. ACS Appl. Mater. Interfaces 8(38), 25193-25201 (2016). https:// doi.org/10.1021/acsami.6b05647

58. Z. Meng, Y. Xie, T. Cai, Z. Sun, K. Jiang, W.-Q. Han, Graphene-like $\mathrm{g}_{-} \mathrm{C}_{3} \mathrm{~N}_{4}$ nanosheets/sulfur as cathode for lithiumsulfur battery. Electrochim. Acta 210, 829-836 (2016). https ://doi.org/10.1016/j.electacta.2016.06.032

59. S.S. Shinde, C.H. Lee, J.-Y. Yu, D.-H. Kim, S.U. Lee, J.-H. Lee, Hierarchically designed $3 \mathrm{D}$ holey $\mathrm{C}_{2} \mathrm{~N}$ aerogels as bifunctional oxygen electrodes for flexible and rechargeable 
Zn-air batteries. ACS Nano 12(1), 596-608 (2017). https:// doi.org/10.1021/acsnano.7b07473

60. M. Je, Y.-C. Chung, Investigation of the initial reactions of lithium oxides on the graphitic carbon nitrides $\left(\mathrm{g}-\mathrm{C}_{3} \mathrm{~N}_{4}\right)$ for catalyst in non-aqueous lithium-air batteries: a first-principles calculations. Thin Solid Films 660, 186-190 (2018). https://doi.org/10.1016/j.tsf.2018.06.017

61. W. Nong, Y. Li, C. Wang, $\mathrm{C}_{3} \mathrm{~N}$ monolayer with substitutional doping and strain modulation serving as anode material of lithium-ion batteries. Appl. Surf. Sci. 510, 145324 (2020). https://doi.org/10.1016/j.apsusc.2020.145324

62. G.-M. Weng, Y. Xie, H. Wang, C. Karpovich, J. Lipton et al., A promising carbon/g- $\mathrm{C}_{3} \mathrm{~N}_{4}$ composite negative electrode for a long-life sodium-ion battery. Angew. Chem. Int. Ed. 58(39), 13727-13733 (2019). https://doi.org/10.1002/anie.201905803

63. W. Zhao, J. Wang, R. Yin, B. Li, X. Huang, L. Zhao, L. Qian, Single-atom pt supported on holey ultrathin $\mathrm{g}-\mathrm{C}_{3} \mathrm{~N}_{4}$ nanosheets as efficient catalyst for $\mathrm{Li}-\mathrm{O}_{2}$ batteries. J. Colloid Inter. Sci. 564, 28-36 (2020). https://doi.org/10.1016/j. jcis.2019.12.102

64. G.-C. Guo, R.-Z. Wang, B.-M. Ming, C. Wang, S.-W. Luo, M. Zhang, H. Yan, $\mathrm{C}_{3} \mathrm{~N} /$ phosphorene heterostructure: a promising anode material in lithium-ion batteries. J. Mater. Chem. A 7(5), 2106-2113 (2019). https://doi.org/10.1039/C8TA1 0972A

65. H. Lin, R. Jin, S. Zhu, Y. Huang, $\mathrm{C}_{3} \mathrm{~N} /$ blue phosphorene heterostructure as a high rate-capacity and stable anode material for lithium ion batteries: insight from first principles calculations. Appl. Surf. Sci. 505, 144518 (2020). https://doi. org/10.1016/j.apsusc.2019.144518

66. J. Bao, H. Li, Q. Duan, D. Jiang, W. Liu et al., Graphene-like $\mathrm{C}_{3} \mathrm{~N} /$ blue phosphorene heterostructure as a potential anode material for li/na-ion batteries: a first principles study. Solid State Ionics 345, 115160 (2020). https://doi.org/10.1016/j. ssi.2019.115160

67. K. Liao, P. Mao, N. Li, M. Han, J. Yi, P. He, Y. Sun, H. Zhou, Stabilization of polysulfides via lithium bonds for $\mathrm{Li}-\mathrm{S}$ batteries. J. Mater. Chem. A 4(15), 5406-5409 (2016). https:// doi.org/10.1039/C6TA00054A

68. N. Feng, F. Liu, M. Huang, A. Zheng, Q. Wang et al., Unravelling the efficient photocatalytic activity of boron-induced $\mathrm{Ti}^{3+}$ species in the surface layer of $\mathrm{TiO}_{2}$. Sci. Rep. 6, 34765 (2016). https://doi.org/10.1038/srep34765

69. M. Chen, X. Zhao, Y. Li, P. Zeng, H. Liu et al., Kinetically elevated redox conversion of polysulfides of lithium-sulfur battery using a separator modified with transition metals coordinated g-C3N4 with carbon-conjugated. Chem. Eng. J. 385, 123905 (2020). https://doi.org/10.1016/j.cej.2019.123905

70. B. Xiao, T. Rojo, X. Li, Hard carbon as sodium-ion battery anodes: progress and challenges. Chemsuschem 12(1), 133144 (2019). https://doi.org/10.1002/cssc.201801879

71. V. Gabaudan, L. Stievano, L. Monconduit, R. Berthelot, Snapshot on negative electrode materials for potassiumion batteries. Front. Energy Res. 7, 46 (2019). https://doi. org/10.3389/fenrg.2019.00046
72. A.M. Garay-Tapia, A.H. Romero, V. Barone, Lithium adsorption on graphene: from isolated adatoms to metallic sheets. J. Chem. Theory Comput. 8(3), 1064-1071 (2012). https://doi. org/10.1021/ct300042p

73. S. Ullah, P.A. Denis, F. Sato, Unusual enhancement of the adsorption energies of sodium and potassium in sulfur - nitrogen and silicon - boron codoped graphene. ACS Omega 3(11), 15821-15828 (2018). https://doi.org/10.1021/ acsomega. $8 \mathrm{~b} 02500$

74. A. Lugo-Solis, I. Vasiliev, Ab initio study of K adsorption on graphene and carbon nanotubes: role of long-range ionic forces. Phys. Rev. B 76(23), 235431 (2007). https://doi. org/10.1103/PhysRevB.76.235431

75. T. Liu, Z. Jin, D.-X. Liu, C. Du, L. Wang, H. Lin, Y. Li, A density functional theory study of high-performance pre-lithiated MS2 (M=Mo, W, V) monolayers as the anode material of lithium ion batteries. Sci. Rep. 10(1), 6897 (2020). https:// doi.org/10.1038/s41598-020-63743-9

76. X. Sun, Z. Wang, Y.Q. Fu, Adsorption and diffusion of sodium on graphene with grain boundaries. Carbon 116, 415421 (2017). https://doi.org/10.1016/j.carbon.2017.01.024

77. J. Yang, Y. Yuan, G. Chen, First-principles study of potassium adsorption and diffusion on graphene. Mol. Phys. 118(1), 1-7 (2019). https://doi.org/10.1080/00268 976.2019.1581291

78. A. Eftekhari, Low voltage anode materials for lithium-ion batteries. Energy Storage Mater. 7, 157-180 (2017). https:// doi.org/10.1016/j.ensm.2017.01.009

79. J.-H. Kim, D.K. Kim, Conversion-alloying anode materials for na-ion batteries: recent progress, challenges, and perspective for the future. J. Korean Ceram. Soc. 55(4), 307-324 (2018). https://doi.org/10.4191/kcers.2018.55.4.07

80. Z. Jian, W. Luo, X. Ji, Carbon electrodes for K-ion batteries. J. Am. Chem. Soc. 137(36), 11566-11569 (2015). https://doi. org/10.1021/jacs.5b06809

81. H. Yin, Q. Guo, D. He, J. Li, S. Sun, Structural characterization and electrochemical performance of macroporous graphite-like $\mathrm{C}_{3} \mathrm{~N}_{3}$ prepared by the wurtz reaction and heat treatment. RSC Adv. 7(69), 44001-44008 (2017). https://doi. org/10.1039/C7RA07707F

82. J. Zhu, P. Xiao, H. Li, S.A.C. Carabineiro, Graphitic carbon nitride: synthesis, properties, and applications in catalysis. ACS Appl. Mater. Interfaces. 6(19), 16449-16465 (2014). https://doi.org/10.1021/am502925j

83. Y. Gong, M. Li, Y. Wang, Carbon nitride in energy conversion and storage: recent advances and future prospects. Chemsuschem 8(6), 931-946 (2015). https://doi.org/10.1002/ cssc. 201403287

84. W.-J. Ong, L.-L. Tan, Y.H. Ng, S.-T. Yong, S.-P. Chai, Graphitic carbon nitride $\left(\mathrm{g}-\mathrm{C}_{3} \mathrm{~N}_{4}\right)$-based photocatalysts for artificial photosynthesis and environmental remediation: are we a step closer to achieving sustainability? Chem. Rev. 116(12), 7159-7329 (2016). https://doi.org/10.1021/acs. chemrev.6b00075

85. X. Dong, F. Cheng, Recent development in exfoliated two-dimensional $\mathrm{g}-\mathrm{C}_{3} \mathrm{~N}_{4}$ nanosheets for photocatalytic 
applications. J. Mater. Chem. A 3(47), 23642-23652 (2015). https://doi.org/10.1039/C5TA07374J

86. Q. Guo, Q. Yang, C. Yi, L. Zhu, Y. Xie, Synthesis of carbon nitrides with graphite-like or onion-like lamellar structures via a solvent-free route at low temperatures. Carbon 43(7), 1386-1391 (2005). https://doi.org/10.1016/j.carbo n.2005.01.005

87. J. Li, C. Cao, J. Hao, H. Qiu, Y. Xu, H. Zhu, Self-assembled one-dimensional carbon nitride architectures. Diam. Relat. Mater. 15(10), 1593-1600 (2006). https://doi.org/10.1016/j. diamond.2006.01.013

88. P. Niu, L. Zhang, G. Liu, H.M. Cheng, Graphene like carbon nitride nanosheets for improved photocatalytic activities. Adv. Funct. Mater. 22(22), 4763-4770 (2012). https://doi. org/10.1002/adfm.201200922

89. J. Mahmood, E.K. Lee, M. Jung, D. Shin, I.-Y. Jeon et al., Nitrogenated holey two-dimensional structures. Nat. Commun. 6(1), 6486 (2015). https://doi.org/10.1038/ncomms7486

90. X. Zhang, X. Xie, H. Wang, J. Zhang, B. Pan, Y. Xie, Enhanced photoresponsive ultrathin graphitic-phase $\mathrm{C}_{3} \mathrm{~N}_{4}$ nanosheets for bioimaging. J. Am. Chem. Soc. 135(1), 18-21 (2013). https://doi.org/10.1021/ja308249k

91. K. Schwinghammer, M.B. Mesch, V. Duppel, C. Ziegler, J. Senker, B.V. Lotsch, Crystalline carbon nitride nanosheets for improved visible-light hydrogen evolution. J. Am. Chem. Soc. 136(5), 1730-1733 (2014). https://doi.org/10.1021/ ja411321s

92. Y. Yin, J. Han, X. Zhang, Y. Zhang, J. Zhou et al., Facile synthesis of few-layer-thick carbon nitride nanosheets by liquid ammonia-assisted lithiation method and their photocatalytic redox properties. RSC Adv. 4(62), 32690-32697 (2014). https://doi.org/10.1039/C4RA06036A

93. Y. Fukasawa, K. Takanabe, A. Shimojima, M. Antonietti, K. Domen, T. Okubo, Synthesis of ordered porous graphitic- $\mathrm{C}_{3} \mathrm{~N}_{4}$ and regularly arranged $\mathrm{Ta}_{3} \mathrm{~N}_{5}$ nanoparticles by using self-assembled silica nanospheres as a primary template. Chem. Asian J. 6(1), 103-109 (2011). https://doi. org/10.1002/asia.201000523

94. Y.-S. Jun, W.H. Hong, M. Antonietti, A. Thomas, Mesoporous, 2D hexagonal carbon nitride and titanium nitride/carbon composites. Adv. Mater. 21(42), 4270-4274 (2009). https://doi.org/10.1002/adma.200803500

95. S.S. Park, S.-W. Chu, C. Xue, D. Zhao, C.-S. Ha, Facile synthesis of mesoporous carbon nitrides using the incipient wetness method and the application as hydrogen adsorbent. J. Mater. Chem. 21(29), 10801-10807 (2011). https://doi. org/10.1039/C1JM10849B

96. X.-H. Li, J. Zhang, X. Chen, A. Fischer, A. Thomas, M. Antonietti, X. Wang, Condensed graphitic carbon nitride nanorods by nanoconfinement: promotion of crystallinity on photocatalytic conversion. Chem. Mater. 23(19), 4344-4348 (2011). https://doi.org/10.1021/cm201688v

97. J. Liu, Y. Liu, N. Liu, Y. Han, X. Zhang et al., Metal-free efficient photocatalyst for stable visible water splitting via a two-electron pathway. Science 347(6225), 970-974 (2015). https://doi.org/10.1126/science.aaa3145
98. S. Kim, W. Cha, K. Ramadass, G. Singh, I.Y. Kim, A. Vinu, Single-step synthesis of mesoporous carbon nitride/molybdenum sulfide nanohybrids for high-performance sodium-ion batteries. Chem. Asian J. 15(12), 1863-1868 (2020). https:// doi.org/10.1002/asia.202000349

99. J.P. Paraknowitsch, J. Zhang, D. Su, A. Thomas, M. Antonietti, Ionic liquids as precursors for nitrogen-doped graphitic carbon. Adv. Mater. 22(1), 87-92 (2010). https://doi. org/10.1002/adma.200900965

100. Z. Lin, X. Wang, Ionic liquid promoted synthesis of conjugated carbon nitride photocatalysts from urea. Chemsuschem 7(6), 1547-1550 (2014). https://doi.org/10.1002/cssc.20140 0016

101. Y. Wang, X. Wang, M. Antonietti, Y. Zhang, Facile one-pot synthesis of nanoporous carbon nitride solids by using soft templates. Chemsuschem 3(4), 435-439 (2010). https://doi. org/10.1002/cssc. 200900284

102. H. Yan, Soft-templating synthesis of mesoporous graphitic carbon nitride with enhanced photocatalytic $\mathrm{H}_{2}$ evolution under visible light. Chem. Commun. 48(28), 3430-3432 (2012). https://doi.org/10.1039/C2CC00001F

103. Y. Wang, J. Zhang, X. Wang, M. Antonietti, H. Li, Boronand fluorine-containing mesoporous carbon nitride polymers: metal-free catalysts for cyclohexane oxidation. Angew. Chem. Int. Ed. 49(19), 3356-3359 (2010). https://doi.org/10.1002/ anie. 201000120

104. Z. Yang, Y. Zhang, Z. Schnepp, Soft and hard templating of graphitic carbon nitride. J. Mater. Chem. A 3(27), 1408114092 (2015). https://doi.org/10.1039/C5TA02156A

105. T. Kesavan, T. Partheeban, M. Vivekanantha, N. Prabu, M. Kundu et al., Design of P-doped mesoporous carbon nitrides as high-performance anode materials for Li-ion battery. ACS Appl. Mater. Interfaces. 12(21), 24007-24018 (2020). https ://doi.org/10.1021/acsami.0c05123

106. Y. Dou, L. Zhang, X. Xu, Z. Sun, T. Liao, S.X. Dou, Atomically thin non-layered nanomaterials for energy storage and conversion. Chem. Soc. Rev. 46(23), 7338-7373 (2017). https ://doi.org/10.1039/C7CS00418D

107. Z. Wang, H. Gao, Q. Zhang, Y. Liu, J. Chen, Z. Guo, Recent advances in 3D graphene architectures and their composites for energy storage applications. Small 15(3), 1803858 (2019). https://doi.org/10.1002/smll.201803858

108. D. Adekoya, H. Chen, H.Y. Hoh, T. Gould, M.-S.J.T. Balogun, C. Lai, H. Zhao, S. Zhang, Hierarchical $\mathrm{Co}_{3} \mathrm{O}_{4} @$ $\mathrm{N}$-doped carbon composite as an advanced anode material for ultrastable potassium storage. ACS Nano 14(4), 5027-5035 (2020). https://doi.org/10.1021/acsnano.0c01395

109. W.-J. Ong, L.-L. Tan, S.-P. Chai, S.-T. Yong, A.R. Mohamed, Surface charge modification via protonation of graphitic carbon nitride $\left(\mathrm{g}-\mathrm{C}_{3} \mathrm{~N}_{4}\right)$ for electrostatic self-assembly construction of $2 \mathrm{D} / 2 \mathrm{D}$ reduced graphene oxide $(\mathrm{rGO}) / \mathrm{g}-\mathrm{C}_{3} \mathrm{~N}_{4}$ nanostructures toward enhanced photocatalytic reduction of carbon dioxide to methane. Nano Energy 13, 757-770 (2015). https://doi.org/10.1016/j.nanoen.2015.03.014

110. Y. Fu, J. Zhu, C. Hu, X. Wu, X. Wang, Covalently coupled hybrid of graphitic carbon nitride with reduced graphene 
oxide as a superior performance lithium-ion battery anode. Nanoscale 6(21), 12555-12564 (2014). https://doi. org/10.1039/C4NR03145H

111. X. Li, Y. Feng, M. Li, W. Li, H. Wei, D. Song, Smart hybrids of $\mathrm{Zn} 2 \mathrm{GeO} 4$ nanoparticles and ultrathin g-C3N4 layers: synergistic lithium storage and excellent electrochemical performance. Adv. Funct. Mater. 25(44), 6858-6866 (2015). https ://doi.org/10.1002/adfm.201502938

112. J. Wang, Z. Meng, W. Yang, X. Yan, R. Guo, W.-Q. Han, Facile synthesis of $\mathrm{rgo} / \mathrm{g}-\mathrm{C}_{3} \mathrm{~N}_{4} / \mathrm{CNT}$ microspheres via ethanolassisted spray drying method for high performance lithiumsulfur batteries. ACS Appl. Mater. Interfaces. 11(1), 819-827 (2018). https://doi.org/10.1021/acsami.8b17590

113. J. Zhang, J.-Y. Li, W.-P. Wang, X.-H. Zhang, X.-H. Tan, W.-G. Chu, Y.-G. Guo, Microemulsion assisted assembly of 3D porous S/graphene@g- $\mathrm{C}_{3} \mathrm{~N}_{4}$ hybrid sponge as freestanding cathodes for high energy density $\mathrm{Li}-\mathrm{S}$ batteries. Adv. Energy Mater. 8(14), 1702839 (2018). https://doi. org/10.1002/aenm.201702839

114. C. Wang, L. Zhang, M. Al-Mamun, Y. Dou, P. Liu et al., A hollow-shell structured $\mathrm{V}_{2} \mathrm{O}_{5}$ electrode-based symmetric full Li-ion battery with highest capacity. Adv. Energy Mater. 9(31), 1900909 (2019). https://doi.org/10.1002/ aenm.201900909

115. M.-S. Balogun, W. Qiu, F. Lyu, Y. Luo, H. Meng et al., Allflexible lithium ion battery based on thermally-etched porous carbon cloth anode and cathode. Nano Energy 26, 446-455 (2016). https://doi.org/10.1016/j.nanoen.2016.05.017

116. H.S.H. Mohamed, L. Wu, C.-F. Li, Z.-Y. Hu, J. Liu et al., Insitu growing mesoporous Cuo/O-doped $\mathrm{g}-\mathrm{C}_{3} \mathrm{~N}_{4}$ nanospheres for highly enhanced lithium storage. ACS Appl. Mater. Interfaces 11(36), 32957-32968 (2019). https://doi.org/10.1021/ acsami.9b10171

117. L. Yin, R. Cheng, Q. Song, J. Yang, X. Kong et al., Construction of nanoflower $\mathrm{SnS}_{2}$ anchored on $\mathrm{g}_{-} \mathrm{C}_{3} \mathrm{~N}_{4}$ nanosheets composite as highly efficient anode for lithium ion batteries. Electrochim. Acta 293, 408-418 (2018). https://doi.org/10.1016/j. electacta.2018.10.020

118. G. Wang, Z. Wen, Y.-E. Yang, J. Yin, W. Kong et al., Ultralonglife $\mathrm{Si} @ \mathrm{rGO} / \mathrm{g}-\mathrm{C}_{3} \mathrm{~N}_{4}$ with a multiply synergetic effect as an anode material for lithium-ion batteries. J. Mater. Chem. A 6(17), 7557-7565 (2018). https://doi.org/10.1039/C8TA0 0539G

119. W. Kong, J. Yu, X. Shi, J. Yin, H. Yang, Z. Wen, Encapsulated red phosphorus in rgo- $\mathrm{C}_{3} \mathrm{~N}_{4}$ architecture as extendinglife anode materials for lithium-ion batteries. J. Electrochem. Soc. 167(6), 060518 (2020). https://doi.org/10.1149/1945$7111 / \mathrm{ab} 8406$

120. Y. Wang, J. Han, X. Gu, S. Dimitrijev, Y. Hou, S. Zhang, Ultrathin $\mathrm{Fe}_{2} \mathrm{O}_{3}$ nanoflakes using smart chemical stripping for high performance lithium storage. J. Mater. Chem. A 5(35), 18737-18743 (2017). https://doi.org/10.1039/C7TA05798A

121. Y. Hou, J. Li, Z. Wen, S. Cui, C. Yuan, J. Chen, N-doped graphene/porous $\mathrm{gC}_{3} \mathrm{~N}_{4}$ nanosheets supported layered- $\mathrm{MoS}_{2}$ hybrid as robust anode materials for lithium-ion batteries.
Nano Energy 8, 157-164 (2014). https://doi.org/10.1016/j. nanoen.2014.06.003

122. M.S.A.S. Shah, A.R. Park, A. Rauf, S.H. Hong, Y. Choi et al., Highly interdigitated and porous architected ternary composite of $\mathrm{SnS}_{2}, \mathrm{gC}_{3} \mathrm{~N}_{4}$, and reduced graphene oxide (RGO) as high performance lithium ion battery anodes. RSC Adv. 7(6), 3125-3135 (2017). https://doi.org/10.1039/C6RA25886G

123. X. Shi, Z. Zhou, J. Yin, S. Li, S. Ji, J. Sun, Z. Wen, Fabrication of $\mathrm{rGO} / \mathrm{g}-\mathrm{C}_{3} \mathrm{~N}_{4} @ \mathrm{SnS}_{2}$ and its rate-performance enhancement. Chem. Phys. Lett. 746, 137296 (2020). https://doi. org/10.1016/j.cplett.2020.137296

124. M. Shi, T. Wu, X. Song, J. Liu, L. Zhao, P. Zhang, L. Gao, Active $\mathrm{Fe}_{2} \mathrm{O}_{3}$ nanoparticles encapsulated in porous $\mathrm{gC}_{3} \mathrm{~N}_{4} /$ graphene sandwich-type nanosheets as a superior anode for high-performance lithium-ion batteries. J. Mater. Chem. A 4(27), 10666-10672 (2016). https://doi.org/10.1039/C6TA0 $3533 \mathrm{G}$

125. J.Y. Hwang, S.T. Myung, Y.K. Sun, Recent progress in rechargeable potassium batteries. Adv. Funct. Mater. 28(43), 1802938 (2018). https://doi.org/10.1002/adfm.201802938

126. K. Song, C. Liu, L. Mi, S. Chou, W. Chen, C. Shen, Recent progress on the alloy-based anode for sodium-ion batteries and potassium-ion batteries. Small 1, 1903194 (2019). https ://doi.org/10.1002/smll.201903194

127. Z. Ali, T. Zhang, M. Asif, L. Zhao, Y. Yu, Y. Hou, Transition metal chalcogenide anodes for sodium storage. Mater. Today 3(35), 131-167 (2020). https://doi.org/10.1016/j.matto d.2019.11.008

128. J. Liu, Y. Zhang, L. Zhang, F. Xie, A. Vasileff, S.-Z. Qiao, Graphitic carbon nitride $\left(\mathrm{g}-\mathrm{C}_{3} \mathrm{~N}_{4}\right)$-derived n-rich graphene with tuneable interlayer distance as a high-rate anode for sodium-ion batteries. Adv. Mater. 31(24), 1901261 (2019). https://doi.org/10.1002/adma.201901261

129. L. Chen, R. Yan, M. Oschatz, L. Jiang, M. Antonietti, K. Xiao, Ultrathin 2D graphitic carbon nitride on metal films: underpotential sodium deposition in adlayers for sodium-ion batteries. Angew. Chem. Int. Ed. 59(23), 9067 (2020). https ://doi.org/10.1002/anie.202000314

130. C.M. Subramaniyam, K.A. Deshmukh, Z. Tai, N. Mahmood, A.D. Deshmukh et al., 2D layered graphitic carbon nitride sandwiched with reduced graphene oxide as nanoarchitectured anode for highly stable lithium-ion battery. Electrochim. Acta 237(20), 69-77 (2017). https://doi.org/10.1016/j. electacta.2017.03.194

131. C. Senthil, T. Kesavan, A. Bhaumik, M. Sasidharan, N-rich graphitic carbon nitride functionalized graphene oxide nanosheet hybrid as anode for high performance lithium-ion batteries. Mater. Res. Express 5(1), 016307 (2018). https:// doi.org/10.1088/2053-1591/aaa6b9

132. V. Vo, X.D. Nguyen Thi, Y.-S. Jin, G. Ly Thi, T.T. Nguyen, T.Q. Duong, S.-J. Kim, $\mathrm{SnO}_{2}$ nanosheets/g- $\mathrm{C}_{3} \mathrm{~N}_{4}$ composite with improved lithium storage capabilities. Chem. Phys. Lett. 674, 42-47 (2017). https://doi.org/10.1016/j.cplet t.2017.02.057

133. K. Liu, J. Man, J. Cui, H. Zhang, T. Li, J. Yang, Z. Wen, J. Sun, $\mathrm{Li}_{4} \mathrm{Ti}_{5} \mathrm{O}_{12} / \mathrm{g}-\mathrm{C}_{3} \mathrm{~N}_{4}$ composite with an improved lithium 
storage capability. Mater. Lett. 234, 117-120 (2019). https:// doi.org/10.1016/j.matlet.2018.09.083

134. Y. Wang, X. Huang, S. Zhang, Y. Hou, Sulfur hosts against the shuttle effect. Small Methods 2(6), 1700345 (2018). https ://doi.org/10.1002/smtd.201700345

135. L. Hencz, H. Chen, H.Y. Ling, Y. Wang, C. Lai, H. Zhao, S. Zhang, Housing sulfur in polymer composite frameworks for Li-S batteries. Nano-Micro Lett. 11(1), 17 (2019). https://doi. org/10.1007/s40820-019-0249-1

136. J. Liu, W. Li, L. Duan, X. Li, L. Ji et al., A graphene-like oxygenated carbon nitride material for improved cycle-life lithium/sulfur batteries. Nano Lett. 15(8), 5137-5142 (2015). https://doi.org/10.1021/acs.nanolett.5b01919

137. L. Qu, P. Liu, Y. Yi, T. Wang, P. Yang et al., Enhanced cycling performance for lithium-sulfur batteries by a laminated $2 \mathrm{D}$ g- $\mathrm{C}_{3} \mathrm{~N}_{4}$ /graphene cathode interlayer. Chemsuschem 12(1), 213-223 (2019). https://doi.org/10.1002/cssc.20180 2449

138. J. Song, S. Feng, C. Zhu, J.-I. Lee, S. Fu, P. Dong, M.-K. Song, Y. Lin, Tuning the structure and composition of graphite-phase polymeric carbon nitride/reduced graphene oxide composites towards enhanced lithium-sulfur batteries performance. Electrochim. Acta 248, 541-546 (2017). https://doi. org/10.1016/j.electacta.2017.07.149

139. Y. Liu, N. Li, S. Wu, K. Liao, K. Zhu, J. Yi, H. Zhou, Reducing the charging voltage of a $\mathrm{Li}-\mathrm{O}_{2}$ battery to $1.9 \mathrm{~V}$ by incorporating a photocatalyst. Energy Environ. Sci. 8(9), 2664-2667 (2015). https://doi.org/10.1039/C5EE01958C

140. Z. Zhao, Y. Sun, F. Dong, Graphitic carbon nitride based nanocomposites: a review. Nanoscale 7(1), 15-37 (2015). https://doi.org/10.1039/c4nr03008g

141. E. Pomerantseva, Y. Gogotsi, Two-dimensional heterostructures for energy storage. Nat. Energy 2(7), 17089 (2017). https://doi.org/10.1038/nenergy.2017.89

142. R. Gao, Y. Zhou, X. Liu, J. Wang, N-doped defective carbon layer encapsulated $\mathrm{W}_{2} \mathrm{C}$ as a multifunctional cathode catalyst for high performance Li- $\mathrm{O}_{2}$ battery. Electrochim. Acta 245, 430-437 (2017). https://doi.org/10.1016/j.elect acta.2017.05.177

143. W.B. Luo, S.L. Chou, J.Z. Wang, Y.C. Zhai, H.K. Liu, A metal-free, free-standing, macroporous graphene@g-C3N4 composite air electrode for high-energy lithium oxygen batteries. Small 11(23), 2817-2824 (2015). https://doi. org/10.1002/smll.201403535

144. P. Lou, Z. Cui, X. Guo, Achieving highly stable $\mathrm{Li}-\mathrm{O}_{2}$ battery operation by designing a carbon nitride-based cathode towards a stable reaction interface. J. Mater. Chem. A 5(34), 18207-18213 (2017). https://doi.org/10.1039/C7TA05009G

145. Q. Guo, C. Zhang, C. Zhang, S. Xin, P. Zhang et al., $\mathrm{Co}_{3} \mathrm{O}_{4}$ modified $\mathrm{Ag} / \mathrm{g}-\mathrm{C}_{3} \mathrm{~N}_{4}$ composite as a bifunctional cathode for lithium-oxygen battery. J. Energy Chem. 41, 185-193 (2020). https://doi.org/10.1016/j.jechem.2019.05.018

146. H. Cha, J. Kim, Y. Lee, J. Cho, M. Park, Issues and challenges facing flexible lithium-ion batteries for practical application. Small 14(43), 1702989 (2018). https://doi.org/10.1002/ smll.201702989
147. T. Xiong, H. Su, F. Yang, Q. Tan, P.B.S. Appadurai et al., Harmonizing self-supportive $\mathrm{VN} / \mathrm{MoS}_{2}$ pseudocapacitance core-shell electrodes for boosting the areal capacity of lithium storage. Mater. Today Energy 17, 100461 (2020). https://doi. org/10.1016/j.mtener.2020.100461

148. X.-Y. Yue, X.-L. Li, W.-W. Wang, D. Chen, Q.-Q. Qiu et al., Wettable carbon felt framework for high loading Li-metal composite anode. Nano Energy 60, 257-266 (2019). https:// doi.org/10.1016/j.nanoen.2019.03.057

149. K. Shen, Z. Wang, X. Bi, Y. Ying, D. Zhang et al., Magnetic field-suppressed lithium dendrite growth for stable lithiummetal batteries. Adv. Energy Mater. 9(20), 1900260 (2019). https://doi.org/10.1002/aenm.201900260

150. X.-Y. Yue, W.-W. Wang, Q.-C. Wang, J.-K. Meng, X.-X. Wang et al., Cuprite-coated cu foam skeleton host enabling lateral growth of lithium dendrites for advanced Li metal batteries. Energy Storage Mater. 21, 180-189 (2019). https ://doi.org/10.1016/j.ensm.2018.12.007

151. X. Luan, C. Wang, C. Wang, X. Gu, J. Yang, Y. Qian, Stable lithium deposition enabled by an acid-treated $g-\mathrm{C}_{3} \mathrm{~N}_{4}$ interface layer for a lithium metal anode. ACS Appl. Mater. Interfaces 12(9), 11265-11272 (2020). https://doi. org/10.1021/acsami.9b23520

152. J. Hu, J. Tian, C. Li, Nanostructured carbon nitride polymer-reinforced electrolyte to enable dendrite-suppressed lithium metal batteries. ACS Appl. Mater. Interfaces 9(13), 11615-11625 (2017). https://doi.org/10.1021/acsami.7b004 78

153. Z. Lu, Q. Liang, B. Wang, Y. Tao, Y. Zhao et al., Graphitic carbon nitride induced micro-electric field for dendrite-free lithium metal anodes. Adv. Energy Mater. 9(7), 1803186 (2019). https://doi.org/10.1002/aenm.201803186

154. D. Jiao, Z. Ma, J. Li, Y. Han, J. Mao, T. Ling, S. Qiao, Test factors affecting the performance of zinc-air battery. J. Energy Chem. 44, 1-7 (2020). https://doi.org/10.1016/j. jechem.2019.09.008

155. F. Ran, S. Chen, Advanced Nanomaterials for Electrochemical-based Energy Conversion and Storage (Elsevier, Amsterdam, 2019), p. 416

156. Y.-J. Li, L. Cui, P.-F. Da, K.-W. Qiu, W.-J. Qin et al., Multiscale structural engineering of ni-doped coo nanosheets for zinc-air batteries with high power density. Adv. Mater. 30(46), 1804653 (2018). https://doi.org/10.1002/adma.20180 4653

157. H.-S. Lu, H. Zhang, X. Zhang, N. Sun, X. Zhu, H. Zhao, G. Wang, Transformation of carbon-encapsulated metallic $\mathrm{Co}$ into ultrafine $\mathrm{Co} / \mathrm{CoO}$ nanoparticles exposed on $\mathrm{N}$-doped graphitic carbon for high-performance rechargeable zinc-air battery. Appl. Surf. Sci. 448, 369-379 (2018). https://doi. org/10.1016/j.apsusc.2018.04.146

158. S.S. Shinde, C.-H. Lee, A. Sami, D.-H. Kim, S.-U. Lee, J.-H. Lee, Scalable 3D carbon nitride sponge as an efficient metalfree bifunctional oxygen electrocatalyst for rechargeable $\mathrm{Zn}-$ air batteries. ACS Nano 11(1), 347-357 (2017). https://doi. org/10.1021/acsnano.6b05914 
159. S.S. Shinde, J.-Y. Yu, J.-W. Song, Y.-H. Nam, D.-H. Kim, J.-H. Lee, Highly active and durable carbon nitride fibers as metal-free bifunctional oxygen electrodes for flexible $\mathrm{Zn}$-air batteries. Nanoscale Horiz. 2(6), 333-341 (2017). https://doi. org/10.1039/C7NH00058H

160. C.-Y. Su, H. Cheng, W. Li, Z.-Q. Liu, N. Li et al., Atomic modulation of $\mathrm{FeCo}-$ nitrogen-carbon bifunctional oxygen electrodes for rechargeable and flexible all-solid-state zincair battery. Adv. Energy Mater. 7(13), 1602420 (2017). https ://doi.org/10.1002/aenm.201602420

161. L. Zhang, J. Xiong, Y.-H. Qin, C.-W. Wang, Porous N-C catalyst synthesized by pyrolyzing g-C3N4 embedded in carbon as highly efficient oxygen reduction electrocatalysts for primary Zn-air battery. Carbon 150, 475-484 (2019). https://doi. org/10.1016/j.carbon.2019.05.044

162. S. Wang, P. Xiong, J. Zhang, G. Wang, Recent progress on flexible lithium metal batteries: composite lithium metal anodes and solid-state electrolytes. Energy Storage Mater. 29, 310-331 (2020). https://doi.org/10.1016/j.ensm.2020.04.032

163. Y. Zhu, X. He, Y. Mo, Origin of outstanding stability in the lithium solid electrolyte materials: insights from thermodynamic analyses based on first-principles calculations. ACS Appl. Mater. Interfaces 7(42), 23685-23693 (2015). https:// doi.org/10.1021/acsami.5b07517

164. Y. Zhu, X. He, Y. Mo, First principles study on electrochemical and chemical stability of solid electrolyte-electrode interfaces in all-solid-state Li-ion batteries. J. Mater. Chem. A 4(9), 3253-3266 (2016). https://doi.org/10.1039/C5TA0 $8574 \mathrm{H}$

165. Y. Huang, B. Chen, J. Duan, F. Yang, T. Wang et al., Graphitic carbon nitride $\left(\mathrm{g}-\mathrm{C}_{3} \mathrm{~N}_{4}\right)$ : an interface enabler for solidstate lithium metal batteries. Angew. Chem. Int. Ed. 59(9), 3699-3704 (2020). https://doi.org/10.1002/anie.201914417

166. Y. Lu, Z. Wen, J. Jin, Y. Cui, M. Wu, S. Sun, Mesoporous carbon nitride loaded with Pt nanoparticles as a bifunctional air electrode for rechargeable lithium-air battery. J. Solid State Electrochem. 16(5), 1863-1868 (2012). https://doi. org/10.1007/s10008-012-1640-8

167. Z. Sun, Y. Li, S. Zhang, L. Shi, H. Wu, H. Bu, S. Ding, G- $\mathrm{C}_{3} \mathrm{~N}_{4}$ nanosheets enhanced solid polymer electrolytes with excellent electrochemical performance, mechanical properties, and thermal stability. J. Mater. Chem. A 7(18), 11069-11076 (2019). https://doi.org/10.1039/C9TA00634F

168. T. Liu, Y. Zhang, C. Chen, Z. Lin, S. Zhang, J. Lu, Sustainability-inspired cell design for a fully recyclable sodium ion battery. Nat. Commun. 10(1), 1965 (2019). https://doi. org/10.1038/s41467-019-09933-0

169. Z. Su, H.Y. Ling, M. Li, S. Qian, H. Chen, C. Lai, S. Zhang, Honeycomb-like carbon materials derived from coffee extract via a "salty" thermal treatment for high-performance Li-I2 batteries. Carbon Energy 2(2), 265-275 (2020). https://doi. org/10.1002/cey2.40

170. M. Sha, L. Liu, H. Zhao, Y. Lei, Anode materials for potassium-ion batteries: current status and prospects. Carbon Energy (2020). https://doi.org/10.1002/cey2.57
171. Y. Shi, G. Liu, R. Jin, H. Xu, Q. Wang, S. Gao, Carbon materials from melamine sponges for supercapacitors and lithium battery electrode materials: a review. Carbon Energy 1(2), 253-275 (2019). https://doi.org/10.1002/cey2.19

172. J. Chen, N.-G. Park, Materials and methods for interface engineering towards stable and efficient perovskite solar cells. ACS Energy Lett. 5, 180-185 (2020). https://doi.org/10.1021/ acsenergylett.0c01240

173. J.-M. Fan, J.-J. Chen, Q. Zhang, B.-B. Chen, J. Zang, M.-S. Zheng, Q.-F. Dong. An amorphous carbon nitride composite derived from ZIF-8 as anode material for sodium-ion batteries. ChemSusChem. 8(11), 1856-1861 (2015). https://doi. org/10.1002/cssc. 201500192

174. L. Chen, R. Yan, M. Oschatz, L. Jiang, M. Antonietti, K. Xiao, Ultrathin 2D graphitic carbon nitride on metal films: Underpotential sodium deposition in adlayers for sodium-ion batteries. Angew. Chem. Int. 59(23), 9067 (2020). https://doi. org/10.1002/anie.202000314

175. J. Liu, Y. Zhang, L. Zhang, F. Xie, A. Vasileff, S.-Z. Qiao, Graphitic carbon nitride $\left(\mathrm{g}_{-} \mathrm{N}_{4}\right)$-derived N-rich graphene with tuneable interlayer distance as a high-rate anode for sodium-ion batteries. Adv Mater. 31(24), 1901261 (2019). https://doi.org/10.1002/adma.201901261

176. D. Adekoya, H. Chen, H.Y. Hoh, T. Gould, M.-S.J.T. Balogun, C. Lai, H. Zhao, S. Zhang, Hierarchical ${ }_{3} \mathrm{O}_{4} @ \mathrm{~N}$-doped carbon composite as an advanced anode material for ultrastable potassium storage. ACS Nano 14(4), 5027-5035 (2020)

177. J. Liu, W. Li, L. Duan, X. Li, L. Ji, Z. Geng, K. Huang, L. Lu, L. Zhou, Z. Liu, A graphene-like oxygenated carbon nitride material for improved cyclelife lithium/sulfur batteries. Nano Lett. 15(8), 5137-5142 (2015)

178. X. Wu, S. Li, B. Wang, J. Liu, M. Yu, Free-standing 3D network-like cathode based on biomass-derived $\mathrm{N}$-doped carbon/graphene/g- $\mathrm{C}_{3} \mathrm{~N}_{4}$ hybrid ultrathin sheets as sulfur host for high-rate Li-S battery. Renew. Energy 158, 509-519 (2020).https://doi.org/10.1016/j.renene.2020.05.098

179. H. Zhang, Z. Zhao, Y.-N. Hou, Y. Tang, Y. Dong, S. Wang, X. $\mathrm{Hu}$, Z. Zhang, X. Wang, J. Qiu, Nanopore-confined g- $\mathrm{C}_{3} \mathrm{~N}_{4}$ nanodots in $\mathrm{N}, \mathrm{S}$ Codoped hollow porous carbon with boosted capacity for lithium-sulfur batteries. J. Mater. Chem. A 6(16), 7133-7141 (2018). https://doi.org/10.1039/C8TA0 0529J

180. X. Wang, G. Li, M. Li, R. Liu, H. Li, T. Li, M. Sun, Y. Deng, M. Feng, Z. Chen, Reinforced polysulfide barrier by $\mathrm{g}_{-} \mathrm{C}_{3} \mathrm{~N}_{4} /$ CNT composite towards superior lithium-sulfur batteries. J. Energy Chem. 53, 234-240 (2021). https://doi.org/10.1016/j. jechem.2020.05.036

181. Y. Gong, C. Fu, G. Zhang, H. Zhou, Y. Kuang, Three-dimensional porous $\mathrm{C}_{3} \mathrm{~N}_{4}$ nanosheets@ reduced graphene oxide network as sulfur hosts for high performance lithium-sulfur batteries. Electrochim. Acta 256, 1-9 (2017). https://doi. org/10.1016/j.electacta.2017.10.032

182. J. Wang, Z. Meng, W. Yang, X. Yan, R. Guo, W.-Q. Han, Facile synthesis of $\mathrm{rGO} / \mathrm{g}-\mathrm{C}_{3} \mathrm{~N}_{4} / \mathrm{CNT}$ microspheres via ethanol-assisted spray drying method for high performance 
lithium-sulfur batteries. ACS Appl. Mater. Interfaces 11(1), 819-827 (2018)

183. Y. Huangfu, T. Zheng, K. Zhang, X. She, H. Xu, Z. Fang, K. Xie, Facile fabrication of permselective $g_{-3} \mathrm{~N}_{4}$ separator for improved lithium-sulfur batteries. Electrochim. Acta 272, 60-67 (2018). https://doi.org/10.1016/j.electacta.2018.03.149
184. G. Angamuthu, D.B. Babu, K. Ramesha, V. Rangarajan, $\mathrm{MoS}_{2}$ anchored carbon nitride based mesoporous material as a polysulfide barrier for high capacity lithium-sulfur battery. J. Electroanal. Chem. 843, 37-46 (2019). https://doi. org/10.1016/j.jelechem.2019.05.006 